\title{
The Knife Edge Election of 2020: American Politics Between Washington, Kabul, and Weimar
}

\author{
Thomas Ferguson, Paul Jorgensen, and Jie Chen*
}

\section{Working Paper No. 169}

\author{
November $7^{\text {th }}, 2021$
}

\begin{abstract}
This paper analyzes the 2020 election, focusing on voters, not political money, and emphasizing the importance of economic geography. Drawing extensively on county election returns, it analyzes how spatial factors combined with industrial structures to shape the outcome. It treats

\footnotetext{
* Thomas Ferguson is Professor Emeritus at the University of Massachusetts, Boston; Director of Research at the Institute for New Economic Thinking, and a Senior Fellow at Better Markets. Paul Jorgensen is Associate Professor of Environmental Studies in the School of Interdisciplinary Programs and Community Engagement at the University of Texas Rio Grande Valley. Jie Chen is University Statistician at the University of Massachusetts, Boston. COVID complicates acknowledgements for this paper. When the pandemic hit, we accepted invitations to work under Chatham House rules with many statisticians and epidemiologists organized in several different working groups. Over time, physicians, reporters, former federal officials, and working people reached out to us in confidence to discuss issues of worker safety, sometimes at genuine peril to themselves. We learned a great deal from these discussions, though we cannot individually name anyone. We are very grateful to Servaas Storm for extended comments on a draft of the paper and to James Kurth and William Lazonick for many discussions. We also thank Arturo Chang, Edward Kane, Pia Malaney, Antonella Palumbo, Ryan Rafaty, Allesandro Roncaglia, Claudia Sahm, Lance Taylor, and Peter Temin for comments on various drafts. The paper represents the views of the authors and not any institution with which they are affiliated.
} 
COVID 19's role at length. The paper reviews studies suggesting that COVID 19 did not matter much, but then sets out a new approach indicating it mattered a great deal. The study analyzes the impact on the vote not only of unemployment but differences in income and industry structures, along with demographic factors, including religion, ethnicity, and race. It also studies how the waves of wildcat strikes and social protests that punctuated 2020 affected the vote in specific areas. Trump's very controversial trade policies and his little discussed farm policies receive detailed attention. The paper concludes with a look at how political money helped make the results of the Congressional election different from the Presidential race. It also highlights the continuing importance of private equity and energy sectors opposed to government action to reverse climate change as conservative forces in (especially) the Republican Party, together with agricultural interests.

\section{https://doi.org/10.36687/inetwp169}

Keywords: political economy, voting, 2020 presidential election, Donald Trump, Populism, trade policy, farm policy, political money, Joe Biden, private equity

JEL Classifications: D71, D72, G38, P16, N22, L51 
As the returns trickled in on Election Night, 2020, the already deeply polarized American political system began to melt down. A furious President Trump first tried to pressure Fox News and other networks not to call the election in favor of his opponent and then began to implore supporters to "stop the steal." Over the next few weeks, as contributions rolled into various Trump campaign vehicles from major donors in industries especially favored by the President, notably oil and gas, the White House mounted increasingly far-fetched legal challenges to individual state voting returns. After all were dismissed, the President and his supporters continued to press their case via social media posts, public events, and demonstrations filled with escalating threats and increasingly blustery rhetoric. ${ }^{1}$

For months before the election, supporters of Joe Biden and many other Americans had fretted over the president's many hints that he might not accept defeat at the polls. Though many details remain shrouded in obscurity, it is clear that in the spring, various groups started talking about possible remedies. Involved were leading figures in both business and labor organizations; many avowed Republicans, and a variety of non-profits. ${ }^{2}$ As we will show later in this paper, widely published claims before the election that Trump's supporters in "big business" were abandoning him were far from the truth, but the President's "Stop the Steal" fulminations did alienate many supporters. The resulting post-election elite consensus is perhaps best summarized by the Conference Board, an old and very prominent big business organization: "On January 4, 2021, the U.S. business community did something remarkable: through statements issued or organized by the Partnership for New York City, the Business Roundtable, US Chamber of Commerce, and National Association of Manufacturers, business leaders called on Congress to accept the results of the Electoral College without delay." Key military leaders had been signaling their tacit agreement with this strategy even before Election Day, but in case anyone missed the implication every living former Secretary of Defense signed a joint public statement that made headlines on January $3 .^{3}$ The message was clear: most of big business, labor and what Trump derided as the "deep state" now wanted him out.

On the sixth of January, 2021, what was now clearly a disjointed campaign to overturn the U.S. constitutional order reached an explosive climax: crowds of angry Trump supporters burst through police lines and entered the Capitol vainly hoping to prevent Congress from certifying President elect Joe Biden's Electoral College win. But for all the future trouble that the long post-election trauma foreshadowed, from a clinical standpoint, the voting returns had hardly changed: in most jurisdictions, turnout soared, but the margins differed only modestly from 2016

\footnotetext{
${ }^{1}$ This paper often collects most references at the end of paragraphs for reasons of space. The final days of the Trump administration have been covered extensively; a convenient source for many separate incidents together is the set of narratives published by (Axios, 2021), (Wolff, 2021), and (Leonnig \& Rucker, 2021) and (Woodward \& Costa, 2021), including the court challenges and the storming of the Capitol. We have tracked political contributions after the election and will analyze them in a subsequent paper.

${ }^{2}$ The most detailed account is (Ball, 2020), but see also (Woodward \& Costa, 2021).

${ }^{3}$ (Washington \& Spierings, 2021); for the former Secretaries of Defense, see, e.g., (Lamothe, 2021); for the military, cf. (Copp, 2020). See also (Carmiel, 2020) for an earlier public statement by top business leaders that marked a new phase in the public campaign.
} 
- just enough to provide Biden with an edge bigger than any possible voting irregularities could have produced. ${ }^{4}$

Where results did diverge, less than perfect polls along with the returns from specific areas suggested that the swerve arose from unexpected quarters: far more Hispanics voted for Trump than in 2016 - as many as 33\%, 8\% higher than in 2016; along with much smaller, but still striking, percentages of Blacks, especially Black males. ${ }^{5}$ Trump's advantage among white women with some college or less education remained very high -27 points more. ${ }^{6}$ While Biden's margins among both union members and affluent voters improved modestly on Hillary Clinton's, little heralded polls showed Trump retained a strong hold on the affections of very affluent voters. Voters making more than $\$ 200,000$ split evenly between Trump and Biden, while voters making between $\$ 100,000$ and $\$ 199,999$ favored Trump by $58 \%$ to $41 \% .{ }^{7}$ Perhaps the most surprising outcomes came in races for the House and Senate. In both Republicans ran stronger than expected, with many of their candidates running ahead of Trump.

In a political system so polarized that assessments of the economy now often display substantial - though rarely overwhelming - dependence on partisanship, the flood of new voting results set off near-cannibalistic rites of scrutiny and exhortation. Democrats debated whether criticism of

\footnotetext{
${ }^{4}$ See, among many sources, CNN's tabulation of election results, at (CNN, 2020a) or (Post, 2020). More Trump supporters appear to have voted on Election Day than by mail and counting the latter meant totals would change. The problem was anticipated, however, and networks and many analysts took that in stride. Trump plainly did not, seizing on the changing tabulations as more evidence of a "steal."

${ }^{5}$ The literature on vote shifts is voluminous and sometimes highly political. The subject is muddied by (mostly) small differences between various polls relied on in both election years; see, for example, the discussion in (Collins, 2020), but also (Griffin, 2020) and (Zhang \& Fox, 2020). Our reading of this literature is that there is more heat than light, in that basic qualitative facts only occasionally are unclear. For example, Collins suggests that Trump gained either 2 or 4 percent more votes from Blacks overall, with a larger margin among males. (Frey, 2020) reports a 6\% difference change overall. Later estimates by (Ghitza \& Robinson, 2021) for Catalist, a Democratic-oriented group with a large database of its own, suggest Biden lost about 3\% of the two party Black vote from 2016, in an election in which turnout rose substantially. The basic finding seems clear enough.

No one disputes the huge change in Hispanic voting, only the reasons for it. The shift, again, varies by sources and polls. Catalist proposed $8 \%$. See also the discussion in (Beard, 2021) comparing analyses of the Hispanic change and the figures in (Lenski, Webster, \& Brown, 2021). That displays a graph from Robert Griffin indicating that most of the shift among Hispanics happened well before the Fall campaign started. More on that below. Note that U.S. Census usage of the term "Hispanic" has stimulated a large literature on race, culture, and related questions, with many authors preferring different terms and usages. See, e.g., (Navarro, 2012). The Census has certainly tried to respond to that discussion. This paper relies heavily on Census data and we perforce follow its nomenclature. ${ }^{6}$ (Post, 2020); see also (Zhang \& Fox, 2020): "'Trump support among women stayed consistent among non-college educated white women and evangelical women,' said Kelly Dittmar, director of research at the Center for American Women and Politics. White women without college degrees voted for Mr. Trump with a margin of between 14 and 27 points, according to various election surveys the organization has compiled."

Discussions of ethnicity, race, and gender would all benefit by reporting controls for stratification by income, which virtually no one does. The step would virtually always reduce the size of reported disparities.

${ }^{7}$ Many accounts of exit polls report only a few levels of income. When fuller results are reported, the limitations of the commonly expressed claim that affluent voters backed Biden are clear. See, e.g., CNN's more detailed exit poll breakdown, (CNN, 2020c). Biden won all the other, lower income cohorts, which speaks volumes about silly claims that Trump's voter base was in blue collar workers. Cf. the discussion below on Trump's support from private equity firms in big business.
} 
police or proposals to abolish the U.S. Immigration and Customs Enforcement agency (ICE) helped explain their failure to do better in Congressional races. Republicans and conservative Democrats hurried to pin responsibility for the lackluster results on the Democratic advocates of social democracy, though with the Democratic victories in the Georgia Senate races in early January and the popularity of the new administration's first big relief package, that debate temporarily died away.

By then, however, it was obvious that American politics only looked like the movie Groundhog Day, in which the characters endlessly cycle through the same routines. In reality, nothing like an eternal recurrence of same is in the cards, for either the U.S. or the rest of the world. Instead a frightening combination of globalized production, deregulated finance, climate change, and the wrenching effects of the COVID 19 pandemic is accelerating the famous spiral of world history. It is bringing forward trends that otherwise might have taken decades to flower, intensifying inequality at many levels, polarizing electoral cultures, and reshaping the world economy, while posing a range of startling new challenges to countries and older great power alignments.

In both houses of Congress, the Democrats' hold on power is razor thin. In the House, their lead is currently a very shaky eight seats. In the Senate, their victories in the January special elections in Georgia boosted them into a dead heat with the Republicans, making their grip dependent on Vice President Kamala Harris' power to break ties. And even before the Democrats' losses in state elections in November, 2021, everyone in both parties was acutely aware of the disasters that engulfed the last two Democratic Presidents in the midterm elections right after each entered the White House. ${ }^{8}$

The result is a riot of speculation about the future of the country that still likes to style itself the "Leader of the Free World." Many foreign observers and Democrats, who never warmed to Trump anyway, keep wondering how he could possibly have rolled up more than seventy-four million votes in 2020 - as he said, more than any sitting president in history. Conversely, supporters of the former President and members of the Republican establishment advance all kinds of theories, some quite outlandish, to explain how the Democrats managed to win. Meanwhile everyone is pondering the long term implications of the Trump movement's transformation into an openly anti-system political formation uncomfortably reminiscent of the Weimar Republic as well as the breathtaking way big tech companies selectively shut off access to their systems following the storming of the Capitol. As the changes sweeping through the international system become more obvious, new worries are also rising: in particular, whether

\footnotetext{
${ }^{8}$ This paper has to stay focused on the 2020 election. We will analyze the 2021 results another time. But it is obvious that many analyses of those elections repeat mistakes made in 2016 and 2020. Many commentators, for example, claim that education was a decisive issue in Virginia. In fact, the Washington Post exit poll shows that voters asked which single issue they considered most important responded by naming the economy (33\%) or taxes $(15 \%)$ - which is twice the percentage of voters who named education (24). See (Washington Post, 2021).
} 
the shocking American exit from Afghanistan is a warning that the establishments of both political parties are living in a fool's paradise.

All this persuades us that a careful look at what happened in the 2020 election is not idle curiosity. Elections, especially in money-driven political systems, are complicated affairs that repay analysis at many different levels. That political money played a vital role in the Democratic primaries was obvious even at the time. For example, regardless of their merits, late entering candidates like Michael Bloomberg would have been ignored by the press and political leaders, were they not billionaires. Nor could anyone except someone from the $1 \%$ ever have garnered more than $12 \%$ of the votes in states culturally light years from New York City, like Tennessee, Oklahoma, Arkansas, Alabama, Utah, Texas, or Colorado after just a few weeks of campaigning. Roughly the same holds for Tom Steyer, whose $12 \%$ of the vote in the South Carolina primary would likely have been zero without all his money. ${ }^{9}$ Even more obvious and more significant was the Golden Hoard of contributions that the Democratic establishment mobilized to turn back Sanders and, with some qualifications, Warren. But for reasons of space, we cannot try to unravel the primaries in this paper nor, because everything else would have to get short shrift, can we analyze the behavior of investor blocs in the election in any detail.

Instead this paper focuses on voters. What factors from their side help explain the differences in the presidential vote between 2016 and 2020? While the question is simple, getting the answers, and, even more, presenting them in an accessible form, are not. One needs first of all to extract important lessons from the long, often acrimonious, debates about the 2016 election. In our view, these point to the desirability of a change in focus in how elections should be analyzed, with far reaching implications for the types of data that are relevant. Then one has to come to grips with how COVID 19 reshaped the entire context of the election, which requires discussion of several important topics that have thus far received very little attention. Only then does it make sense to assess the familiar economic, demographic, and other factors that analysts traditionally investigate.

We thus divide this paper into seven distinct sections. The first reviews previous work on the 2016 election. It explains why this paper concentrates on place, industrial structure, and related variables to account for 2020's outcome. A second long section looks at COVID 19. We analyze how failed policy responses led to sweeping economic and social changes, with heavy costs to most of the population and dramatic alterations in the distribution of healthy, wealth, and income that affected the election.

Sections 3, 4, and 5 set out our formal spatial model of 2020's differences from 2016. The discussion is designed to be widely accessible; the actual formal model is presented in Appendix 1. Section 3 critically reviews accounts of the election that suggest that COVID 19 did not matter

\footnotetext{
${ }^{9}$ (CNN, 2020b); for Steyer's campaign including various controversies involving spending, see, e.g., (Golshan,
} 2020). 
that much. We set out a new approach that shows it mattered a great deal. Section 4 explores the unusual ways the economy influenced voters in 2020. We consider not only unemployment but differences in income and industrial structures, together with demographic and other factors more commonly discussed, including religion, ethnicity, and race. Section 4 analyzes Trump's very controversial trade policy. Section 5 describes how Trump's rarely discussed farm policies turned into his secret weapon, amounting to a dramatic political business cycle of remarkable proportions. Section 6 analyzes the influence on voting of the waves of wildcat strikes and social protests that punctuated most of the year. Section 7 considers what the future may hold. We take a first look at why the presidential election differed so dramatically from the outcome of the Congressional elections. Building on our earlier analysis of Trump's support within big business in 2016, we also highlight the continuing importance of private equity and other champions of free market fundamentalism in the Republican coalition along with the outsized importance of sectors like coal and oil opposed to government action to reverse climate change. ${ }^{10}$

\section{Learning From 2016: The Importance of Place and How To Analyze It}

Our research design tries to take seriously lessons from studies of the 2016 election. At the time, mainstream analysts were all but unanimous in rooting the Trump phenomenon in cultural reactions against the Other: foreigners, women, and racial minorities, to the exclusion of economic issues. But research that looked more closely into geography, economics, and local industrial structures revealed more complex patterns betraying obvious economic influences. ${ }^{11}$ Comparative research into right wing populism has also identified parallel cases in other countries. $^{12}$

Since 2016 studies of the American "dual economy" have piled up, making even stronger the case for taking a more holistic view of the economy's role. ${ }^{13}$ The already substantial literature on trade, technological change and voting has proliferated. While we cannot critically examine all this work here, studies of the 2020 election have begun to draw on it. ${ }^{14}$

To make further progress in understanding the Trump phenomenon, we think two moves characteristic of this growing literature are especially important. The first is to take place - that is: geography - very seriously. The second is to look carefully at how particular industrial structures in places link with broader social patterns in voting.

\footnotetext{
${ }^{10}$ (Ferguson, Jorgensen, \& Chen, 2018) exhaustively analyzes business support in the 2016 presidential campaign.

${ }^{11}$ See the references and discussion in (Ferguson, Page, Rothschild, Chang, \& Chen, 2020).

12 On the role of import polarization in other countries, see (Dippel, Heblich, \& Gold, 2015), (Dipple, Gold, Heblich, \& Pinto, 2021), inter alia. For the U.S. cf. (Autor, Dorn, Hansen, \& Majlesi, 2020). This paper presses a more general case for labor market deterioration, roughly equivalent to a dual economy approach. For the dual economy, see, e.g. (Taylor \& Ömer, 2020); (Temin, 2016); (Lazonick, 2016); (Lazonick, 2017); (Dipple et al., 2021) (Storm, 2017); (Ferguson et al., 2018); compare the discussion of local austerity on Italian voting (Cavallaro, 2021).

13 See e.g., (Temin, 2016); (Taylor \& Ömer, 2020); (Storm, 2017); (Lazonick, Sakinç, \& Hopkins, 2020) and the discussion in (Ferguson et al., 2018).

${ }^{14}$ See e.g., (Lake \& Nie, 2021) and the discussion of trade in the election below.
} 
Neither task is advanced simply by paying more attention to customary demographic variables about cities or town, or tacking those on to data about voters' occupations or even what industries they work in. The problem is more complicated: to recognize that in the dual economy that has developed in the United States, relatively affluent people in declining regions or poor people in areas dominated by specific industries such as the oil industry are likely to react rather differently - in some cases very differently - from similar individuals in other circumstances. In 2016, for example, researchers who took the trouble to look found telling evidence of how place mattered in election outcomes. An especially striking example was how voters in Congressional districts with high percentages of defective bridges from years of austerity warmed to Trump - a phenomenon that shows up in elections in other countries contested by right wing populists. ${ }^{15}$

2016 also offered striking lessons about how, in a society where the power of organized labor has shrunk so much, industrial structures themselves help structure mass political choices. Where the oil and gas industry was strong, for example, the Trump vote ran higher. The same was true for agriculture, mining, coal, and manufacturing in general. A large high tech information sector had a strong negative influence on votes for Trump. ${ }^{16}$ Evidence that imports negatively affected Hillary Clinton's chances in certain districts in 2016 is also compelling, and, again, shows many parallels with other countries. ${ }^{17}$

Research designs taking place into account are in principle not complicated. Ideally researchers combine survey data about individual voters with evidence about industry structures and regional patterns of economic growth. In practice, though, the way American voter surveys are typically conducted makes complications.

One problem, which can be exaggerated, arises from concerns about the reliability of many polls in recent elections. When the 2020 election turned out to be closer than most polls anticipated, many commentators invoked the specter of 2016 and advanced sweeping claims about how 2020 confirmed the general uselessness of polls. The conclusion is far too strong. The actual record of serious polls in 2016 is much better than their reputation. Most national polls were not far off at all - about 2 percent. ${ }^{18}$ Some crucial state polls were off, most likely because they underweighted groups that went heavily for Trump, such as voters with high school educations or less. In a very close election in which the Electoral College gets the last word, that was a formula for true embarrassment. And predicting who actually turns out to vote has always been difficult, whether in 1948, 1980, 2016, or 2020. But as a celebrated German philosopher wrote long ago, the owl of Minerva, the goddess of wisdom, flies at dusk. For understanding elections afterward, errors of this kind are not fatal. One makes due allowance and continues.

\footnotetext{
15 (Ferguson et al., 2020); on the general importance of place in 2016, see especially (Monnat \& Brown, 2017). For the comparative evidence, see above, Note 12.

${ }^{16}$ (Ferguson et al., 2020) for the industry and high tech influences. That data concerned congressional districts, not counties, as in this paper.

${ }^{17}$ (Autor, Dorn, Hanson, \& Majlesi, 2017); (Autor et al., 2020); (Dipple, Heblich, \& Gold, 2015).

${ }^{18}$ For 2016, cf. (Gelman, 2016); for 2020, (Gelman, Morris, Vittert, \& Xiao-Lee, 2020).
} 
The more intractable problem arises from the high cost of quality, nationally representative social science surveys, such as the American National Election Survey - widely esteemed as the gold standard for understanding electoral behavior. These are superb for what they are designed to do, which is to represent a true cross section of voters (and non-voters) in the country as a whole. But they face limits on feasible sample sizes: they cannot afford to poll in depth all over the United States. Inevitably, in jurisdictions with small populations, only a handful of voters find their way into the samples. That creates difficulties for using them to generalize about local influences. Vast, dense areas like New York City or Los Angeles likely contain more than enough cases to do this. By contrast, in Alaska, good luck finding, for example, even one Native American; remote rural areas in general pose a problem, though they are important for understanding the Trump vote. The need to safeguard the privacy of respondents adds a hurdle. Information about areas other than the Congressional district in which a respondent lives is protected. These problems create serious technical problems with survey weights optimal for multilevel models of the type we would prefer to run. Nor does it help that in contrast to work in regional science, the special statistical problems of analyzing areas spatially adjacent to each other are not widely appreciated in political science or economics. ${ }^{19}$

These caveats come with a silver lining: Where place is a central concern, not too much is gained by waiting for the major social science national election surveys to open to researchers. They are not designed to address many problems that most interest us. This paper, accordingly, tries to make a virtue out of necessity. Our universe of analysis is by design frankly spatial: the more than 3,000 counties of the United States, analyzed via a research design that takes explicit account of the states each is located in. Formally our model is a spatial regression model with separate intercepts for each state. The technical details are in the Appendix; our main text strives to be as accessible as possible.

With the qualification that data about individual counties are sometimes imperfect, this focus suggest a host of factors mattered that rarely appear in accounts of the 2020 vote that rely on individual poll responses. This point holds with special force for conclusions from election night exit polls, though the problem also afflicts even very good social science surveys. The exit polls, for example, said virtually nothing about the impact of the Trump tariffs and retaliatory measures these triggered from China and other U.S. trading partners on voters. They mostly seem not to have asked the question. Nor, a fortiori, did they offer any hints on the importance of the remarkable system of agricultural subsidies that the administration quietly set in motion to cushion farmers from the effects of its China policy. Amounting to one of the greatest political business cycles of all time, these passed under the radar of most analysts on election night and after, even as pundits puzzled over the immense Trump vote.

\footnotetext{
${ }^{19}$ See the discussion and references in (Ferguson et al., 2020). A good general account of spatial statistics is (Cliff \& Ord, 1981)
} 
A focus on space also throws sharp new light on Trump's economic appeal to many voters. Nothing was normal about the economy of 2020. But that makes even more valuable the ability to isolate the effect of small area differences in economic growth on voting in both the short term and over longer periods of time. Both of these approaches are illuminating, as we will see. The spatial emphasis also affords high resolution accounts of COVID 19's differential effects on particular areas. We can analyze not only how county differences in COVID cases mattered, but also consider effects of the U.S. K-shaped recovery that have so far received little attention from election analysts, such as the waves of labor protests and wildcat strikes spawned by the grave threats to worker safety and deepening of inequalities that the pandemic brought.

We are particularly interested in understanding how protests associated with the Black Lives Matter movement and the police killings that inspired it affected the election. Finally, attending to space throws sharp new light on how industrial structures shaped the 2020 vote. Though some thorny data problems require care, it is likely that not only vertically, but horizontally, industrial structures often mattered not just for investor blocs, but mass politics. While many analysts noticed that higher income voters turned toward the Democrats in 2016, few pondered the sectoral composition of these shifts. The consequence is that the historically specific mainsprings of the system's political economy get lost in vague generalities about higher or lower income voters.

It is possible to overplay even strong hands, however. A focus on analyzing specific areas does mean some very significant questions are virtually impossible to address. The most important come from the simple fact that all our findings are about aggregates. The literature on the "ecological fallacy" in statistics is very long. The way patterns at aggregate levels translate into the behavior of individuals is often far more complicated than readily imagined. Often what appears to be a straightforward inference from general results to specific voters is deceptive. Before surveys became ubiquitous, for example, election analysts often drew their evidence about how specific ethnic groups voted from returns in precincts where the group lived en masse. That skipped past questions about whether voters in less concentrated areas might be different or whether other groups in the district might alter their behavior in response and change overall results. Similar mistakes are easy to make with county data. ${ }^{20}$

An issue of this sort relevant to the Trump phenomenon concerns the much discussed question of the roles race and sexism plays in his appeal. That the former President went out of his way to invoke stereotypes to fire up his "base" is obvious by now, one hopes. His various appeals to white supremacy - some coded, many rather less so - certainly helped bring some voters to him. So did his targeting of specific women in public life and the news. But strong claims entered by many mainstream analysts that these factors powered the whole vast movement we think are plainly wrong: direct comparisons using poll data for individual voters show economic factors

\footnotetext{
${ }^{20}$ The classic paper is by (Robinson, 1950); the literature since is enormous.
} 
were also important. ${ }^{21}$ Careful attempts to measure how racial antagonism aligned with individual voting decisions between 2008 and 2016 suggest that such sentiments increasingly took the form of differences between rather than within the major parties. ${ }^{22}$ Or in other words, whites harboring strong animosities toward non-whites tended to drift away from the Democrats over to the Republican Party. Despite the very slight uptick in Black voting for Trump, we doubt that that trend was truly broken in 2020. The question is not easily addressed in studies like our's, though our findings about unemployment rates once again underscore the importance of economic considerations.

Many other mistakes translating between wholes and parts are possible, indeed, likely. In 2020, for example, some changes in counties' votes may simply reflect differential turnout - an important result, but not the same as the evolution of views within groups. And where protests are heavy, it should be obvious that differences in final election results could stem from any number of factors, ranging from real changes in views by supporters and former opponents or differential mobilization rates. Conclusions about how religion factored into the vote are hazardous for similar reasons, though on that subject we are reasonably confident of one interesting result.

Data on individual county industrial structures also pose unique problems that have no counterparts in individual surveys. U.S. government economic statistics mask data that might yield information about specific companies. In areas the size of counties, the concealment is sometimes obtrusive. One chillingly instructive example discussed in our Appendix 3 makes the point: what appears to be the largest producer of a certain type of aluminum in the country completely disappeared from Bureau of Labor Statistics figures for one county.

The many possibilities for misinterpretation raise yellow, not red flags, in our view. As we discuss in Appendix 3, most of the problems involving masked data for industries have workarounds, thanks to researchers who have used sophisticated techniques to reconstruct the original data. ${ }^{23}$ Using the corrected data means some very small counties, mainly in Virginia, have to be dropped from our dataset, but the accuracy of the rest is much improved. Our analysis of the effects of the administration's farm subsidies on producers of grains, fruits, and vegetables escapes the problem entirely, since we rely on new data produced by agricultural economists where masking is unlikely to be a problem. We acknowledge that our estimates for livestock are more problematic, but they concern only one industry and, as we explain below, there are reasons to believe our estimates are likely not far off the mark.

Concerns about aggregate inferences also need to be kept in proportion. Social scientists, and especially economists, have long debated the need for microfoundations. We are skeptical of

\footnotetext{
21 (Ferguson et al., 2020).

${ }^{22}$ See the evidence from the American National Election Surveys for those years in (Ferguson et al., 2020).

${ }^{23}$ See the discussion in Appendix 3; the basic source is (Eckert, Fort, Schott, \& Yang, 2021b) and their data Appendix to that paper. (Eckert, Fort, Schott, \& Yang, 2021a).
} 
general cases for that, but not for voting studies. ${ }^{24}$ Ideally one would like to reintegrate aggregate results back into specific accounts of how individual voters are affected. Given the problems with surveys and data, though, that implies more than one paper. Meantime one has to start somewhere: we think it is sensible to proceed while keeping careful watch on individual surveys, in all their imperfections, even if their data cannot be directly linked to the broad patterns under investigation.

The mutual conditioning between method and object in our study requires a few more comments. Firstly, our research question is about the differences in voting between 2016 and 2020. These we know in the aggregate are relatively small. Approaching the election in this way means that the many cases in which views about Trump or the parties did not change recede into the background. The caution is important, because it can lead to confusion: for example, the evidence of great enthusiasm in 2016 for Trump in areas where oil and gas interests bulked large is very strong. ${ }^{25}$ The President delivered for the industry in high style once he took office, but it is unlikely that he made many new converts in 2020 - probably everyone in the sector and many who lived off its fruits were on board already. Finding that his vote changed little in these areas does not mean that the voting bloc or the oil concerns were not important. It just means their influence did not change much over four years. Certainly, as discussed below, the ranks of his contributors show Trump's powerful appeal to oil and gas interests. The principle holds for several other groups, as will shortly be evident. A few, notably coal, also faced strong campaigns mounted by green political groups that rather clearly affected voters likely not affiliated with the industry in some districts. Given the many continuities in the vote, an accumulation of small changes is more likely than dramatic new evidence of major sectoral or group shifts - though hints of a few exist.

Secondly, our focus on counties inevitably raises a question about spillovers across borders. It is surely reasonable to ask how localized the effects and causes that we analyze really are. Whether, in other words, some people working in counties might live (and thus vote) in one of the neighboring counties.

Our answer is twofold. First, in principle of course they might. But there is a second reason to take this possibility seriously. As our Appendix 3 explains, most of the industrial data we and others rely on reflects establishment employment totals, rather than residential counts. To see the difference, just reflect on what that means for Manhattan: all those people working in skyscrapers downtown are counted as employed in New York county (Manhattan), even if they reside in one of the nearby counties and thus vote there.

\footnotetext{
${ }^{24}$ See, on the general position, esp. (King, 2012)

25 (Ferguson et al., 2020). Note that financing patterns for Trump's 2016 campaign changed considerably over time. Contributions from both oil and coal rose sharply in the closing "populist" phase of his turnaround campaign. See the discussion and Table 6 in (Ferguson et al., 2018).
} 
The problem, though, is less than meets the eye. We will bypass one obvious retort, that if you are trying to identify counties where, for example, finance is important, you could do much worse than use the raw figures. We will just stipulate the desirability of focusing on voting bases. Instead, we note that we can compare residential and establishment differentials for every county; these suggests strongly that the disproportion in New York is uniquely large, with a few other urban agglomerations showing the syndrome to a lesser degree.

More broadly, the "neighborhood" problem is one of the major reasons we routinely employ various spatial models when we analyze our data. These take account not only how neighboring areas behave, but also of patterns of errors. These methods should catch many kinds of spillovers, especially since most U.S. counties are substantially larger than towns. They stretch for good distances, so that everyone is not constantly transiting over nearby borders. But to be safe, rather than sorry, we run our regressions with dummies for New York, Kings, and Bronx counties, which our tests indicated may have unique problems of disproportion. The results did not change.

This paper's focus on county data also comes with a real benefit: U.S. counties are very numerous. Their abundance offers real advantages for testing research findings from many different fields: not simply history and political science, but economics, sociology, and geography. Each of these disciplines approaches elections in somewhat different ways. They sometimes depart from radically different premises and lavish most of their attention on particular forms of data, with little consideration of what other fields do. Fair tests of the different points of view thus require sorting through many variables. Small sample sizes can paralyze such efforts, but with more than 3000 U.S. counties, genuinely synoptic efforts are possible, despite the well-known statistical hazards all such efforts can encounter. The broad range of approaches, though, means one has to be prepared to consider many variables.

A final qualification is in order. Because Donald Trump and government policies figured so significantly in the chain of catastrophes COVID touched off, discussion of the pandemic and the economy has already generated a large, often highly partisan, literature. The role of experts, the President, lockdowns, state governors, vaccines - almost every topic is now intensely ideological. Even basic facts are often contested. Because this is a paper and not a book, we have to move swiftly through many topics to focus on those that mattered most directly. Alternative interpretations and many details all have to be treated in footnotes, to the extent we can consider them at all. We have to save space to discuss factors that have received little or no attention as possible influences on the election, such as the wave of wildcat labor disturbances - many over health and safety issues - that COVID spawned. Those have been treated in no election analysis.

\section{The Anatomy of Policy Failure: COVID 19}

Our spatially centered analysis of Biden's narrow victory rests on a statistical model of the change in the percentage of the total vote Donald Trump received in each county between 2016 
and 2020. ${ }^{26}$ To make our discussion as accessible as possible, we set out our formal model in Appendix 1; Appendix 4 displays a map of the differences across the entire United States. Our main text here reviews and critically analyzes the many factors that have been invoked to explain the election's outcome by other analysts and explains our reasoning and data.

In early February, 2020, the Trump team's own polling indicated that Trump would sweep to victory on the strength of his economic record. The calculation was that while the President would "lose on personality," his economic record was so strong that he would "win in a landslide." 27 Then came COVID.

Bob Woodward's account of his private conversations with the President demonstrates that top American officials knew far more than they were saying from very early on, but details of who knew what and exactly when remain shrouded in obscurity. ${ }^{28}$ It does not help that two features of the disease - the role of airborne transmission in spreading it and the fact that many people carrying it displayed no symptoms but could pass it along to others - sowed early confusion. The uncertainty helped sustain illusions to which many policymakers and interested lobbies were deeply attached and, because ventilation changes in buildings and workplaces would be very costly, gave many interested parties reasons to dig in.

In the end, though, the plague's swift and relentless spread provided the perfect squelch to postmodern claims that decisions rendered by hierarchies of credentialed experts settle questions of what is real. In a globalized world, the disease took off with the speed of jet aircraft, regardless of whether national medical authorities acknowledged airborne transmission or not. Some Pacific Rim countries, with greater experience of internationally transmitted diseases and closer links to China, reacted fast, shut down airports and economies, encouraged mask wearing, and launched intensive campaigns to test, trace, and isolate cases. ${ }^{29}$ Until vaccines arrived - most were slow to take those up, sometimes for the excellent reason that vaccines were expensive and rationed - these countries stood out as paragons of intelligent policy.

But most of the world, including financial markets, could not quite believe what was happening until the toll of the sick and dying made it impossible to continue with business as usual. In Austria, Italy, and many other countries, national authorities were loath to close ski resorts, sporting events, and other seasonal activities that packed crowds of people into small spaces and

\footnotetext{
${ }^{26}$ Like many other analysts, we do not include Alaska in our sample. The peculiar nature of the state's organization and the difficulties that creates for linking data from many sources creates prohibitively high barriers.

${ }^{27}$ (Leonnig \& Rucker, 2021), pp. 51-52; the quotations are from Brad Parscale to Trump and are on p. 52. The implied balancing out of personal and economic factors is very close to the view of voting in 2016 in (Ferguson et al., 2020).

${ }^{28}$ (Woodward, 2020).

${ }^{29}$ The literature on the diffusion and efforts to remediate COVID is far too large to survey here. We are struck by how differently countries fared at various times. A fine comparative review is (Storm, 2021b), one of the few to take full account of the many years of cuts in health care budgets in many countries. For COVID, we use the statistics compiled at https://github.com/nytimes/covid-19-data No set of COVID statistics is innocent but debating details would take us too far afield.
} 
were vital for local economies. The result was a rash of super-spreading incidents and virulent propagation.

As the scale of the impending disaster became clear, business groups and allied experts around the world began speaking up about dangers arising from even temporary shutdowns of the economy. Prominent industrialists of the European Business Roundtable, German economic experts, and many U.K. Conservatives all piped up about the potential threats to social order that could arise from prolonged unemployment. They derided ideas that the most reliable way to save the economy was to save lives and looked for ways to avoid shut downs. ${ }^{30}$

Evidence on the record and from investigative reporting suggest that many top political leaders and health experts were aware from very early on of the possibility that the disease might spread through the air. Regardless of what the World Health Organization did or did not know or say, social media, reports from cruise ships in which passengers who never left their cabins still became ill, and other forms of news across countries crackled with warnings. Even if doubts remained, at least the potential importance of masks was fairly obvious, simply from watching how China and other Pacific Rim countries were successfully combatting the disease. Not for nothing did White House China experts quickly don masks and stick with them, while many individual doctors, nurses, and some official experts proposed wearing masks as prudent precaution. ${ }^{31}$ But the vast extension of globalized supply chains meant that most western countries had off-shored production of masks and other personal protective equipment to China and other developing countries. Those far off lands faced problems of their own ramping up production to meet surging domestic demand. The embarrassment of admitting this in public would have been great. ${ }^{32}$ It would have raised fundamental questions about the wisdom of so much off shoring and whether national crash programs were necessary. After a generation of Neoliberalism, however, ideas of special government run programs to produce any but high tech products were anathema to governments in the west. Though governments sometimes invoked war time analogies, they only rarely followed through.

Grasping at straws was easier and stirred up less trouble. Not only political and business leaders, but many national medical authorities chimed in that masks would not help. More than a few

\footnotetext{
${ }^{30}$ For the Roundtable, see (Milne, 2020); for Lars Feld, (Seibel, 2020); for the Netherlands, whose Prime Minister wavered, see e.g., (Cohen, 2020); for the UK, (Shipman \& Wheeler, 2020).

${ }^{31} \mathrm{Cf}$. the transcript of the interview with former Trump NSC China adviser Mathew Pottinger, (CBSNews.com, 2021).

${ }^{32}$ Pottinger, (CBSNews.com, 2021), is clear on the role domestic shortages played in the advice the CDC, Anthony Fauci, and other medical advisers rendered in public early in the pandemic. The slowness of the CDC to acknowledge airborne transmission has since attracted considerable adverse comment. We ourselves know American researchers or officials who received warnings about airborne transmission early in the pandemic, including at least one very senior adviser who had gathered important evidence directly.
} 
politicians and business figures in Sweden, Netherlands, and UK at least coquetted with notions of allowing the disease to run its course in hopes of rapidly attaining "herd immunity."33

At the time, relations between the White House and U.K. Prime Minister Boris Johnson were unusually warm. Trump had endorsed Johnson's challenge to take over as leader of the Conservative Party. He had also cheered on the aggressive "Leave" campaign that carried Johnson to victory in the December, 2019 British election. The American President, a strong champion of "free enterprise," so consistently downplayed the hazards of COVID 19 that some critics, such as Thomas Friedman of the New York Times, eventually described him as really favoring "herd immunity." 34

In any case, the President's misgivings about lockdowns were clear from the earliest days, as were some sources reinforcing his thinking. Trump consulted regularly with a "Kitchen Cabinet" of business leaders that he trusted more than federal bureaucrats and policymakers in D.C. Press reports instanced Rupert Murdoch, a force in both the UK and the US press, Larry Ellison of Oracle, Blackstone CEO Steven Schwarzman, and some other Wall Street private equity executives, as leading members. According to news reports, "the advice the president receives from corporate moguls he trusts has been to worry about the effect of an extended lockdown on the economy." 35

With cases rising, talk about herd immunity in the UK abruptly diminished when researchers associated with the Imperial College published a statistical model projecting enormous number of deaths. This led to a painful reappraisal and a decision to lock down. ${ }^{36}$ That news reverberated around the world, not least in Washington, D.C.

As COVID cases galloped ahead in the U.S., "the president continued to be surrounded by divided factions even as it became clearer that avoiding more aggressive steps was not tenable. Mr. Trump had agreed to give an Oval Office address on the evening of March 11 announcing restrictions on travel from Europe, where the virus was ravaging Italy. But responding to the views of his business friends and others, he continued to resist calls for social distancing, school closures and other steps that would imperil the economy...Always attuned to anything that could trigger a stock market decline or an economic slowdown that could hamper his re-election effort, Mr. Trump also reached out to prominent investors like Stephen A. Schwarzman, the chief

\footnotetext{
${ }^{33}$ For the UK, (Shipman \& Wheeler, 2020); for the Netherlands, (Cohen, 2020); for Sweden, (Bjorklund, 2020) is revealing on government officials' real calculations, though it takes no notice of the early comments of the Swedish member of the European Business Roundtable in (Milne, 2020).

34 (Friedman, 2020); see also (Wilson, Diaz, \& Klein, 2020), for clear evidence that Trump administration appointees pursued that strategy. We expect that as more files become public, evidence on this point will grow. Scott Atlas, another controversial Trump adviser, was an outspoken admirer of Sweden and herd immunity (Abutaleb \& Dawsey, 2021).

35 (Dealbook, 2020), quoting the Times White House correspondent Maggie Haberman. For Ellison, see, e.g., (Leonnig \& Rucker, 2021). References to the Kitchen Cabinet are strangely absent in the latter work.

${ }^{36}$ (Shipman \& Wheeler, 2020); more recently dramatic testimony about the UK by former Boris Johnson adviser Dominic Cummings has brought new attention to the story. We leave this discussion for another time.
} 
executive of Blackstone Group, a private equity firm. 'Everybody questioned it for a while, not everybody, but a good portion questioned it," Mr. Trump said earlier this month. "They said, let's keep it open. Let's ride it."

Though both Trump and Johnson bent under pressure as COVID cases ballooned, neither stuck with lockdowns for very long. In both cases, business lobbying pressures to ease off were powerful. Vice President Pence, whom Trump eventually placed in charge of coordinating the administration's response to COVID, repeatedly delayed crucial decisions for fear of "alienating corporate America." 38 The White House also worked up cheerier economic models of its own with the idea, according to reporters, of weakening the authority of its own medical experts. ${ }^{39}$ Stories and headlines in major news media vividly register the resulting decision trajectories: "Tory grandees tell PM: it's time to ease the coronavirus lockdown." "A pincer movement of Conservative Party donors, cabinet ministers and senior Tory backbenchers is putting Boris Johnson under concerted pressure to ease the lockdown." 40 In the U.S.: "Conservative groups advising White House push fast reopening, not testing." Social media sites, half of them bots, meaning they were simply reflecting messages from another source, echoed this claim. "Top executives from some of America's biggest companies pressed President Donald Trump to move toward reopening the U.S. economy, while urging him to ensure that robust testing regimes are in place, according to people familiar with the discussions." 41

The last set of headlines points to differences within the business community that became salient as the number of cases rose. In the early days of the pandemic, prominent Silicon Valley business leaders were prone to grandiose proclamations about how their technological prowess could work miracles to fix the situation. The precise miracles promised varied with their firms' specialties. Some proposed new COVID tests they claimed could be scaled up to produce timely data on who was getting sick and where. ${ }^{42}$ The tests that garnered headlines mostly proved problematic: they were often not reliable, making high numbers of mistakes, both positive and negative. Nor were many really that inexpensive. When the Trump administration abandoned all interest in a national testing program, following an epic series of management failures and crony capitalist profiteering, those efforts petered out. ${ }^{43}$

\footnotetext{
37 (Lipton et al., 2020).

38 (Leonnig \& Rucker, 2021), p. 74.

39 (Leonnig \& Rucker, 2021), p. 98.

${ }^{40}$ (Wheeler, Shah, Harper, \& Calver, 2020); the second quotation is from that story. See also the artless Daily Mail: "Six donors including Phones4U founder John Caudwell and three cabinet ministers join calls for action"(Elsom, 2020).

${ }^{41}$ (Lawder, 2020); (Holmes, 2020); (Fabian \& Jacobs, 2020).

42 (Bruggeman, 2020).

${ }^{43}$ See the striking account in (Burleigh, 2021). The administration declined to use a World Health Organization test that became available before the pandemic had really hit the U.S. It did not want to do anything that would redound to that organization's credit. The CDC botched its own test. Later efforts to work with Silicon Valley by a taskforce organized by the President's nephew, Jared Kushner sank into a swamp, to put it politely.
} 
Other firms pushed contact tracing of infected patients through cellphone apps, though this idea inspired widespread resistance from skeptics who mistrusted what the firms would do with the data. ${ }^{44}$ The possibility of partnering with the White House to build a website that desperate Americans could consult to locate nearby testing sites intrigued several internet giants. But while the firms realized that this venture could yield a treasure trove of data, they were wary of repeating the disastrous experience of the rollout of the Obama administration's Affordable Care website. Amid a saturnalia of behind the scenes lobbying, the big players first checked one another and then pulled back. ${ }^{45}$ A consortium of major high tech firms that had been planning a broad campaign for increased government support keyed to the idea that the U.S. needed a much bigger response to China's economic challenge abruptly retooled, to take advantage of the pandemic. ${ }^{46}$ With less fanfare, key leaders of that effort also lined up with the Biden campaign. All the while, of course, pharmaceutical firms talked up treatments for the disease or the possibilities of developing vaccines.

The Trump administration was closer to Big Pharma than most of high tech, despite occasional bluster from Trump about regulating prices. Support for innovative technologies under terms highly favorable to the companies was something the Trump White House was comfortable with. Indeed, the strategy was time worn and not especially partisan: every single new drug approved by the Federal Drug Administration for sale since 2010, for example, developed with important federal government support, usually from the National Institutes of Health but sometimes other agencies, notably the Defense Advanced Research Projects Agency. ${ }^{47}$ The administration moved quickly to fund not one but a suite of vaccine candidates using procedures outside of customary conflict of interest standards. ${ }^{48}$

Otherwise, however, the administration hewed pretty much to the spirit of the pandemic laissez faire favored by the President's kitchen cabinet. Trump was quite unwilling to superintend major government efforts directed at ordinary Americans. The White House rejected a plan to distribute free masks to people using the post office. It also declined to mount a large scale national testing effort. Instead it rapidly devolved responsibility for combatting COVID to the

\footnotetext{
44 (Rita Rubin, 2020), for early contact tracing.

45 (Eban, 2020) has some relevant material, but our main sources came through investigative reporting.

${ }^{46}$ (Klein, 2020); see also the FOIA memos and other material cited in (Webb, 2020).

${ }^{47}$ (Cleary, Jackson, \& Ledley, 2020); funding from the Defense Advanced Research Projects Agency has received much recent attention. See, e.g., (Burleigh, 2021).

${ }^{48}$ (Burleigh, 2021). Her account shows how lame a common justification for the lax procedure - that the effort did after all develop vaccines - really is. Many key innovators received nothing for their work, while connected executives, scientists, and officials claimed huge awards. Right now the public image of the vaccine program treats it as a rousing success; more temperate views suggest that the number of candidate vaccines was really too low and that some rethinking about how to deal with pandemics is urgently necessary. Note that parallel efforts to produce remedial treatments did not meet with the same success and the vaccine roll out was much less than ideal. On the defects of private markets for vaccine production, see, e.g., (Monrad, Sandbrink, \& Cherian, 2021). See also the notable series of articles on vaccine production by (Lazonick, Tulum, \& Jacobson, 2021).
} 
states, clearly anticipating that state Governors, not the White House, would take the heat for individual lockdown decisions, school closings, or mask mandates. ${ }^{49}$

Pitting states against each other to find and bid for supplies was predictably disastrous. State health agencies had never been very large and years of austerity had enfeebled them still more. In addition, state governors often preferred to marginalize them in favor of politically connected new vendors with no track records in the area. Trump's own public disdain for efforts to combat the disease and readiness to treat lockdowns as violations of individual freedom diffused rapidly throughout the Republican Party, greatly complicating crisis management by state governors. ${ }^{50}$ Neither did it help that so many people occupying high administration positions in health and welfare were there not because of their expertise in those areas but because they could be relied upon to fervently support conservative social values, such as opposition to abortion. ${ }^{51}$

How much support the administration's vanishing act and overt contempt for taking precautions against COVID cost it in the election has been disputed, but there is no question that Trump's handling of the pandemic disgusted many Americans, including many high level business executives. For many of these, working from home posed only modest problems. For them and other affluent - and mostly white - Americans who could afford to pay other people, many of whom were not white, to shop for them, lockdowns and even school closings were relatively tolerable, especially after they relocated to suburban homes. ${ }^{52}$

Not surprisingly, accordingly, prominent financiers and big business executives in capital intensive firms or high tech were much more tolerant of lockdowns and open to formal collaboration with medical experts than the Trump White House, whose disdain for even its own health care specialists was already evident. Former Clinton Treasury Secretary Robert Rubin, who was then working in the background on behalf of Joe Biden, the presumptive Democratic nominee against Trump, for example, urged the administration and Congress to work together. They should, he urged, "convene a small group of independent and respected public health experts and economists to weigh...interdependent health and economic considerations. The experts' framework should reflect economic forecasts under different health scenarios and start with the emerging consensus that the transition will be gradual, that large-scale testing is essential, that different cities or regions may be on different timelines and that the guidance for people with antibodies may differ from that for those who remain vulnerable." He also urged

\footnotetext{
49 (Burleigh, 2021); (Collman, 2020).

50 (Burleigh, 2021) is a detailed account, though many confirming analyses exist.

51 (Burleigh, 2021).

${ }^{52}$ For who was able to work from home, see, e.g.,(Dingel \& Neiman, 2020); (Mongey, Pilossoph, \& Weinberg, 2021) add some important details. Some outdoor or transitory indoor jobs probably have low rates of danger. By contrast, some white collar jobs may be turning into "Information Age blue collar positions": notably teaching at all levels and vast parts of the non-profit sector, including much of the arts. Health care may share features of this, where random contacts with patients without much protection are likely inevitable. Intersectional studies suggest Hispanic women and Black women were especially hard hit by unemployment. See (Gezici \& Ozay, 2020) A substantial literature suggests that women were disproportionately burdened by COVID's impact, not least because working at home came on top of taking care of children and other problems.
} 
much larger packages of aid to both individuals and small businesses than anything on the administration's radar. Remarkably similar to what President Biden later proposed, Rubin suggested a multistage plan: a substantial first program for quick relief should be followed by another for large scale reconstruction. ${ }^{53}$

The White House had very different views. Often openly berating health experts, the President and his key advisers initially favored a set of very modest relief and spending measures heavily weighted toward big business and specific industries, such as airlines and hospitals, and a temporary cut in the payroll tax. The latter would, of course, do nothing for workers who had already lost their jobs and would accelerate projected shortfalls in Social Security.

The package pointedly did not include any significant support for restructuring the ways firms organized work to keep their employees healthy. ${ }^{54}$ The administration's main policy on that score was simply to continue dismantling the Occupational Safety and Health Agency, which had legal responsibility for regulating safety conditions in most industries. ${ }^{55}$ The administration also looked askance at more than small expenditures to supplement paltry state levels of unemployment assistance, suspensions of apartment evictions, or moratoria on student loan payments. As key Republican Senators openly avowed, a major consideration was fear that temporary support programs would reduce pressures on workers to remain employed - a goal that hardly mattered for high tech and capital intensive firms, but was very important to the many American businesses whose business models were built around abundant supplies of low wage labor. ${ }^{56}$

But Democrats controlled the House of Representatives and thus could not be ignored. When they proposed and actually passed a much larger package of relief and support spending totaling \$3 trillion, the White House and Republican Congressional leaders dug in. The Republican dominated Senate, with erratic White House support, countered with a proposal a third of that size and flatly rejected a Democratic offer to split the difference. With the economy nosediving, though, the pressure to act was intense.

Amid intense infighting, the administration and the Democrats eventually hammered out a series of compromise agreements in March and April, though with important adjustments later. The full package comprised not one, but several major pieces of legislation and executive actions. Trump and the Republicans had to accept some large scale relief assistance, including supplementary unemployment assistance to many more workers than would normally have qualified for it, temporary federal aid to pay costs of COVID testing and some medical bills, and a bitterly

\footnotetext{
${ }^{53}$ (Robert Rubin, 2020). There is one clear switch with Biden: the emphasis on later deficit reduction. There sits a striking change in viewpoint, of which more another time. For a brief discussion of changes, see (Ferguson, 2021) ${ }^{54}$ (Nilsen \& Zhou, 2020).

${ }^{55}$ (Michaels \& Wagner, 2021); (Rosenberg, 2021); a detailed critical evaluation of OSHA under Trump by the U.S. Department of Labor's Office of Inspector General is (General, 2021).

${ }^{56}$ (A. Smith, 2020); a fine empirical criticism of claims advanced in the Wall Street Journal and other organs that the unemployment insurance provisions killed jobs by Casey Mulligan and Stephen Moore is (N. Smith, 2020).
} 
contested one time stimulus payment of $\$ 1,200$ per person and $\$ 500$ per child. ${ }^{57}$ When the spring legislation's short, imperfectly enforced moratorium on evictions expired in July, the Center for Disease Control issued another on September 1 that ran until the end of the yearwell after the election. Some forms of unemployment insurance expired in July; they were extended in September under prodding from the Democrats through the end of the year. In the end, the additional stimulus payments prevented broad wage deflation and kept many Americans out of poverty. ${ }^{58}$

The administration's fiscal response to the pandemic thus represented a compromise that compelled it to accept far more spending than it wanted. But its answer to the crisis had another track that was much less equivocal - one that moved with the speed of light and on a scale that took the world's breath away. As bad news from Italy and other western countries piled up in late February, financial markets swooned. A dash for cash of colossal dimensions began. Facing calls for more margin and demands for loan repayments, many firms had to sell off U.S.

Treasuries and other safe assets for whatever the market would offer. Their urge to purge drove prices down further, intensifying the squeeze with each turn of the downward spiral. Not just finance, but the real economy threatened to collapse completely.

As markets melted down, the champions of laissez faire on Wall Street who had mocked Senator Bernie Sanders" "Medicare for All" as fiscally irresponsible abruptly lost any misgivings about reaching into Uncle Sam's wallet. Suddenly "whatever it takes" became the order of the day. Almost overnight they embraced socialism of a very special sort: a gigantic government financed bailout all their own. The Federal Reserve and Trump's Treasury Department collaborated to launch the greatest "single payer" insurance program in world history. The aim was to bring financial markets back to life, not just in the U.S., but across the world. The Fed flooded markets with "liquidity" using open market operations, bank repurchase agreements, quantitative easing, and a brace of new special credit facilities and special purpose vehicles for purchases in particular markets. Through swap lines with other central banks and other means, the central bank also poured dollars out to world markets, snuffing out fire sales of assets and bank failures elsewhere. The Fed privatized much of the bailout to large private asset managers like BlackRock and kept widening classes of assets it bought, while pushing interest rates down close to zero. ${ }^{59}$

\footnotetext{
${ }^{57}$ The bill, however, did not require that patients be told their costs would be covered. Many hospitals did not, leaving people under heavy pressure for no legal reason. See (Farmer, 2020).

${ }^{58}$ (Levine \& Bresnahan, 2020); (Cochrane \& Tankersley, 2020); (Emma \& Levine, 2020). For the importance of low wage labor, see the dual economy literature cited earlier. It is striking that the Federal Supplementary Poverty Measure for 2020, which reflects a broader range of federal support than the official poverty definition, produced a lower estimate of Americans in poverty. (Fox \& Burns, 2021)

${ }^{59}$ There is no end of literature on the Fed's response to the pandemic. A good overview of some basic facts is (Congressional Research Service, 2021). For the contracting out, see, e.g.,(Podkul \& Lim, 2020) and (E. Brown, 2020). The economic issues are mostly obscured in the literature, but see the series of papers Edward J. Kane for the Institute for New Economic Thinking, esp. (Kane, 2020).
} 
The massive interventions, backed by a provision in one of the fiscal packages providing $\$ 454$ billion dollars to the Treasury to absorb any Fed losses, dramatically reconfirmed the Fed's status as the world lender of last resort. The effort was so successful that in the end most special programs barely were needed and could be rapidly wound down. ${ }^{60}$ The rapid fall in interest rates made issuing new private debt very cheap while also raising the values of firms' discounted future cash flows. The result was a wave of new private debt issuance, a dramatic stock market revival, and new rounds of corporate takeover bids. In effect, the central bank was indirectly financing the restructuring of the economy by private firms by providing selective access to credit, even as soaring unemployment and short time work wrecked the lives and livelihoods of millions of ordinary Americans.

Resonant promises that the bailout would help "Main Street" along with Wall Street were hollow: even the parts of the package that were supposed to be reserved for small businesses went heavily to affluent clients of major banks responsible for making the loans. ${ }^{61}$ The result was the eerie K shaped recovery: news reports spotlighted gains to billionaires' wealth and income in the same breath as they tracked ever rising unemployment, small business shutterings, and COVID ravaging through low income and minority communities and nursing homes. Statistics compiled by the Federal Reserve indicate the extent of the upward shift in wealth to the $1 \%$ that ensued.

\footnotetext{
${ }^{60}$ (Congressional Research Service, 2021). For the details of the Treasury support for the Fed, cf.(Wiggins \& Feldberg, 2020).

${ }^{61}$ (O'Connell, Dam, Gregg, \& Flowers, 2020), among many sources. ProPublica published a notable series of articles available on its website: https://www.propublica.org/ including racial disparities in lending under the program.
} 


\section{Figure 1}

\section{Total Net Worth of the 1\%: The Big Jump Under COVID}

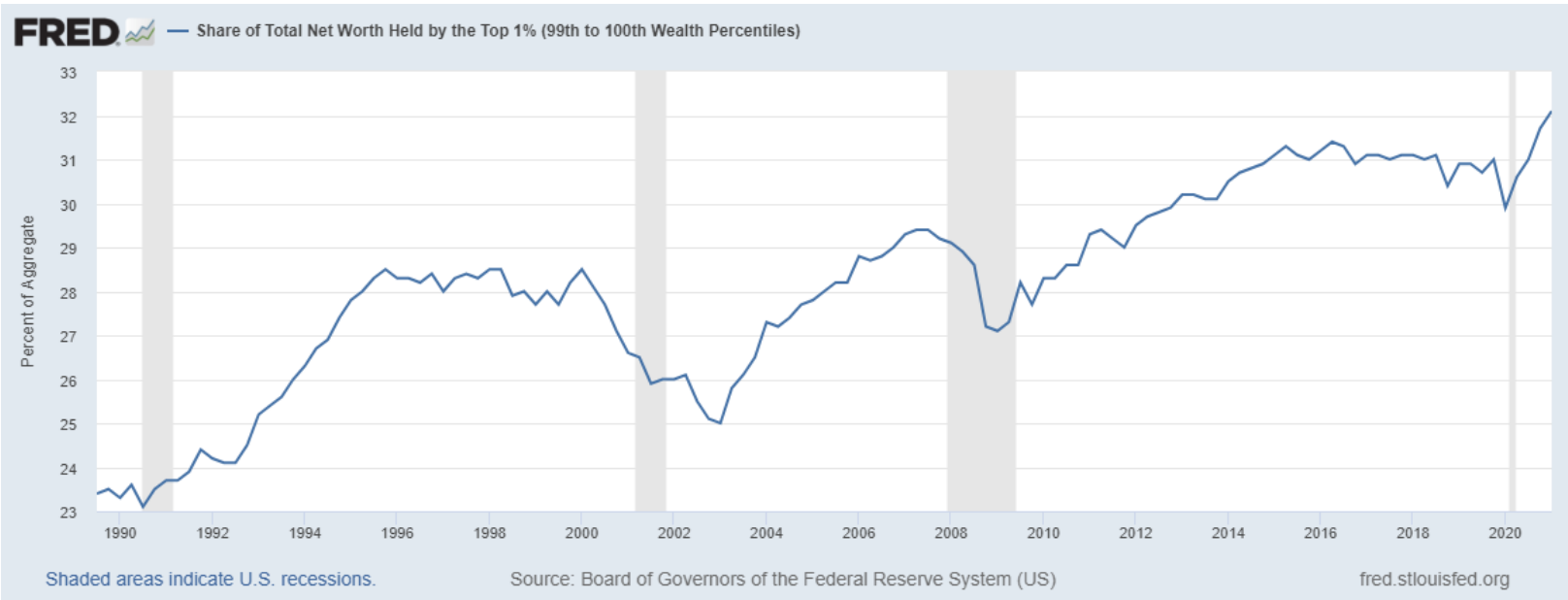

Source: Board of Governors of the Federal Reserve System (US), Total Net Worth Held by the Top 1\% (99th to 100th Wealth Percentiles) [WFRBLT01026], retrieved from FRED, Federal Reserve Bank of St. Louis; https://fred.stlouisfed.org/series/WFRBLT01026, August 16, 2021.

With some obvious exceptions -- airlines, tourist facilities, retail stores, restaurants, and other sectors hard hit by lockdowns or the collapse of demand for their products - white collar executives were mostly able to work remotely from comfortable homes and continued to be paid. While they toiled, their stock holdings and pension funds soared in value as the stock market rocketed back up. Meantime vast numbers of small businesses suspended operations, cut back, or failed. Pushed to the wall, individual owners laid off workers or put them on short time. Only rarely able to get loans from banks, owners of small enterprises, like many of their employees, rolled up credit card debt. Major parts of the non-profit sector, along with many in arts, found themselves in the same situation and without a lot of help. See Figure 2, which shows that until the Biden administration took over, the percentages of families losing income varied heavily by social class and were only modestly recouped by jobless benefits. ${ }^{62}$

${ }^{62}$ We are grateful to Dr. Claudia Sahm for the chart. 
Figure 2

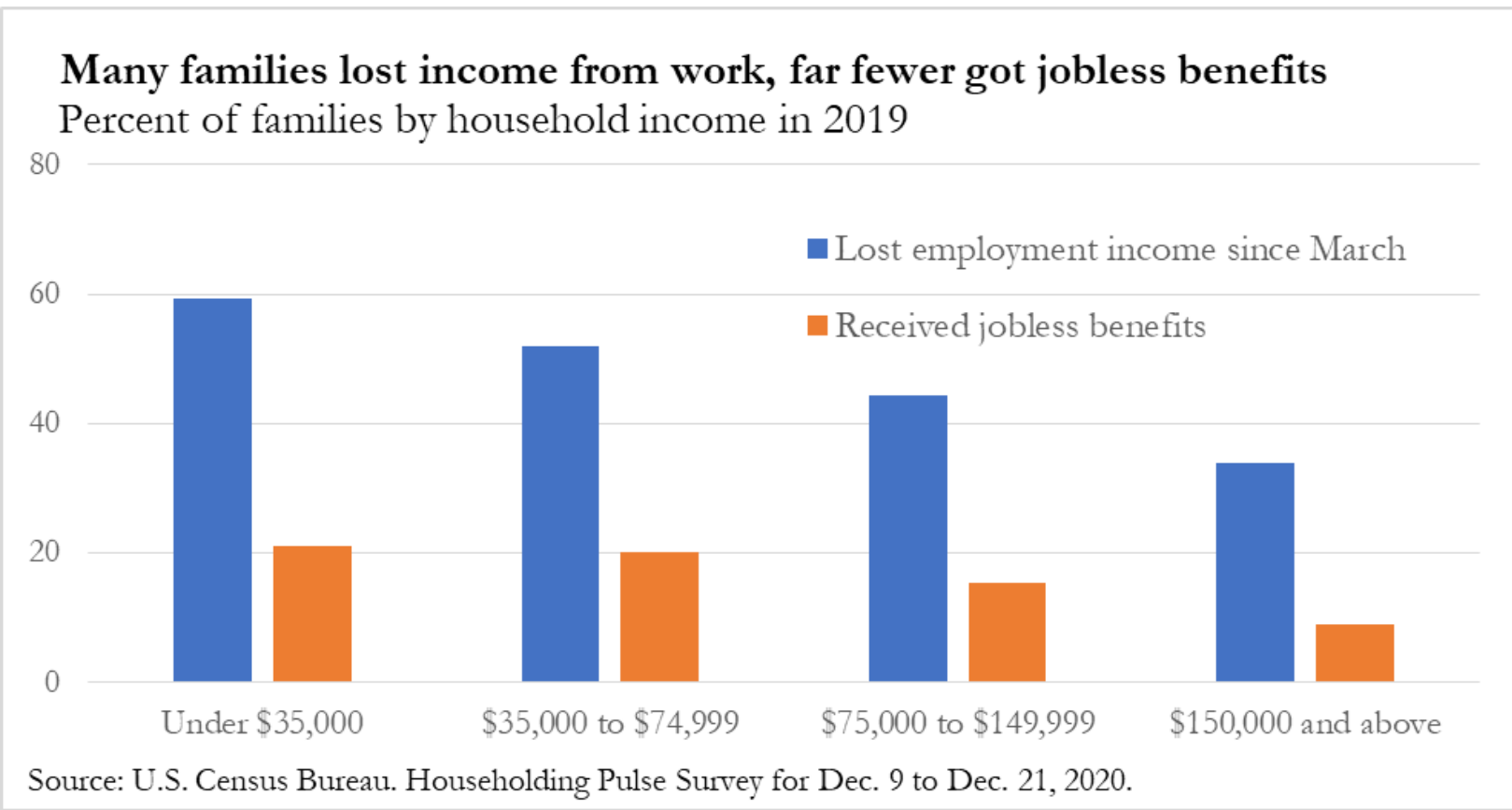

\section{Graph courtesy Claudia Sahm}

The Trump administration had quite deliberately downgraded the Occupational Health and Safety Agency since taking office. The haste with which the agency rolled back existing regulations, and its failure to issue emergency rules or even enforce existing regulations eventually became a scandal, albeit a very low key one. ${ }^{63}$ Though steep racial and ethnic disparities in exposure to occupational hazards were obvious, interest in safety issues by most of the media was very minimal, even from news outlets and reporters who in other contexts rushed to flash their credentials as "woke."64

While some outdoor construction jobs were perhaps not too dangerous, much indoor work was, with many jobs in specific sectors such as meat packing, being very dangerous indeed. ${ }^{65}$ Given all the holes in the U.S. safety net, especially the lack of regular medical insurance coverage, many individual workers could not afford to take time off from work if they felt ill. They had to show up to work because they needed the paycheck, endangering not only themselves but coworkers. A large subset of white collar workers whose routines involved intensive personal contact also faced substantial hazards, unless or until their workplaces improvised some form of remote work, as ultimately many educational institutions finally were driven to. The pandemic,

\footnotetext{
${ }^{63}$ See the references and discussion above, but especially (General, 2021).

${ }^{64}$ An exception was Bloomberg, on meat packing, as will become clear below.

${ }^{65}$ (General, 2021); (Michaels \& Wagner, 2021). Studies of occupations, though, suggest that construction work was fairly dangerous.
} 
in this respect, confirmed that many white collar jobs were firmly lodged in the lower tier of America’s dual economy. ${ }^{66}$

Meantime, as unemployment soared to among the highest levels in the developed world, blue collar workers, many of whom were non-white, struggled to survive. In many states unemployment benefits were meager and health insurance, even with special temporary federal support, was less than complete. Few enterprises tested very much for COVID; small ones could not afford to, while many bigger businesses simply refused to do more than the law required. We are sorry to report that medical safety device experts have related to us how in their conversations with corporate managements, many executives stated forthrightly they would not do more than the law required. At Amazon, which expanded fabulously during the pandemic, a senior executive with a distinguished record resigned after the firm fired employees protesting safety conditions, citing "evidence of a vein of toxicity running through the company culture." 67

Meat packing and, ironically, hospitals and nursing homes provided especially shocking examples of how regulatory neglect and the pursuit of profit combined to produce disastrous outcomes. The industrial organization of the meat industry has changed greatly in recent decades. Many meat packing plants now employ large numbers of Hispanic and Black workers in relatively remote rural areas. In many, COVID raged out of control at least part of the time. In some instances, white collar managers even placed bets on how many employees would sicken. ${ }^{68}$ Nursing homes were also heavily exposed and, again, Hispanic and Black workers, along with patients, were disproportionately at risk. ${ }^{69}$

In hospitals, many doctors and nurses were in touch via social media with physicians, nurses, and analysts in other countries. Some knew virtually from the outset that COVID 19 almost certainly transmitted through the air, though top U.S. health experts and the Center for Disease Control for a long time did not highlight that possibility. But when they improvised masks for themselves (good ones were virtually unavailable at any price) or their patients, they often met with stern official disapproval. When they protested the lack of appropriate personal protective equipment or encouraged colleagues and patients to wear masks, they were often threatened. More than a

\footnotetext{
66 (Michaels \& Wagner, 2021)

${ }^{67}$ For unemployment rates, cf. (Storm, 2021b); for workplace responses, (General, 2021); for levels of unemployment insurance, see, e.g., (Porter, 2021); for Amazon, cf. (Zaveri, 2020).

${ }^{68}$ (Hirtzer, 2020); (Mosendz, Waldman, \& Mulvaney, 2020) comment that: "The actual work of processing animal carcasses is hidden, tucked away in small towns and rural areas. Workers are often minorities and immigrants, who lack significant political representation. There are no exact statistics on how many undocumented or noncitizen workers are employed in the industry, but the nonprofit Food Empowerment Project found that 38\% of meat processing workers were born outside the country." For the betting pool, (Dorning, 2020). Overall rates of COVID in meatpacking and chicken processing were very high. See (Saitone, Schaefer, \& Scheitrum, 2021). A recent House of Representatives investigation of meatpacking revealed that both fatalities and the number of workers who became ill were much larger than previous studies suggested (Telford, 2021).

${ }^{69}$ (Artiga, Rae, Pham, Hamel, \& Muñana, 2020). In some states, hospitals appear to have sent desperately ill patients to nursing homes. That artificially forced up counts of death rates for the latter, while lowering them for the senders. New York has been instanced as such a case, but there were others. See (Barker \& Harris, 2021)
} 
few were dismissed by hospitals and clinics. OSHA remained virtually moribund; a long campaign by very dedicated researchers finally brought the airborne character of the virus to the attention of the CDC, which only haltingly recognized it. ${ }^{70}$

Meantime American workers who suspected they were at high risk at work had to find ways to save themselves. With virtually no publicity, many tried. In perhaps the least appreciated chapter of COVID's deadly surge, a wave of wildcat strikes, walk outs, demonstrations, and campaigns by workers welled up. Many focused on safety; others also sought hazard pay or simply higher wages. A few protested dismissals of other workers. ${ }^{71}$

A labor reporter who realized that something unusual was afoot started trying to tabulate these mostly unsanctioned workplace actions. He and colleagues began to track them. Our Figure 1, based on a reworking of data from their website, displays trends over time. From the start the numbers are impressive; by summer, around the time that a separate - and separately tabulated wave of protests and demonstrations associated with the Black Live Matter movement took off, workplace protests soared, too. Though precise numbers are unlikely ever to be pinned down, it seems safe to conclude that Black and Hispanic workers were heavily represented in these protests. We converted geographic coordinates in the original dataset to yield counts by county so that we could explore their impact on the vote. We discuss that below, when we consider the much larger and better covered Black Live Matter movement.

\footnotetext{
${ }^{70}$ The case of the first physician fired in the United States remains an object lesson. See the discussion in (Parramore, 2020); for many more examples of health care workers, see the entries for various days in Mike Elk's Payday website at https://paydayreport.com/ and (McNamara, 2020); on the slowness of the CDC, see, e.g., (Gale, 2021); helpful also is (Molteni, 2021). Work by Dr. Kim Prather and her colleagues at the Scripps Institution of Oceanography and the Department of Chemistry and Biochemistry at UC San Diego certainly played a substantial role in bringing the airborne hypothesis to the attention of senior government medical advisers, but the government responses remained weak for a long time. Note that recognition of the importance of airborne transmission would entail substantial costs to refitting buildings and schools. See the discussion in (Gurdasani, Alvelda, \& Ferguson, 2021) and the subsequent exchanges between Randi Weingarten of the American Federation of Teachers, the CDC, and the Department of Education in (Erickson, 2021).

${ }^{71}$ For the basic data, see the account in (Leon \& Elk, 2021) on the Payday website. We reviewed and corrected a number of entries for the time period we analyzed. Some critics have questioned whether this data series can be fairly compared to the government's official strike statistics, which show much lower rates based on higher cut off points for the size of the strike and also benefits from large scale efforts obtain full coverage. A few also probably were sanctioned by one or another local labor organization, though since there are so few of those now, the numbers must be small. Our comment is that such criticism misses all the important points. We think this dataset most resembles the various indices compiled by historians for eras in which official statistics for strikes and protests were rudimentary; cf., for example, (Shorter \& Tilly, 1974). It does not have to be perfect to be very informative.
} 
Figure 3

Wildcat Labor Disturbances 2020

Over Time

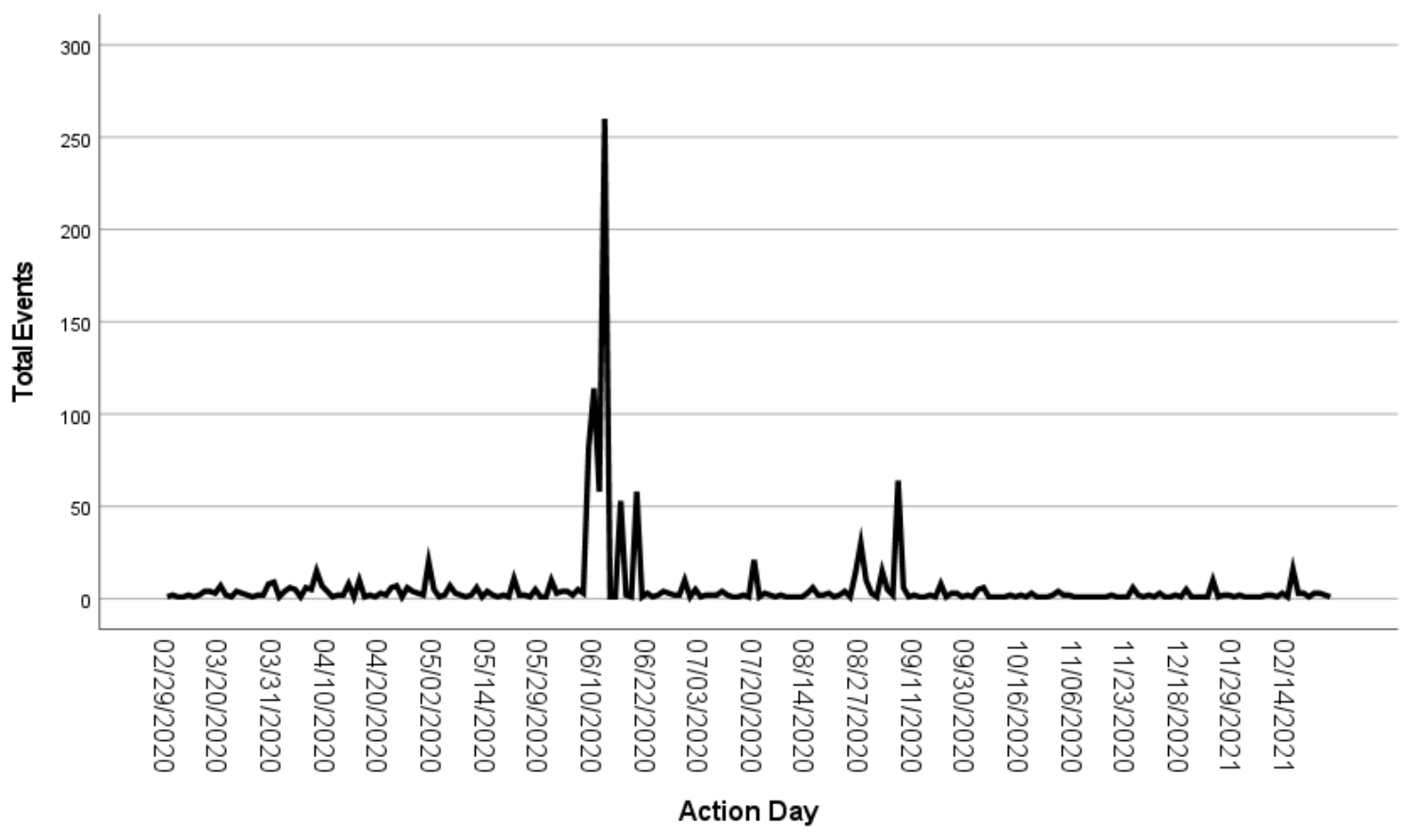

Source: Leon and Elk, See Text 
Figure 4

\section{States Won by Biden or Trump and Number of Wildcat Strikes}

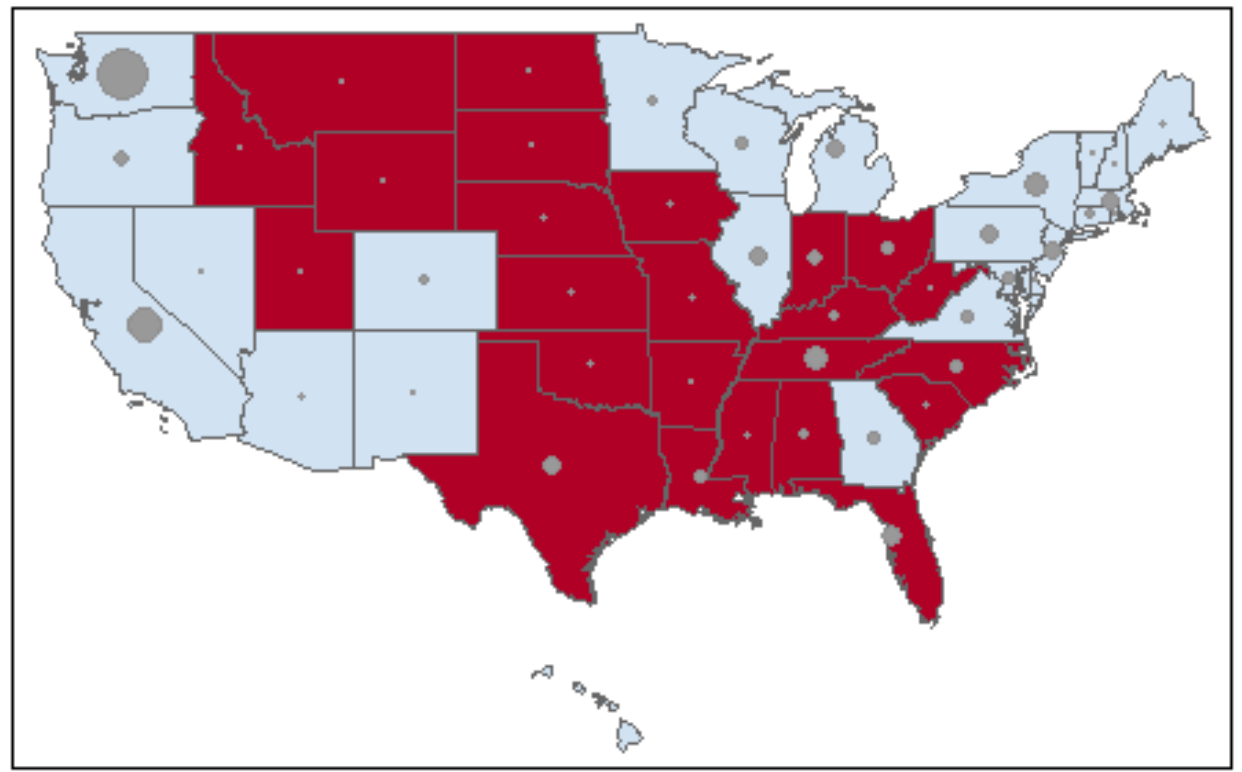

Trump Biden Labor Protests

50100200300

\section{COVID, Economy, Demography and the Vote: Empirical Tests}

The wave of wildcat strikes was one among many the many effects of COVID on the U.S. political economy and highlights the need to arrive at an estimate of how much of a difference the pandemic really had on the election. With our focus on county data, that question can be reinterpreted as asking how varying county rates of COVID 19 affected local electoral results. Here, however, is the rub: this question has already been tackled by several groups of researchers. As bizarre as it may sound, their conclusions differ sharply. Two carefully researched papers, for example, reach divergent conclusions. One is confident that Trump's mishandling of COVID cost him rather heavily; the other concludes that COVID's influence on the vote was negligible. The small army of media polling analysts reach similarly discordant conclusions. $^{72}$

The problem cannot be solved by simply correlating votes for candidates with county rates of COVID. A famous pitfall of election analysis, committed all the time by talking heads in the media, is to assume that views on issues are prior to individual decisions to support candidates.

\footnotetext{
72 (Lake \& Nie, 2021); (Baccini, Brodeur, \& Weymouth, 2021). For a survey of post-election polls, see (Masket,
} 2021), which concludes: "Not as much as one might expect." 
But in the case of COVID 19, the possibility of "rationalization" - that voters may adapt their views on issues to positions espoused by candidates they like - is quite real. In 2020, Trump's public contempt for social distancing, lockdowns, and mask wearing transformed these everyday precautions into bitterly partisan litmus tests. ${ }^{73}$ Some of his maskless and anything but socially distanced campaign rallies and White House events even turned into super-spreader events. One therefore has to reckon with the possibility that Trump voters may well have not blamed him, regardless of local conditions. They could also have contracted COVID at higher rates simply because they were strong supporters, which would not imply that higher rates of COVID led to more Trump voting.

The classic statistical method for resolving problems of reciprocal causation ("endogeneity" in the jargon) is to find a stand in for the explanatory variable that you suspect is contaminated because it is both cause and effect. This proxy variable has to meet very demanding conditions: it needs to be correlated with the suspect explanatory variable (in this case: COVID) but it cannot itself exercise any separate influence on what you are trying to understand (Trump voting). The cleaned up "instrumental variable" is then used instead to estimate the true effect. ${ }^{74}$

In practice resorting to instrumental variables is akin to treating COVID patients with untested personal protective equipment. One can only try and hope for the best. There is usually no way to verify the absence of indirect effects. The main piece of evidence offered is typically that no one can think of any. ${ }^{75}$ The previous papers that have tackled this question represent sophisticated and thoughtful attempts, but we are not persuaded that the instrumental variable both use - the presence within counties of meatpacking plants or nursing homes - does the job. Meat packing and nursing homes are both certainly correlated with higher rates of COVID cases, but they are also industries that employ many non-white workers. Minority populations not only contract COVID at higher rates, but our statistical analysis reveals that percentages of Hispanics and Blacks both affect county voting results (see Appendix 1). Members of these groups were also prominent in the wave of wildcat labor disturbances discussed above and those protests, as we will show shortly, also affected voting. The evidence is also strong that firms in sectors tried to hide the real totals of both illnesses and fatalities. ${ }^{76}$

As in some of our previous work on political money, our skepticism leads us to try a different tack. What matters in 2020 are possible spurious correlations between Trump votes and COVID incidence - Biden was not downplaying the threat or urging his followers not to take precautions. As many have noticed, many U.S. counties display fairly heavy majorities for one or the other candidate. For this paper, we use those lopsided districts as natural experiments. Let us accept that Trump voters do not believe that masking and other non-pharmaceutical interventions matter

\footnotetext{
73 (Gollwitzer et al., 2020).

74 (Stock \& Watson, 2010).

75 (Stock \& Watson, 2010); cf. also the extended discussion in (Ferguson, Jorgensen, \& Chen, 2019).

76 (Baccini et al., 2021); (Lake \& Nie, 2021) and the discussion below on meatpacking and wildcat labor disturbances for voting influences. For efforts to hide totals, see above, notes 68 and 69.
} 
or even that COVID is real - any rationalization they accept that gets Trump off the hook for making the pandemic worse suffices for our stratagem. What matters is that his supporters just will not hold him responsible. But heavy Biden districts should be much less cavalier.

We separate counties into High and Low Biden districts. The former are counties in which Trump won less than $40 \%$ of the vote; all other districts are designated as Low Biden districts. Then we assess how rates of COVID 19 (adjusted for county population) affected each type of district. The differences are dramatic: as our statistical results in Appendix 1 show, in High Biden counties increases in COVID 19 rates drastically affect the vote. For every $1 \%$ increase in the rates, Trump voting falls by .16 from 2016. In the low Biden districts, rates of COVID do not matter. Fully a quarter of all counties endured rates of COVID above 3.85, implying substantial losses for the President.

Our solution is not perfect - every county, after all, mixed Trump and Biden voters - but this method yields a better estimate than other approaches based on aggregate data. Because of the Electoral College and peculiarities of the distribution of High Biden counties across states, we are cautious, but it seems likely that the effect of Trump's handling of COVID was indeed substantial: possibly enough by itself to indeed have cost him some states and perhaps the election. (See Figure 5, which graphs changes in Trump's share of the vote together with the number of High Biden counties in each state.) 


\section{Figure 5:}

\section{States Won by Biden or Trump and Number of High Biden Counties}

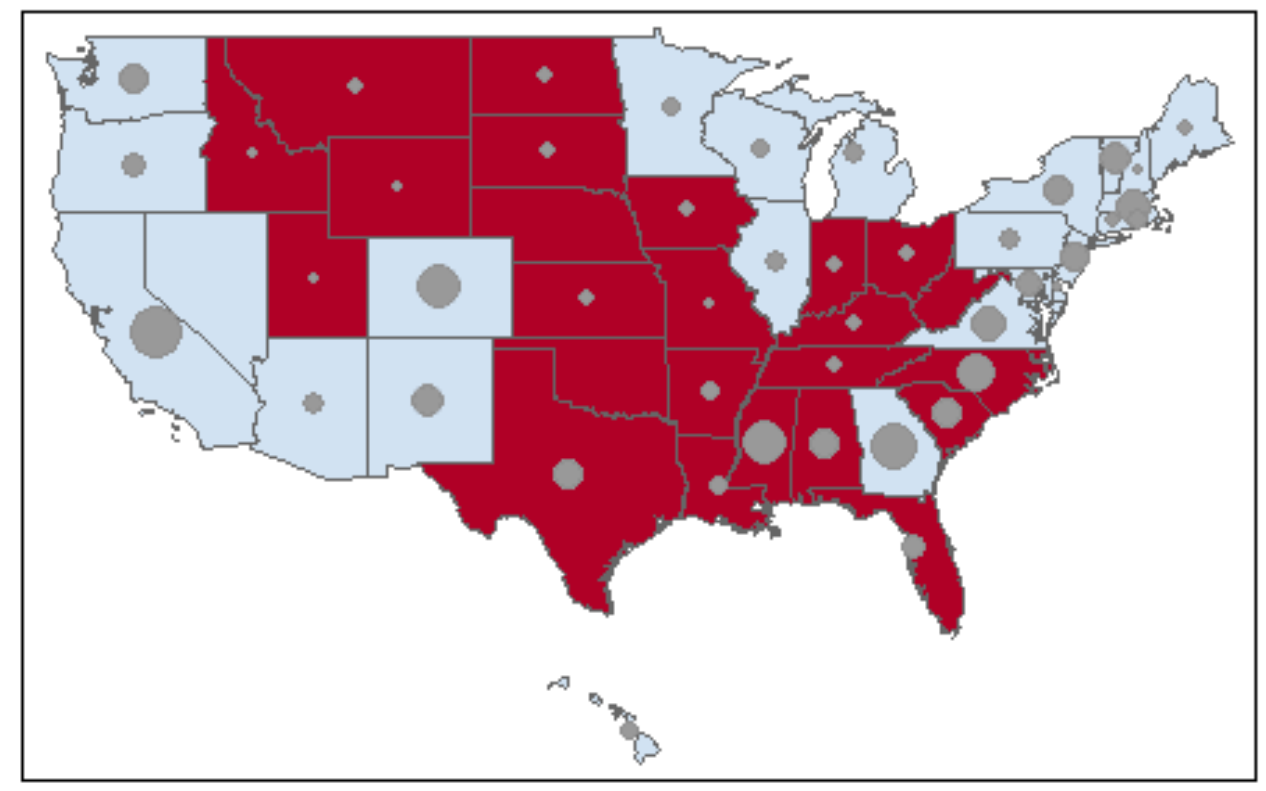

Trump

Biden

High Biden

510152025

This assessment of how COVID affected the vote leads naturally to questions about how the economy figured in the election. Theories about how economic considerations affect voters' decisions come in many flavors, even excluding the very special case of Trump. Thoroughly examining each in light of the extraordinary circumstances of 2020 would hopelessly complicate our discussion. Here we cut to the chase and focus on what our empirical research suggests really matters.

The problem in 2020 is understanding how COVID's irregular but savagely bipolar economic impact changed electoral behavior. Normally with an incumbent president running for reelection, one would consider how the usual indicators behaved through time - rates of growth and unemployment, real disposable personal income per capita, etc. But the economy's shocking plunge in the second quarter of 2020 from unemployment rates near historic lows to Depression levels means that customary benchmarks are likely to mislead. Economic performance in the tailspin that followed COVID will be overshadowed by questions of who or what voters blamed and the key question of which candidate they trusted most to bring the economy back. That, in turn, is likely to be heavily influenced by events and trends before COVID struck. 
Our evidence suggests strongly that that is indeed the case. We tested a variety of models. All point in one very interesting and clear direction. Actual economic performance in 2020 does count, but not in any normal fashion. The economy's slow and uneven recovery in 2020 from its Spring nadir for example, does not seem to matter. County level changes in unemployment rates between February and October, 2020, are not statistically significant for predicting Trump voting. The rate of unemployment in October is important, but in a manner drastically different from what one would customarily expect: counties with higher unemployment vote at higher rates for the incumbent. For every 1 percent increase in the October 2020 unemployment rate, Trump's expected change of votes from 2016 increases by $0.06 \%$. Given that rates in some counties ran over $10 \%$, this variable mattered. ${ }^{77}$

We think these results are less paradoxical than they look. Two other findings help to understand them. First, the change in unemployment from 2016 through 2019 is very strongly related to higher rates of Trump voting. That time period spans the full length of his term up until national income collapsed. It suggests forcefully that many voters were impressed by the strength of the economy that Trump constantly boasted about and when they voted they remembered that.

Another strong predictor of Trump voting in 2020 points in the same direction: counties with the biggest increases in population between 2010 and 2019 show markedly lower rates of Trump voting in 2020. For every 1\% increase of the population from 2010 to 2019, Trump's expected share of the vote decreases by $5.2 \%$. We are hardly the first to notice this, but we think this fact is best interpreted in the light of the evidence about the changes in unemployment rates in just discussed. Not accidentally, as a group the counties that grew the most after 2010 also have higher median incomes than most others over the whole period. We have already alluded to 2016 evidence suggesting that voters in places left behind by the Obama recovery were disproportionately attracted to Trump's promises to Make American Great Again (MAGA) even in the face of strong misgivings about him personally. The 2020 evidence suggests that such considerations remained strong.

We repeat that racism and sexism were plainly woven into Trump's appeals to voters. But an exclusive focus on those factors obscures a vital part of his appeal - one that we suspect may matter for the future. Excessively partisan assessments of his record have not helped clarify matters, either. Even through 2020's roughest moments, the President and his supporters trumpeted his success in achieving an economic revival of historic proportions - an upturn that brought down rates of unemployment for Blacks, Hispanics, and other minority groups to levels not seen in decades. Along with the big drops in unemployment came modestly higher

\footnotetext{
${ }^{77}$ For details see our Appendix.
} 
participation rates in the labor force and substantial increases in median family incomes in all these groups. ${ }^{78}$

The President's partisans typically credit this success to his outspokenly pro-business policies. They point in particular to the giant business tax cuts enacted in 2017; his broad deregulatory initiatives, his championing of oil and coal, and his dramatic turnabout from the environmental priorities of the Obama administration. Critics riposte that the revival began under Obama and that Trump administration mostly just went along for the ride. Nor was its strength measured as a percent of GDP at all remarkable from a long term perspective. ${ }^{79}$ They also point to compelling evidence that the tax bill failed miserably to deliver the promised spur to U.S. investment, with much money flowing into corporate stock buybacks that simply enriched managements and shareholders. ${ }^{80}$ Skeptics also note that deregulation and broad neglect of the environment are not magic sources of new wealth; they are simply devices to shift costs on to customers, workers, citizens -indeed now, on to the rest of planet earth. Assessments strictly in terms of income also leave out entirely a vital point: that modest rises in incomes do essentially nothing for wealth accumulation of Blacks and many other minorities, which continued to stagnate. ${ }^{81}$

We agree completely with all these strictures, but they skip too lightly past one very important consideration, an error that some compound by their choice of a base year for assessing Trump's economic record. Normally it takes the better part of a year for a new President's economic policies to take hold. It thus usually makes sense to chalk up the first year's economic record mostly to his predecessor. But precisely because Trump piggybacked on the Obama boom, that procedure is misleading. 2016 should count as the zero point, not 2017.

The reason is simple: though the Federal Reserve only formally enshrined its commitment to moving preemptively against inflation a few years before Trump assumed office, in fact the Fed had for decades has been almost preternaturally sensitive to any sign of economic overheating. When it thought it perceived that, it typically moved rapidly - "preemptively" - to nip inflation in the bud, usually by raising interest rates. The justifications for pursuing this policy changed over time, though most had roots in some version of the Phillips Curve, a supposed tradeoff between inflation and unemployment in the short run. The increasingly feeble evidence for these rationales hardly mattered; over and over the Fed moved to choke off economic expansions when

\footnotetext{
${ }^{78}$ For a representative survey of claims, cf. (Hilsenrath, 2020); for unemployment, labor force participation and other basic data, see e.g., FRED, the site maintained by the St. Louis Federal Reserve Bank, https://fred.stlouisfed.org/

${ }^{79}$ See the comparative statistics presented in (Amadeo, 2021).

${ }^{80}$ For the meager effect of the tax bill, (Kopp, Leigh, Mursula, \& Tambunlertchai, 2019); for the tax bill and stock buy backs, see (Lazonick et al., 2020).

${ }^{81}$ (Addo \& Derity, 2021).
} 
the US still had a long way to go before reaching full employment, to the growing ire of many critics, including, eventually, some within the Fed itself. ${ }^{82}$

When Trump assumed office, an expansion was indeed underway. But with inflation hawks already circling, the question was whether the Fed would try to put the brakes on. In stark contrast to his predecessors, Trump flatly refused to abide by the time honored convention that Presidents do not openly criticize Federal Reserve policies. On many occasions he went out of his way to warn the Fed against aborting the recovery. The political and economic establishment in both parties was shocked. They reproached him, but he persisted. ${ }^{83}$

When Fed Chair Janet Yellen's term as Fed Chair expired, Trump replaced her with Jerome Powell. Fed Chairs typically strike the posture that they do not respond to political pressure. When Powell raised rates soon after he took over Trump laid into him in public. Observers have different views about the effect of Trump's critique, not least because Yellen and some other economists in and out of the Fed were indeed reconsidering the evidence about the Phillips Curve and related macroeconomic rules of thumb. But to put it kindly, we doubt that the Fed's rethink - which continued under Powell - would have been so powerful so fast if the President of the United States were not loudly commenting from the outside. Certainly Powell's quick move after he was appointed to raise rates tells against such hopes. We thus credit the statistical studies indicating that under Powell the Fed did respond to Trump's pressure to refrain from raising rates. Trump, accordingly, should be given a share of the credit for the Fed's willingness to let the recovery run, even if he did not start it. ${ }^{84}$

We would not like to be misunderstood. It is absolutely true that by historical standards, the time path of economic growth under Trump was not remarkable, even before 2020. For all the reasons just mentioned, his overall economic policies powerfully reinforced the stark divides of America's dual economy. But as 2018 turned into 2019 and inflation failed to take off despite story after story in the business press about the difficulties businesses were having finding workers, only the most doctrinaire economists could cling to traditional macroeconomic and central banking dogma. Wages were hardly rising despite the economic revival; that was precisely the important result for theory. But in the short run incomes were increasing because people could at last get more hours of relatively low paid work as employers became more willing to look at people they had previously written off. People were reentering the labor force and even long term rates of unemployment were falling. ${ }^{85}$ It was also easier to find second and third precarious gig jobs, if people wanted them.

\footnotetext{
${ }^{82}$ For the Fed and inflation cf. (Taylor \& Barbosa-Filo, 2021). For the evidence that potential output in the U.S. has for a long time been far more than usually realized, see, above all, (Fontanari, Palumbo, \& Salvatori, 2019a) and (Fontanari, Palumbo, \& Salvatori, 2019b). See also discussion in (Meloni, Romaniello, \& Stirati, 2021).

83 (Condon, 2019).

${ }^{84}$ See, e.g., (Camous \& Matveev, 2019); (Bianchi, Thilo, \& Kung, 2019).

${ }^{85}$ See, inter alia, (Fontanari et al., 2019b).
} 
Figure 6

\section{Unemployment by Race and Ethnicity}

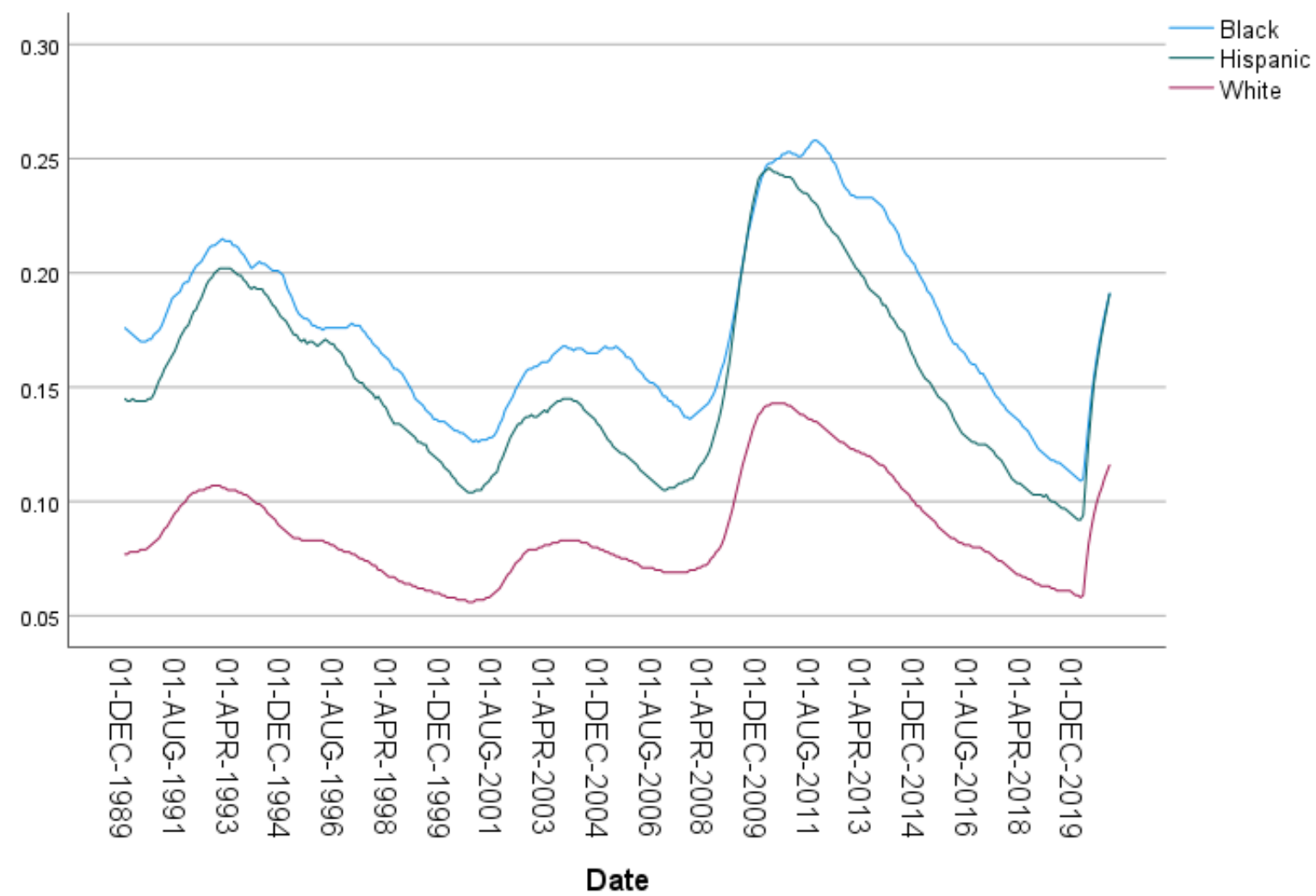

Source: Bureau of Labor Statistics Data,

As rates of unemployment for Blacks, Hispanics, and other groups fell to historically low levels before the pandemic, it should not be too surprising if, as can be documented from voter survey data for 2016, some voters, including minority voters, concluded that Trump with all his failings might still be the best ticket to economic recovery in 2020 . County voting data indicate that Trump's percent of the vote fell tailed off from 2016 in counties with higher percentages of Black residents - by about $.024 \%$ for every $1 \%$ increase in the percentage of the Black population. This is consistent with many reports of large-scale efforts by the Democrats to turn out voters in those districts. We don't believe that either those reports or the facts are inconsistent with individual survey results earlier discussed indicating that a very small percentage of Blacks (3\%), mostly males, voted in slightly higher proportions for Trump. 
By contrast, both our results and surveys suggest that Hispanics voted much more heavily for Trump than in 2016. ${ }^{86}$ As we discuss below, the precise effect on Trump voting of the percentage of Hispanics in counties varies with the level of social protests. But when those are controlled, questions remain about factors emphasized by other analysts. Analyses drawing on surveys have focused on how diversity within the communities falling within the broad Census designation might provide an explanation. Many suggest, for example, that high proportions of Venezuelan and Cuban immigrants living in Florida helped push up Trump's vote, though some analysts have pointed to the failure of the Democratic campaign in that state to emphasize issues like the minimum wage which were likely important for Hispanics. ${ }^{87}$ By contrast, the big increase in votes Trump garnered in Texas and in some other western states has triggered all kinds of speculation. Perhaps the most popular accounts focus on traditional values that many Hispanics are said to subscribe to. ${ }^{88}$

Anyone familiar with the region is likely to find that explanation reasonable, but also a bit lame: the allegiance of many Hispanics to traditional values had not kept many from voting heavily Democratic in many elections before 2020. Or prevented many in those counties from showing heavily in favor of Senator Bernie Sanders in the Democratic primary.

What really explains the changeover? Some polls of Hispanic opinion over time suggest that the Democratic loss came mostly in 2019 and was not primarily an Election Day phenomenon. ${ }^{89}$ No test of our's can say anything directly about that. But some newspaper accounts suggest that anxieties about employment in the oil industry played a role. ${ }^{90}$ It is a fact that oil and gas industry payrolls for extraction in Texas peaked in 2018 and then started to decline rather sharply. ${ }^{91}$ Some Hispanic voters in Texas also explained their vote for Trump in exactly those terms. ${ }^{92}$ We thus looked carefully, but our results do not support strong claims. Tests of interactions between high percentages of Hispanic voters and a substantial presence of the oil

\footnotetext{
${ }^{86}$ As explained below, the Hispanic vote's effect on Trump voting varies with the level of social protests. The estimated coefficient for the percent Hispanic is 0.049 with no social protests. In other words, for every $1 \%$ increase in the Hispanic percentage of the population in a county, Trump's expected change of votes from 2016 to 2020 increases by $0.049 \%$. The overall county average number of social protests is 6.6 . At the average level, the estimated coefficient (slope ) for the Hispanics $\%$ is .344 , which means that for every $1 \%$ increase in the percentage of Hispanics, Trump's expected change of votes from 2016 to 2020 increases by $0.344 \%$. We caution against any simple interpretation of where those votes come from, though, for reasons explained earlier. In particular, it is possible most did not come from Hispanics at all. One will need surveys to learn much more, though the cost in small areas is formidable.

${ }^{87}$ (Campo-Flores \& Findell, 2020); (Ghitza \& Robinson, 2021); (Cadava, 2020); for the minimum wage in Florida (Schueler, 2020), whose point is equally germane to Texas. Contemporary historians stressing business orientations of Hispanics seem loath to develop this obvious fact.

88 (Campo-Flores \& Findell, 2020).

${ }^{89}$ See the discussion in Note 5, above.

${ }^{90}$ (Findell, 2020).

${ }^{91}$ See the striking graph and statistics over time, available at "Oil and Gas Extraction Payroll Employment in Texas," at the Federal Reserve Bank of St. Louis FRED site: https://fred.stlouisfed.org/series/TX10211000A674FRBDAL . Oil prices had also fallen in 2014-15 and risen after Trump's election.

92 (Ferman, 2020)
} 
industry is perhaps hazardous in a national study with heavy regional concentrations, but we did run them. They were positive but only without proper spatial controls; when those were applied, the effect disappeared.

We also checked claims that the spread of Evangelical Protestant groups among Hispanics might help explain the shift. The data are less than perfect, but we cannot find any evidence confirming that view, though in this case surveys of individual voters in specific areas would surely be better instruments. Percentages of either Catholics or evangelical Protestants within counties does not appear to matter. The only really substantive case where religion did appear significant is one we have nowhere seen discussed: the case of the Mormons. In sharp contrast to 2016, where Trump's vote in Utah and a few other states with large Mormon contingents was off normal Republican levels, in 2020 most of the waverers returned to form. ${ }^{93}$ But that is irrelevant to the Texas case.

We think the question of what happened with the Hispanic vote and the Democrats can stand more analysis. Future research should reckon with the possibility that fears about the local economic effects of suspending construction of Trump's famous wall worried voters, even though most of the money for that venture did not flow directly to border counties. We are struck by one result of our analysis: that while counties with high percentages of foreign born citizens usually voted at lower rates for Trump - which is hardly surprising - counties at or near the southern border of the United States display markedly higher rates of voting in favor of him. The effect is substantial: the Trump voting percentage is 3.8 percent higher in the border counties compared with the rest. By contrast, a 10\% increase in the percentage of the foreign born population (a very large jump) decreases the vote for Trump by 0.23 percent, a relatively small effect. The border advantage admits of a variety of interpretations, but local Keynesian anxieties surely are a possible contributing explanation.

No matter how one finally assesses the Texas results, in 2020, as in 2016, industry effects clearly mattered in many places. Like other analysts, we find that counties with higher median incomes voted less enthusiastically in the aggregate for Trump, though finer grained individual survey data reveals that he remained popular among the much smaller numbers of super-rich Americans. But with a spatial approach, it is relatively easy to test hypotheses that go well beyond a simple focus on income differences ("social class"). ${ }^{94}$

\footnotetext{
${ }^{93}$ Statistics for religion by counties come from the Association of Religion Data Archives, https:/www.thearda.com/ The data are from its last complete census for 2010; COVID slowed the planned 2020 effort. The results come from surveys of local churches and similar bodies. For some denominations, that may lead to gaps in coverage where very few adherents live. That leads to a decision about missing data; we treat no entries as zero; this is likely not far from the truth, especially for groups heavily concentrated in certain regions. Our scrutiny of the regional distribution of such counties convinces us that results for Mormons are likely highly accurate. So does a visual examination of the vote shifts from 2016 in Utah, Idaho, and Nevada, where Mormons are known to be concentrated.

${ }^{94}$ See our Appendix 1. This is as good a place as any to mention a negative result. As (Lake \& Nie, 2021) indicate, several analyses of the 2018 Congressional elections suggest that Democratic efforts to expand health care insurance
} 
We can analyze how sectoral differences mattered - something that students of American voting behavior rarely consider. Even controlling for median income, our results show that counties with particularly heavy concentrations professional, scientific, and technical workers voted less for Trump than they did in 2016. Counties with high percentages of the labor force in finance were also markedly less enthusiastic. But we caution that this latter finding is treacherous.

Finance as a sector is almost impossibly diverse and our result is for the sector as a whole. As we discuss below, data on political contributions indicate that some of the most affluent segments of the industry remain attached to Trump.

For now, the point we want to emphasize is that our data raises major questions about some of the most popular generalizations about the political economy of the Trump era. Contrasts between successful globalizing firms and others more narrowly national in their focus have become ubiquitous, even in the popular press. Our data suggest that they are also misleading. Take the quintessential pro-Trump industries - coal and oil. American coal companies export around the world and Trump spent considerable time and effort trying to widen their market. Within the oil industry, it is true that many domestic shale producers - such as Harold Hamm were outspoken supporters of the President - but, as we discuss below, our analysis of political contributions reveals that many people working in the multinational giants also supported him and his policies, if sometimes less flamboyantly. On close examination, many of the "domestic" shale producers also turn out to have significant overseas operations.

The conclusion has to be one that is very familiar from the perspective of an investment approach to political coalitions: many significant political divisions often have sectoral roots, though within-sector differences are also frequently important. Counties in which coal and oil are heavy presences - which, in the latter case, for sure include major multinational firms - do not display any significant differences from 2016. As already suggested, we do not find this mysterious: industries that started close to $100 \%$ for Trump cannot do much better than that. ${ }^{95}$ Large scale sectoral differences matter, not just for political money, but for voting behavior, especially when labor organizations are weak.

\section{Trump's Secret Weapon: From Trade to Unique Agricultural Political Business Cycle}

Sectoral conflicts certainly figured importantly in the most sensational of all of Trump's departures from traditional establishment policies: his readiness to employ tariffs as weapons in

\footnotetext{
aided the party at that time. They suggest that continued Republican resistance also cost Trump in 2020. Their three election panel design includes improvements in coverage after 2012. We do not doubt that the expansion after that time may have helped the Democrats, but most of growth predates Trump's victory in November, 2016. We thus tested whether Democrats benefited from expanding social insurance during Trump's presidency. The test is muddied because later estimates of coverage were affected by COVID, but we found no effect. It is possible that local effects in 2018 were stronger given the absence of a national candidate with his own very distinct brand that may not have been entirely aligned with local Republican candidates.

${ }^{95}$ In Pennsylvania and some other states green opponents mounted intensive campaigns against political champions of these industries. They may have shifted some votes, but not enough to show in our results.
} 
both commercial and foreign policy disputes. We have always thought that the most bizarre aspect of the vast literature ascribing Trump's voter appeal exclusively to racism and sexism was the way it blankly ignores his forthright statements on foreign economic policy in the 2016 campaign and the world wide reverberations of his tariff battles with Mexico, Canada, Japan, China, the European Union, South Korea and other countries once in office. As one study aptly summarized "there are virtually no modern episodes of a large, advanced economy raising tariffs in a way comparable to the U.S. in 2018-2019." "96

In 2020, many media accounts of the campaign covered Trumps views on tariffs and industrial reconstruction sparingly or not at all, but no serious analysis of the election can ignore the subject. In both his speeches and ads, he was as forthright as ever. ${ }^{97}$ But whether this commitment to protectionism helped or hurt him is not obvious. In 2020, as in 2016, the contrast between Trump and his Democratic opponent was so clear cut that one might reasonably expect that on trade, as with the oil and coal, not too many votes switched.

Some analysts have examined the evidence and indeed concluded that trade played only a "limited role in the election outcome." 98 We reach the same conclusion but by a more circuitous route. We think another look at trade is worthwhile, in part because we disagree with some claims about agriculture, but also because there is a genuine puzzle about the issue's role in 2020: The evidence is strong that the Republicans' poor showing in the 2018 off year elections stemmed in part from the economic costs of the President's trade wars, especially with China. Presidential campaigns are distinctly different from mid-term elections (though 2018's soaring voting turnout was more typical of the former), so an obvious question is what changed between 2018 and 2020.

Here again, we preface our analysis with a wall of yellow caution flags. In the best of times, linking gains and losses from trade to specific localities involves a series of calculations akin to stacking Russian dolls. In Trump's case, the problem is intensified because while the administration appears to have carefully prepared at least the first parts of the package dealing with China, the way it put its policies into effect was classic Trump: flamboyantly transactional, bombastic, and erratic. Announced tariff changes were subject to constant renegotiation and frequently withdrawn or altered by exclusions sometimes before actually going into effect, with details emerging only weeks later in the fine print of regulations. As one skeptical analysis summarized the process: "More often than not, presidential Tweets differed from White House announcements, which differed from policy implementation. Headline numbers were often meaningless, and dates of policy changes would often shift considerably or disappear entirely." 99

\footnotetext{
96 (Flaaen \& Pierce, 2019).

${ }^{97}$ It is illuminating to compare the text of Trump's speech at the Convention with media accounts. The speech had many passages on rebuilding American manufacturing. See (Trump, 2020); few reports we saw devoted much space to those.

98 (Lake \& Nie, 2021).

99 (C. Brown, 2021), p. 7.
} 
But this policymaking parody of Heisenberg's Uncertainty principle - in which one could glimpse where trade policy was or in what direction it was heading, but not both at once - only scratches the surface of the difficulties in discerning how Trump's tariff policies impinged on the election. As an instrument for interpreting the world, mainstream international trade theory is a blunt instrument, problematic at many levels. To start with, we are troubled by what we regard as its essentially question begging nature. Few analysts acknowledge that most growth in East Asia would never have happened if those countries had followed traditional free trade policies, though the reality of the "East Asian miracle" is obvious. Almost everyone now concedes, too, that American trade analysts and policymakers badly misjudged the domestic effects of opening up the American economy as they negotiated China's entry into the World Trade Organization, though in public many still cannot quite bring themselves to admit this. ${ }^{100}$

While orthodox trade theory continues to evolve, its trajectory resembles mainstream macroeconomics after the Great Financial Crisis - theory and practice have altered, but mostly on the margin. As critics have trenchantly observed, most expositions still hurry past the empirically minuscule sums of "Harberger Triangles" that purport to capture the overall gains from trade envisioned in the theory's static versions. More sophisticated cases for substantive advantages arising from "dynamic" versions of free trade theory involve much hand waving. The presumption in favor of full employment that lies just below the surface of many modeling exercises - and sometimes, even now, right on the surface - remains ubiquitous. Such accounts continue to nourish exaggerated claims about the welfare gains from trade. They also ignore the reality that losers are almost never compensated for losses. ${ }^{101}$

Most efforts to apply the theory rely on computable general equilibrium models. These are first cousins to the now much criticized dynamic stochastic general equilibrium models and they vary widely in how they incorporate several key considerations. ${ }^{102}$ One concerns the ease with which companies, if not countries, can escape the impacts of tariffs by relocating production to other countries. ${ }^{103}$ The models actually used to estimate the effects of the U.S. trade wars also mostly pass over in silence conflicts of interest within firms and their employees; the companies may prefer to shift production, which does nothing for their local workforces except threaten their livelihoods. Neither do these models have any means for assessing whether or not the administration was successful in some of its key objectives, because they are designed to analyze short run trade in goods, rather than more basic, longer term issues of property rights and changes in legal and institutional processes: the point of the U.S. tariffs on electrical

\footnotetext{
${ }^{100}$ The literature is too large to survey, see, e.g., (Stiglitz, 2003). For later misgivings, see, e.g., (Setser, 2018).

101 (Kohler \& Storm, 2016) is a fine statement of widely shared views with detailed empirical discussion.

102 On the problems of DSGE models, see (Storm, 2021a) and the symposium in that issue of International Journal of Political Economy.

${ }^{103}$ (W. Li, Qiu, Whang, \& Zeng, 2021); a contrary view is (Cigna, Meinen, Schulte, \& Steinhof, 2020). The range of empirical claims about the Trump tariffs is strikingly wide, but we cannot examine the full literature here.
} 
manufacturing (and likely many others), for example, was to squeeze the Chinese to tighten their laws on intellectual property. That is in nobody's computable general equilibrium model. ${ }^{104}$

An emerging literature relying on newer statistical approaches to analyzing regional growth patterns deepens these doubts. This research suggests that trade linkages are less important in explaining regional growth differentials than commonly supposed and that concentrating on, for example, export shares, is not especially helpful. Instead trade linkages are heavily mediated by how local industrial structures affect the pass through of costs and local wage bargaining. ${ }^{105}$

But the most important issue pushed aside in the mainstream literature is that views about tariff protection are sometimes highly "ideological," not in the sense that they are impervious to facts (though of course they may also be that), but that they reflect deeply held, preexisting views. Public opinion polling in recent years has tended to underestimate these. Careful comparisons of closed with open ended questions about foreign trade and tariffs in the 2016 American National Election Survey highlighted the likelihood that reservations about free trade ran considerably deeper than most conventional surveys suggest. They also showed that Trump's openness to tariffs made him attractive to significant numbers of voters, in both the primaries and the general election. ${ }^{106}$ Major media press accounts have often downplayed this to the point of disregarding warnings from losing Democratic candidates in farm areas that the administration's tariff measures were not in fact turning farmers against him. ${ }^{107}$

Given the problems with existing surveys, the true extent of protectionist sentiments within the electorate is hard to assess. Older polls with better formulated questions commissioned by the Chicago Council of Foreign Relations, along with some other data, suggest that the numbers may be very substantial. ${ }^{108}$

Some facts, though, are clear. In 2020, if you liked tariffs, Trump was obviously your man and, in contrast to 2018 , he was on the ballot himself, which surely affected voter responses. Given the many rapid reversals, suspensions, and sotto voce changes in the administration's policies, along with the fact that we know many voters recognized, that for much of Trump's term, the U.S. was nearer to full employment than it had been in years, it is not obvious that many voters, especially those with strong opinions, would have had sufficient time to sort out either the precise nature of the rapidly changing policies or assay their consequences, especially if they sympathized with the administration's claims about the importance of the long term. These

\footnotetext{
${ }^{104}$ It is extraordinary how the many papers trying to estimate the effects of the Trump tariffs on the economy pass over this fundamental point. An exceptionally clear statement that the tariff policy was not basically about tariffs, is (Kimball, 2019).

105 (Chudik \& Pesaran, 2016) (Elhorst, Gross, \& Terenau, 2021); (Chudik, Koech, \& Wynne, 2021); cf. the latter's "indicators of size and industry composition dwarf the explanatory power of trade linkages in explaining the regional differences."

106 (Ferguson et al., 2020); a detailed examination of common poll questions is (Chang, Ferguson, Rothschild, \& Page, 2021).

107 (Barth, 2019).

${ }^{108}$ See the discussion in (Chang et al., 2021).
} 
considerations buttress the comparison with coal or oil: why switch, if you liked Trump in 2016 for his tariff policy? Some communicants, indeed, might have appreciated a politician who actually seemed to be trying to redeem his promises, even at the price of infuriating critics they already distrusted. ${ }^{109}$

All the models by economists skip past such considerations. Instead they take the structure of production for granted and focus on very short run estimates of income flows to grind out estimates of how the economy as a whole reacted to the tariffs. ${ }^{110} \mathrm{We}$ then have to infer that the claimed gains and losses affected voters. Not surprisingly, the cottage industry that has grown up debating the finer points of the trade war, especially with China, differs on important details. Some analysts who critically evaluated the elasticity of substitution of products in the tariff war between the U.S. and China, for example, suggest that the big winners from Trump's tariff were countries like Vietnam and Canada, but the range of estimates is fairly large and some papers dash past that point. That would imply lower losses for American consumers out of the whole imbroglio. That would reinforce the point that until COVID hit, many workers were seeing rises in incomes, albeit at the cost of working for long hours with modest rises in wages. After COVID stuck, as we have seen, the evidence is strong that many of those affected trusted Trump more to return to prosperity. Resting one's case on computable general equilibrium models of trade effects in such cases is quite a leap of faith.

Doubts increase the more one scrutinizes the exact calculations. How data on trade and industries in the U.S. (and many other countries) are compiled is a first problem, though we can only touch on the issue here. As an approach to understanding the actual behavior of firms, especially large firms, existing classification schemes for products and industries bring to mind the English proverb about the dangers of slips 'twixt the cup and the lip. Empirical studies of trade policy impact usually start from data for products reported in terms of an internationally harmonized system of product and industry classifications. They then translate that classification system back into the different grids used by individual countries, such as the U.S. North American Industrial Classification (NAICS - the successor to the old Standard Industrial Classification or SIC System). Levels of detail in all these are exceedingly fine - virtually at the product level, as one might expect for schemes designed for use in tariff negotiations. The translations from one classification system into the other inevitably lose a bit of detail at a simple descriptive level. ${ }^{111}$ Most government data involving industries also deliberately masks entries that might identify

\footnotetext{
${ }^{109}$ In 2018, Trump was not on the ballot himself; offset payments were generally smaller than later, and the din over the tariffs was huge. But as discussed below, we are struck that what we consider the most believable account of voter responses following very carefully targeted Chinese responses were so small: four House seats (Kim \& Margalit, 2021). That is not to be dismissed, but neither is it at all impressive. A reasonable policymaker might well conclude that with a bit more of an effort to counter the costs, she or he could continue in relative safety.

${ }^{110}$ A common procedure is to assume that overall national patterns are evenly or close to evenly distributed across the national economy.

${ }^{111}$ See the discussion in (Flaaen \& Pierce, 2019).
} 
individual firms. This is not news, but as discussed in our Appendix 3, our exploration of this data convinced us that this problem poses much bigger challenges than generally recognized.

Sifting out what the data about products means for firm policies is even more daunting and we are convinced that the existing literature has skipped past this too quickly. Everyone agrees that real firms typically operate not in one, but in broader sets of the fine grained "industries" distinguished in the classification systems. If, as certainly happened in aluminum, steel, and other industries caught up in the trade war, the intermediate imports companies rely on are hit by tariffs while their final products benefit from protection, then the firms face short run price rises or interruptions in supplies they need for their own production of protected final products. They then must make judgment calls about their political stances toward the tariff package as a whole. The same holds for their workers and incentives to misstate everyone's public views are sometimes strong. But there are no government statistics on such things, though one can draw inferences from other data, such as corporate political contributions and occasional public statements. We believe key steps local and national politicians take in response to trade pressures are explicable only in terms of political money, which is different from talk or aggregate economic statistics. Models involving median voters, which dominate much of the literature, fail to explain the weakness of counter-pressures and, though the subject is too big for this paper, misstate how the trade desires of elites relate to other issues used locally as diversions. ${ }^{12}$

Finally, the most common ways analysts map industrial data back into political structures adds additional layers of complexity. We are very skeptical about the tangled chains of calculation (often involving masked data) usually used to estimate county economic gains or losses. The towering pile of approximations stretches too high in the clouds. If one is testing for political effects, as distinct from economic impacts, we strongly prefer methods that minimize reliance on assumptions of how aware the locals were of those estimated losses, multiplier effects on the local economy, or assessments about how local investment responded. A bright spot in all the darkness is that in practice no one makes allowances for second order price effects on consumers spread out over the rest of the landscape. ${ }^{113}$

Simpler and more directly testable procedures are preferable, particularly for cases like the Trump tariffs, many of which came and went like the grin of the Cheshire Cat. Our preferred methods are akin to those we used to assess how oil or coal affected voting in 2016: identify

\footnotetext{
${ }^{112}$ In particular, they fail to explain why at the presidential level especially, the Democratic Party was so completely dominated by free trade advocates. The Party's voting constituency was devastated by the free trade policies. See., e.g., (Wright, 2020) or (Ferguson, 1995b). The latter explains in simple English what really happened. See also (Ferguson \& Rogers, 1986). Current discussions of Congressional voting on tariffs, in our view, should pay more attention to why the national party establishments that - until Trump - stuck with free trade so long and should more carefully consider what apparent votes against trade by in Congress really meant. But that is for another time. For now, we observe that when a real protectionist showed up, you didn't need a weatherman to tell that the weather had shifted.

${ }^{113}$ Much work starts with commuting zones, for which the data is often quite dated, then traces how those fared through a series of changing congressional districts. See, e.g., (Autor, Dorn, Hanson, \& Majlesi, 2016).
} 
specific industries that are affected and check if the percentages of employment in those sectors in districts affects voting results, using data that, as far as possible, corrects for government masking. ${ }^{114}$ Especially if you cannot reliably sum all the aggregate effects, this procedure should offer a useful guide to net effects on the vote, with proper controls.

We apply these methods to Trump's tariffs by building on Flaaen and Pierce's discussion of the three principle ways the tariffs affected specific leading industries in the short run. ${ }^{115}$ First, some profited from protection. Secondly, because tariffs were sometimes levied on intermediate goods used in their own production processes, certain industries - sometimes the same protected industries - faced higher prices, though how those affected them depends on variables that are even more difficult to assess in ensembles. Finally some American industries lost export markets due to retaliatory tariffs imposed by countries hit by Trump's tariffs. In a twist we had not initially expected, this last set of cases became of towering significance, though by a route that received little recognition outside of specialized sectoral media: the magic of executive action and agency discretion transformed trade policy into a hardy perennial of American politics, lavish aid to the farm belt.

The flux in the administration's trade policy mentioned earlier was a stumbling block for our examination and impels us to warn again that our results are more than usually tentative. We began by cataloging "industries" to test. The full list contains more than the industries discussed by Flaaen and Pierce, but many of the later tariffs were in effect only briefly either because the duties were slapped on late or they were simply not very high. ${ }^{116}$ We thus began by examining the three different rosters of "top ten" industries compiled by Flaaen and Pierce. ${ }^{117}$ We tested each industry in all three groups individually and ran tests on the entire ensembles since those should most readily show effects since they sum employment in all the industries. ${ }^{118}$ Our tests for all three ensembles were almost uniformly negative; only results for tariffs on electrical manufacturing and some forms of steel appear to have affected any votes and the steel result was perverse, though it can perhaps be rationalized in terms of tariff-affected input costs. The one industry that stood out as strongly pro-Trump, saw mills, has a far more direct interpretation than

\footnotetext{
114 That can be done industry but industry, but one also needs to test entire ensembles, since the whole might add up to much more than subsets of parts. In some, mostly low frequency, cases, the BLS veils data to protect identities of specific firms. There are also other errors, including some missing data. Some researchers make various adjustments for these; but we are not working on large regions and we need to analyze only a few industries. To deal with the masked data problems, we relied on the new, recalculated datasets developed by (Eckert et al., 2021a) and (Eckert et al., 2021b). Our Appendix 3 discusses this in more detail. Perforce, we use employment rather than any form of value added, since the data concern the former.

115 (Flaaen \& Pierce, 2019). Their paper covers tariffs put on in 2018; there were additional tariffs put on later, but these were often unevenly implemented. In some cases they were postponed to avoid antagonizing American consumers during the Christmas season or waived for other reasons. And many rates were quite low. See the discussion in (C. Brown, 2021).

${ }^{116}$ We drew on all the papers mentioned earlier, but also (M. Li, Balistreri, \& Zhang, 2020).

${ }^{117}$ Some on the lists overlap for reasons already explained about intermediate imports.

${ }^{118}$ Of course the expected results vary, depending on whether the industry is receiving higher protection or higher costs or losing market share abroad.
} 
the tariffs, as we discuss at the conclusion of the paper. We conclude that Trump's protectionism was indeed old news in 2020 and did not affect many votes.

The case of agriculture is more complicated. No search for answers to the question of how Trump amassed more than seventy four million votes can bypass this sector, which only a very small number of specialized media sources paid attention to around the time of the election itself. As will shortly become obvious, by 2019 Trump's offsets to the consequences of his tariffs on agriculture were morphing into a much grander shift in farm policy, swamping the tariff controversies.

\section{The Ace in the Hole That Almost Worked: Trump's Farm Policy}

Here again, still more advance cautions are necessary. Next to finance and perhaps defense, one might argue that agriculture constitutes the most important case of full throated socialism within the American economy. Federal government subsidies over long periods have played a vital role in the industry's rise to world dominance and state aid remains ubiquitous. ${ }^{119}$ It is also noteworthy that the usual intense partisanship in American politics often seems to stop at the Farm Belt. A closer inspection will reveal a more discriminating picture, but the frequency with which farm state Republicans and Democrats close ranks in favor of lavish aid for big farmers, giant grain companies, specialized insurers, and other firms in the agricultural circuit is obvious. But this paper cannot review the tangled history; we must pass rapidly to how the Trump administration engineered one of the most remarkable agricultural political business cycles in American history.

The starting point was, indeed, the tariffs Trump slapped on industrial imports from China in 2018. These came in several waves: first in February, when the administration relied on Section 201 of the Trade Act of 1974; then in April, this time citing Section 232 of the Trade Expansion Act of 1962. When the Chinese retaliated by placing tariffs on American agricultural exports, the administration responded by levying additional tariffs, appealing to different sections of existing trade and national security legislation. The result was several more rounds of tit for tat from each side before the November election. ${ }^{120}$

Up to then China had figured as an important, but not decisive market for American farm produce. For soybeans, cotton, and several other crops, however, Chinese demand bulked very large. Comparative analysis of how various countries responded to Trump's tariffs suggests that the Chinese responses were much more carefully calibrated than, for example, those of the

\footnotetext{
119 (Ferleger \& Lazonick, 1993) is a particularly acute formulation. But see also (Donald Hadwiger, 1971) on how the research program shortchanged small producers.

120 (C. Brown, 2021), which also references various chronologies he compiled; (Flaaen \& Pierce, 2019) are also helpful on the part of the trade war they deal with.
} 
European Union. They focused sharply on borderline districts in agricultural areas and likely did cost Republicans a few seats - but only a few, perhaps 4 - in 2018. ${ }^{121}$

The administration continued sparring with China (and other U.S. trading partners) both verbally and administratively through 2019. But with the presidential election looming, it started dialing down its bellicosity. In January, 2020, the administration signed a new "Economic Trade Agreement" with China. This went into force, ironically, on Valentine's Day. As one might expect with Trump, this "Phase I Agreement" departed dramatically from conventional multilateral trade agreements. It eschewed traditional "most favored nation" clauses that passed advantages automatically to other trading partners. It also bypassed the World Trade Organization in favor of a bilateral accord between the U.S. and China. The Chinese agreed to a "voluntary import expansion" agreement committing them to purchase substantial amounts of American agricultural, manufacturing, and other goods and services. They also promised to refrain from currency manipulation and to reform their laws on intellectual property and in a few other areas. $^{122}$

By the time agreement came into force, of course, COVID had begun its deadly march across the earth. Economies were crashing, along with world trade volumes. The steep fall in U.S. imports, coupled with the still sizeable Chinese purchases of U.S. goods (amounting to about two thirds of what they had promised, despite the pandemic) lowered the temperature between the two most powerful countries in the world.

But for American farmers, COVID brought a host of new problems that could not be pinned on China. Domestic restaurant and school demand for their products collapsed. In addition, bad weather, fires, and droughts ravaged important growing areas. With many farm areas facing deeper disaster, the Trump administration responded with another historic single payer insurance program, this time using existing farm programs. As one journal summarized an account for practicing farmers by an agricultural economist:

To compensate farmers directly impacted by retaliatory tariffs, the Trump administration began making Market Facilitation Payments (MFP) in the summer of 2018, and a second round was made in the spring of ' 19.

Those payments were expected to cease after a trade deal with China was announced Schaefer said. However, the COVID-19 pandemic began wreaking havoc on agricultural markets in early 2020 with the closing of schools, restaurants and other institutions dependent on food deliveries.

To keep farmers in business and families fed, Trump's USDA [United States Department of Agriculture] instituted the Coronavirus Food Assistance Program (CFAP). Between MFP and CFAP, the government paid out $\$ 46$ billion, creating

\footnotetext{
${ }^{121}$ (Cheng \& Hillberry, 2018) for the trade significance; for the politics, see (Kim \& Margalit, 2021).
}

122 (C. Brown, 2021) 
a "massive spike" of agricultural support unlike any since the original farm bill passed in 1933.

"This is the most support we've ever seen for agriculture" Schaefer said. These (payments) were unique in size and the way paid. Previously, through the farm bill, these kinds of payments were negotiated in a bipartisan fashion under Congress."

"Both the MFP and CFAP were appropriated solely by the Administration Trump didn't go through Congress to get these." 123

Assessing how these programs affected voting in specific farming areas is a formidable task, not least because no one with access to detailed data responded to our queries for basic data. A U.S. General Accounting Office report detailed the program's broad features, though not the allimportant roster of quantitative assistance to counties. But we were able to locate support price lists by county for the Market Facilitation Program expressly created to compensate farmers who suffered losses from the trade war with China. ${ }^{124}$ Their most important provision was that "specialty crops" were treated differently from "non-specialty crops." These latter included most crops, and their payment rates were set not by crop, but by which county they were grown in. Payment rates diverged widely - from $\$ 15$ to $\$ 190$ an acre - a truly gigantic disparity. A close reading of farm periodicals shows that many informed observers read between the lines and sensed that perhaps not everything in the scheme hinged on Chinese trade losses. A handful of articles appearing around the time of the election voiced suspicions that the program involved favored counties likely to vote for Trump. Our test for relations between the Trump vote in 2016 and the county prices suggested that there was nothing foolish about the guess, but the relationship fell short of statistical significance $(.20)$.

This tantalizing but inconclusive result left in abeyance the question of all the spending's impact on the election. Compounding the problem was the fact that, as suggested just above, while the Market Facilitation Program was a major part of the Trump administration's election year farm support program, it was not alone. Along with the Food program already mentioned, came vast subsidized loan programs and new assistance for areas impacted by bad weather, among others.

Given the dearth of relevant information, it made sense to treat agriculture as a special case of industrial structure analysis as we have long practiced it and test whether counties dominated by specific farm sectors showed clear evidence of changes in voting patterns. The logic is exactly the same as our other tests: with proper controls, the sector's influence should show, just like oil

${ }^{123}$ (Grinczel, 2021), quoting Aleks Schaefer, a Michigan State University Extension economist.

${ }^{124}$ For the GAO analysis, see (Office, 2020). The report is enclosed with a letter from GAO Director of Natural Resources and Environment Steve D. Morris to The Honorable Debbie Stabenow. Ranking Member, Committee on Agriculture, Nutrition, and Forestry, United States Senate, USDA Market Facilitation Program: Information on Payments for 2019, on the web at https://www.gao.gov/pdf/product/708942 The price lists by county can be found at (Agriculture, 2019). 
or coal. The data required for this are not, alas, available off the shelf. We used newly published estimates of production by county for specific crops produced by independent agricultural economists for most tests. ${ }^{125}$ But those didn't cover livestock and a few other sectors. For these, we had to rely on Bureau of Labor Statistics data for farm employment by sectors to run the tests. $^{126}$

Our results are striking and tally closely with claims in the specialized farm literature: a number of sectors, notably cotton, did not change materially from 2016 (when it showed heavily for Trump). Neither did milk and dairy where regional and local rules are very important. But apple producers, who bitterly protested being left high and dry in the China offset programs, swung sharply against the President, though for Trump the cost was limited since they are not numerous. ${ }^{127}$ But three big sectors with significant sales to China showed substantial swings in favor of Trump: soybeans, corn silage, and rice. A final sector that also tilted heavily in favor of Trump, which we report without comment save to note that it has been sharply criticized for endemic pollution and water problems, was pig farming.

\section{Social and Labor Social Protest}

This paper has already alluded to the surges in labor walkouts and protests that the onset of COVID triggered. These received very little press attention and most too small to show in official Labor Department statistics. By contrast the tidal wave of protest that brought the Black Lives Matter movement to national attention received very intense coverage. (See Figures 7 and 8.) The dramatic video showing George Floyd's brutal death in the custody of Minneapolis police ran and reran in the media, on Twitter, and elsewhere. The outpouring of anger and indignation was overwhelming, leading to demonstrations and protests across the nation. These ebbed and flowed for weeks, rising to dramatic climaxes when counter-demonstrations by Trump supporters, police clampdowns, and other police killings made headlines.

\footnotetext{
125 (Wagner, Niles, \& Roy, 2019). The data include estimates of total production, so the relative concentration is easily assessed.

126 These, and only these, are likely subject to some government masking. We looked closely, comparing data for individual counties from state agricultural associations with the federal data. The masking is obvious in the case of a state like Indiana. In the one case that proved out discussed below, pig farming, we concluded that corrections to the masked data would likely strengthen our result.

${ }^{127}$ For the apple producers, see, e.g., (Blaine, 2019).
} 


\section{Figure 7}

\section{Social Protests}

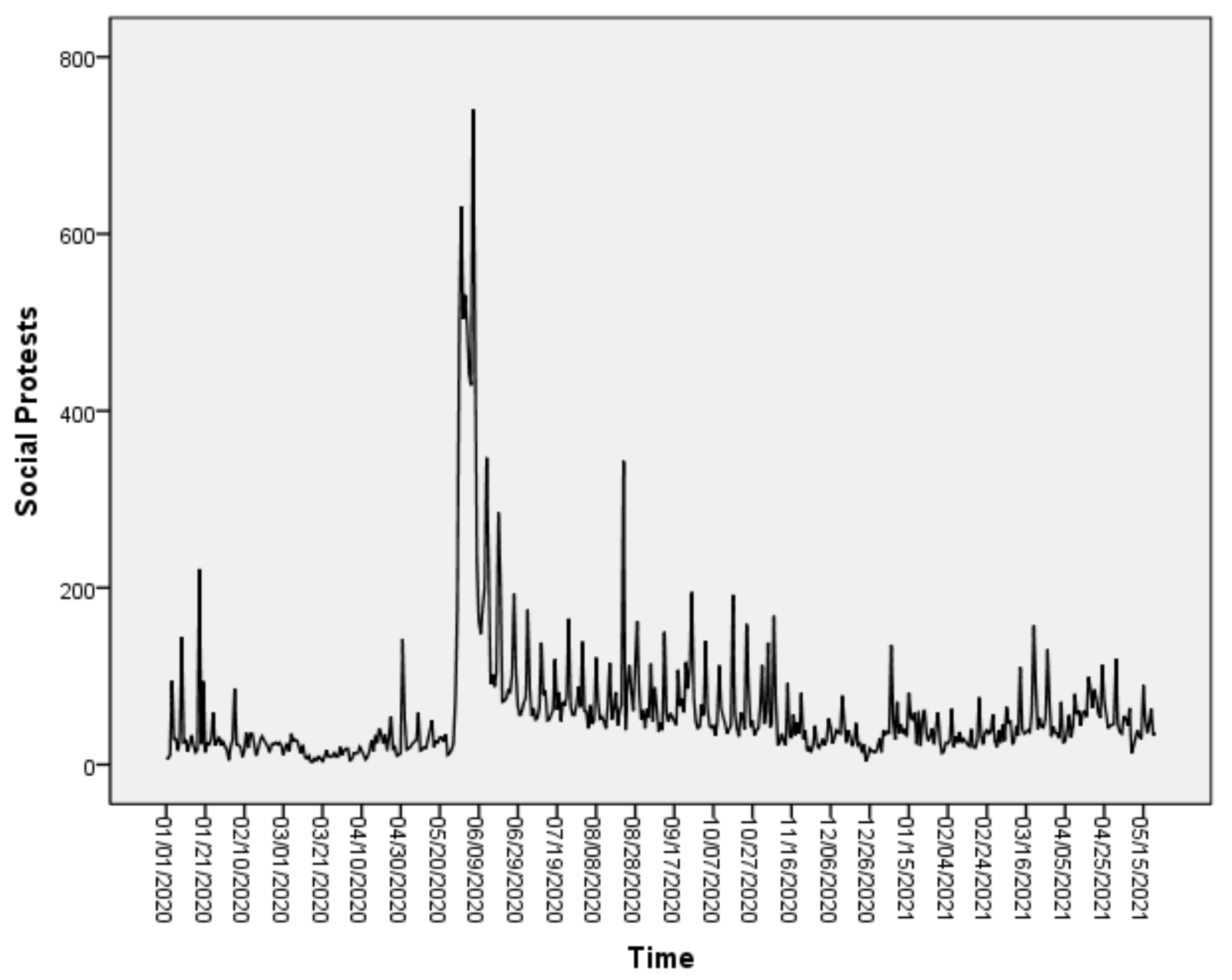

Source: Armed Conflict and Event Location Project, see text 


\section{Figure 8:}

\section{States Won by Biden or Trump vs. Number of Social Protests of All Kinds}
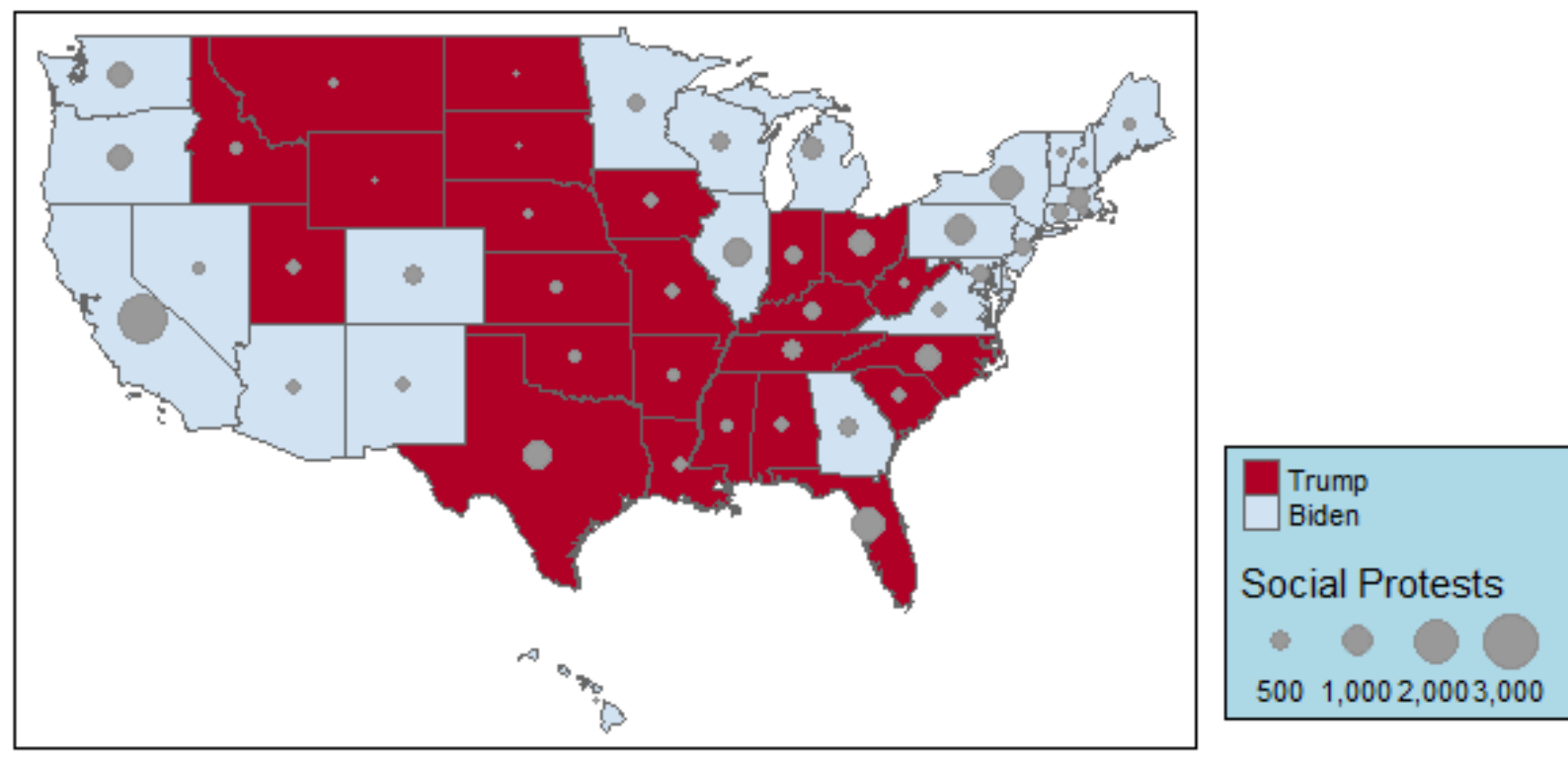

For a while it seemed possible that police behavior and the protest movement might restructure the entire campaign. Suspicions that the Trump administration was hoping for a reaction similar to those of earlier Republican campaigns, especially Richard Nixon's famously effective 1968 and 1972 campaign pitches, have been confirmed by post-election accounts. ${ }^{128}$ The President kept trying to turn the question of "law and order" into a decisive political issue and sought opportunities to dramatize himself as its foremost champion. His "made for television" spectacle in front of St. John's Episcopal Church on June 1 in Washington, D.C., sent shock waves around the world. His Bible waving speech on the steps of the Church and images of the dispersal and tear gassing of park protesters that preceded his appearance there sent powerful messages to many different audiences. The President kept encouraging state governors to respond to protests with heavy hands, demanding that they call out the National Guard to restore order. At times, he even threatened to use regular army troops. The messages did not go down well with big city mayors, who were nearly all Democrats, or with the Chair of the Joint Chiefs of Staff. As national Democratic leaders rather clearly held their collective breath, the mayors sought to avoid confrontations. Meantime claims and counterclaims blaming violence on right wing

${ }^{128}$ See, e.g., (Wolff, 2021) and (Leonnig \& Rucker, 2021); (Woodward \& Costa, 2021). 
militias, or "Antifa," and its alleged connections to "socialists" and communists filled the airwaves. $^{129}$

This paper cannot do justice to the myriad events and incidents in this epochal tapestry or the wildcat labor disturbances. We can only treat a few key points summarily. Thanks to the Armed Conflict and Event Location Project, an excellent statistical record of the social protests associated with the Black Lives Matter movement and many other groups all through the year exists. Though many accounts by partisan Republicans implied the opposite, it is clear that the police responded far more often with force to protests from the left than those from the right. Right wing demonstrations were also far more likely to involve violence, though it featured in a small proportion of left events. Police killings also continued with dismaying frequency. ${ }^{130}$

It is also important to note that Black Lives Matter groups long predated the Minneapolis incident. The various groups usually regarded as leading that movement received an influx of support, including money, from various foundations, while some prominent corporations also started to take public stands in favor of racial justice. ${ }^{131}$

But 2020 witnessed many other events and demonstrations from a wide array of groups in favor of other causes. If we refer to all of these collectively as "social protest" events, they were running at very high levels even in January, as groups protesting on behalf of the environment, human rights causes, and issues associated with the political right all took to the streets. COVID's advent also led to the waves of walkouts, wildcat strikes, and labor-related protests already discussed. As jurisdictions locked down from COVID, protests against those also erupted, to an extent that is perhaps not widely appreciated.

We are convinced that studying how each of these different kinds of protest affected the election would likely be rewarding. But the more than 23,000 events for which data exists are hugely diverse and a proper effort to distinguish among them would be a major undertaking in its own right. ${ }^{132}$ Thus in this paper we focus on what we consider the most important point: how did the entire set of disturbances affect the change in the presidential vote?

Our reading of history suggests that pooling the labor disturbances, which come from a different data set anyway, with the much bigger dataset covering the broader social protests is unwise. We

\footnotetext{
${ }^{129}$ In the voluminous literature, see, e.g., (Wolff, 2021) and (Leonnig \& Rucker, 2021).

${ }^{130}$ The data comes from the Armed Conflict and Event Location Project, "US Crisis Monitor Releases Full Data for 2020"; https://acleddata.com/2021/02/05/us-crisis-monitor-releases-full-data-for-2020/ For the assessment and statistics comparative violence, see (Kishi, Stall, Wolfson, \& Jones, 2021). They suggest $14 \%$ for events on the right vs. just under $7 \%$ for leftist events, though they note that who instigated is often unclear. Their police statistics are dramatic.

131 The follow through was complicated, but less than rousing. See the tabulation for large companies in (Jan \& Hoyer, 2021)

132 These data, again, come from the Armed Conflict and Event Location Project, "US Crisis Monitor Releases Full Data for 2020"; https://acleddata.com/2021/02/05/us-crisis-monitor-releases-full-data-for-2020/
} 
thus separately estimate the effect of the two types of protests on county voting. Incomplete estimates for the sizes of crowds makes it impossible to use those as an indicator. So we sum all types of "social protests" within counties and then analyze how the total influenced voting. Our results indicate that "law and order" responses did not in general rally voters to Trump's cause: as the number of social protests rose in counties, votes in favor of Trump declined. There is an interesting exception: in communities with many Hispanics as defined by the census, voting for Trump rises somewhat as the protests increase. The effect is particularly marked in a number of large cities mostly in the west and southwest. ${ }^{133}$

By contrast, outside of a few big cities with very high costs of living, higher numbers of wildcat strikes and other labor disturbances tend to occur in counties with modestly higher shares of Trump vote. It may be that the various ethnic and racial cleavages overlay economic differences arising from low wages and dangerous working conditions and heightened those tensions. But that is for another paper. A striking fact is that Google Trends searches for "strikes" show rather surprisingly - that by far the highest relative number of searches in the period from February 2 to Election Day occurs in three southern states: Georgia, South Carolina, and Alabama, not in the old industrial heartland. Our results indicate that higher levels of the "wildcat protests" slightly pushed up Trump voting. ${ }^{134}$

\section{In Lieu of A Conclusion: American Politics Between Washington, Weimar, and Kabul}

All through the many years we have studied American politics, one or another set of analysts could usually be found voicing fears that the system was sliding into crisis. We have generally resisted this siren song: we are greatly impressed by the ability of money-driven political systems to regenerate themselves even in the face of challenges as formidable as the Great Financial Crisis. But the evidence that something fundamental is altering is now too strong to ignore. If the litany of striking developments ticked off at the opening of this essay does not convince, then some of the juicier details trickling out from the stream of memoirs, official investigations, and "inside" accounts of the President's Final Days should. When the Chair of the Joint Chiefs of Staff starts talking about a "Reichstag Moment," everyone needs pay attention. And the revelation that Rupert Murdoch personally gave the go ahead for Fox News to call Arizona for Biden on Election Night, carries an equally clear message: that, as we have stressed for many years, big business and corporate media are active players in American politics. They do not

\footnotetext{
${ }^{133}$ Appendix 1 shows the estimated coefficient of social protests varies with the percentage of Hispanics in the county. Where the Hispanic percentage is zero, Trump's expected change of votes from 2016 to 2020 falls by $1.276 \%$ for every increase of 100 social protests. At the average $\%$ of Hispanics in counties ( $9.7 \%$ ), for every 100 social protests, Trump's expected vote shift decreases by $.84 \%$. Note that while the median number of protests is zero, some counties have hundreds. We caution again about simple inferences from aggregate results.

134 The number of wildcat strikes is much lower, so the basic unit is one strike. For each, strike Trump's expected percentage rises .02 .
} 
delegate critical decisions to faceless bureaucrats or "independent" editors devoted to higher truths, no matter how many journalists assure us otherwise. ${ }^{135}$

This paper, though, has concentrated almost entirely on voters, which complicates the task of writing a succinct conclusion. The fundamental problem is that the US political system is money-driven, full stop. The direct statistical evidence that voters do not drive policy just keeps mounting and has recently been buttressed by a creative use of machine learning techniques. These give a striking new twist to older statistical findings. ${ }^{136} \mathrm{We}$ have also carefully reviewed the quantitative evidence on role small contributions played in 2020; as our Appendix 2 shows in detail, their much ballyhooed role is way overblown. While some candidates - mostly losing candidates - build campaign war chests heavily out of small donations (defined as those totaling less than $\$ 200$ from a single contributor), that is not true for most major party winning candidates and for the parties themselves. In 2020, we estimate, seventy percent of all political money came from contributions over that cut off. With the conspicuous exceptions of the Sanders movement, the Justice Democrats, and similar groups that are authentically "populist" in the sense that media discussions of that term largely ignore, an unsympathetic observer might well conclude that the waves of small contributions just help float a system that is then steered by the major donors.

As a consequence, any serious assessment of the dynamics of the system must concentrate on precisely what this paper has treated only glancingly. Since a full scale analysis of political money in 2020 would require another paper at least as long as this one, we must content ourselves with some closing observations that draw heavily from research in progress.

We begin by reviewing this paper's findings, with all the cautions concerning the limitations of data and methods that we have previously discussed. We think that the story that emerges is straightforward and forms a credible whole.

Though no one can say for sure, it seems likely that the Trump camp's calculation that they were cruising to reelection in January 2020 was likely right. For all his barely coded racist and sexist appeals, the advantages of incumbency together with the steady drop in unemployment and increases in very modestly remunerated working hours for so many low paid groups might well have secured his reelection.

But then came COVID, which as Trump himself later acknowledged, "changed the whole ballgame." 137 The President's insistence on keeping the economy open was fatal. By framing the policy choice as a decision on locking down to save lives or sustain the economy, Trump, like the UK's Boris Johnson, simply guaranteed a disastrous cycle of stop/go policies. The only real

\footnotetext{
${ }^{135}$ For the Chair of the Joint Chiefs, see (Leonnig \& Rucker, 2021); for Murdoch, see (Wolff, 2021).

136 (Maguire \& Delahunt, 2020); (Ferguson, 2020).

137 (Wolff, 2021), p. 300.
} 
way to save the economy was to save the people. But the failure to quickly put in place systems to test, trace, and isolate COVID cases, procure and distribute personal protective equipment and medical supplies, and mandate serious worker safety standards led straight to longer and bigger lockdowns along with vast numbers of unnecessary deaths and illnesses, especially among minorities and the poor. Among developed countries, the US and UK, which pursued much the same course on COVID, show uniquely disastrous outcomes. ${ }^{138}$ Both spent fortunes propping up the economy with comparatively dismal results. Until the god from the machine - the vaccines came on stage, the US expended far more resources pumping up the economy, without any comparable rate of economic success. It also failed to protect its population, especially its low income and minority citizens.

Unlike some studies, our results indicate that COVID cost Trump heavily. Our findings suggest that his mishandling of the pandemic turned off many upper income voters who might otherwise have been willing to hold their noses and vote for him, as many had in 2016. The revulsion ran especially deep in sectors with large numbers of scientific, technical, and professional workers and in finance. The administration's lack of interest in worker safety also stimulated thousands of workers left without protection to take matters into their hands and mobilize. While the waves of small, often wildcat walkouts appear to have strengthened reactions by conservatives in many communities, we suspect that the broader wave of protests associated with Black Lives Matter and other groups likely also drew strength from the President's obvious disinterest in safety and health issues, though that remains to be shown. What does seem clear is that the giant swelling wave of social protests worked on the whole to increase the Democratic vote, helped along by the COVID induced legal changes that made voting easier. Trump's calculations that he could counter the mobilization from below with a Nixon-like counter-mobilization of the right were mistaken overall, though in some places the appeals to law and order may have played well.

This diagnosis helps only modestly in answering the most important question of all: what our results imply about the future. Here is where focusing on political money immediately brings important clarification. As mentioned earlier, a major question is why the Democrats fared so much worse in the Congressional races. Though it won the presidency, the party actually lost seats in the House and failed in its bid to take control of the Senate. The disappointment - or, for Republicans, relief - was all the greater in that in the weeks before the election, virtually every major media outlet trumpeted stories of what was said to be overwhelming Democratic advantages in fundraising - more than twenty, by our incomplete count. ${ }^{139}$

The morning after the election, though, the press flip-flopped. Without stopping to wonder if the October pre-election counts were misleading or simply wrong, the major media ran story after story highlighting the extravagance of strong claims about the money-driven character of

\footnotetext{
${ }^{138}$ (Storm, 2021b); (Alvelda, Ferguson, \& Mallery, 2020); the reference is not merely to total deaths but to the huge but fruitless expenditures involved, as both of these papers illustrate well.

139 (Ferguson, Jorgensen, \& Chen, 2021). The next few paragraphs draw heavily on our discussion there.
} 
American elections. Reporters celebrated how canny voters in Maine and other states saw through the clouds of out of state big money. Our favorite summary - it should be enshrined forever in the Madame Tussaud's of hasty social science misjudgments - was a tweet by Edward Luttwak that "The very good news of 2020: money does not win elections in America. Because of the proclivities of American billionaires, Democratic candidates had x 2 or $x 3$ or $x 4$ the money of Republicans in House, Senate \& WH elections. Holder, Obama's AG spent hugely in States but Dems lost." 140

Before the election, when we were asked, we cautioned about claims of a one-sided Democratic advantage. We did not doubt the stories drawing on partial, pre-election fundraising reports, testified to strong Democratic fundraising efforts. Nor did we believe that polls suggesting that the Democrats were probably then ahead in the polls were necessarily wrong. But we knew that the flows of money streaming into campaigns in the final weeks of elections are often gigantic and do not necessarily reflect polls. The epic, come from behind struggle in 2016 to salvage Republican control of the Senate was particularly fresh in our minds, since we had just published a study analyzing it in detail. That effort's defining feature was a rip tide of late money that turned around an apparently hopeless situation at a time when most observers believed their party's presidential standard bearer was doomed. ${ }^{141}$

In 2020, signs that similar efforts might be afoot were obvious. In Maine, for example, in midOctober, a single private equity magnate dropped his third contribution of $\$ 500,000$ dollars in the election cycle into a single candidate super-PAC supporting Republican Senator Collins. ${ }^{142} \mathrm{We}$ were confident that our "linear model" of House and Senate races - so-called because the relation between the two-party split of the money and the outcome of the vote looks like a straight line when you plot it - would prove out, as it had in every previous election for which the data exists to compute it. And we doubted that trailing in the polls would put off many big Republican contributors, any more than in 2016. The whole point of our work is that political money does not move in lockstep with the prospects of candidates; it independently reshapes them.

Figures 9 and 10 confirm we were right. At a moment when everything appears to be up for grabs in American politics, some things have not changed: the system is still money-driven. The figures for both the House and the Senate are simple scatter diagrams. Along the bottom from left to right runs the Democratic percentage of the total amount spent on any given race - not the cost of votes per ballot or other measures that vary with district size and other characteristics. The vertical axis going up the left side benchmarks the percentage of the two-party vote that the Democrats garner. That axis is scaled as the difference between the Democratic and Republican shares of the vote, meaning that as the difference goes positive for the Democrats (roughly in the

\footnotetext{
${ }^{140}$ The Luttwak tweet is quoted in Ibid.

141 (Ferguson et al., 2019).

142 (McFadden, October 28, 2020).
} 
middle of the figure), they start winning seats. At the bottom left corner, in other words, the Democrats get no or hardly any money and win no or hardly any seats. At the upper right, they slurp in all the money and get all the votes.

Figure 9

The Straight Truth: Money and Major Party Votes in the House

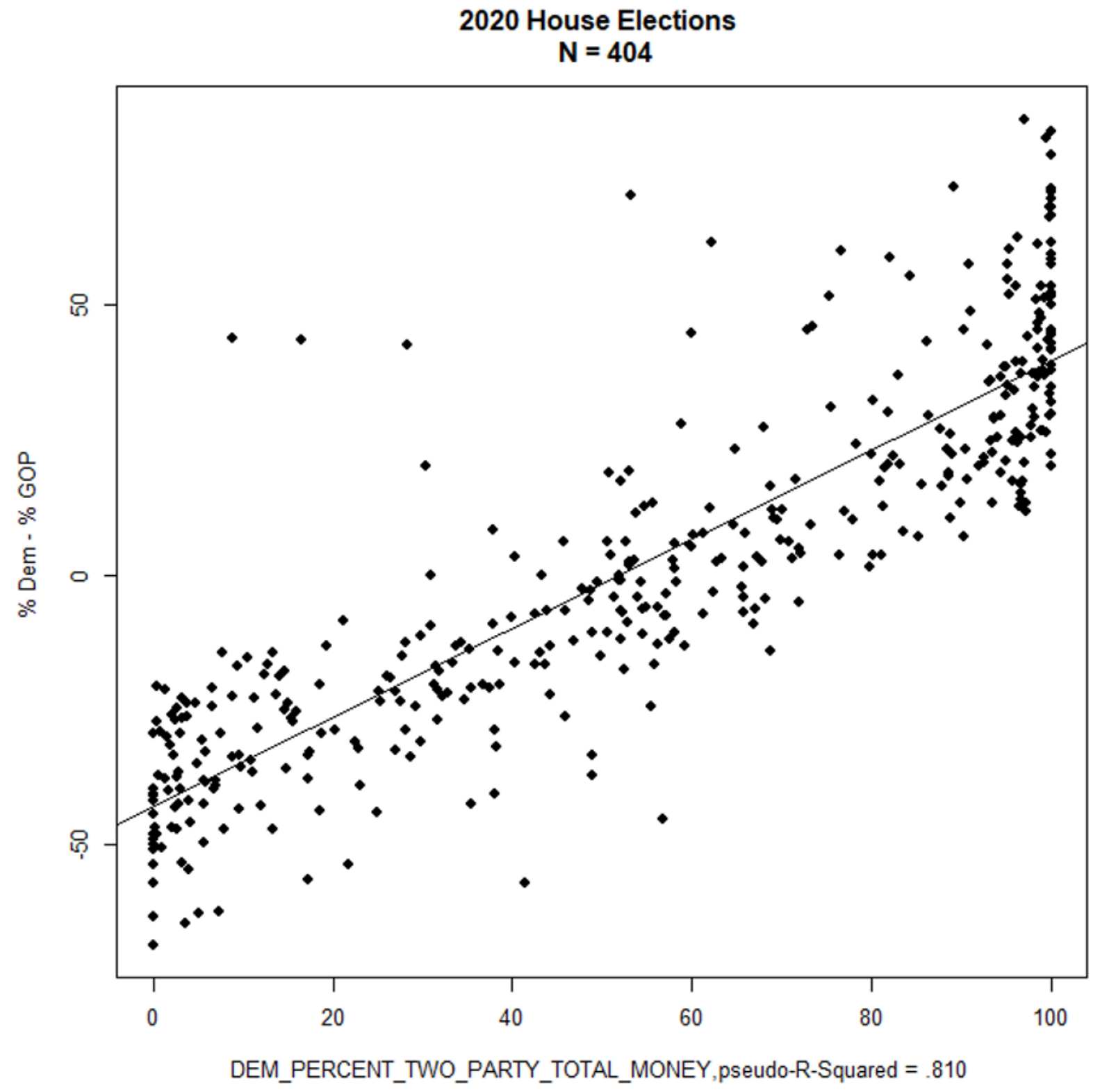

Data: Money From the FEC; Votes from Leip's Atlas of U.S. Presidential Elections 
Figure 10:

The Straight Truth: Money and Votes in the Senate

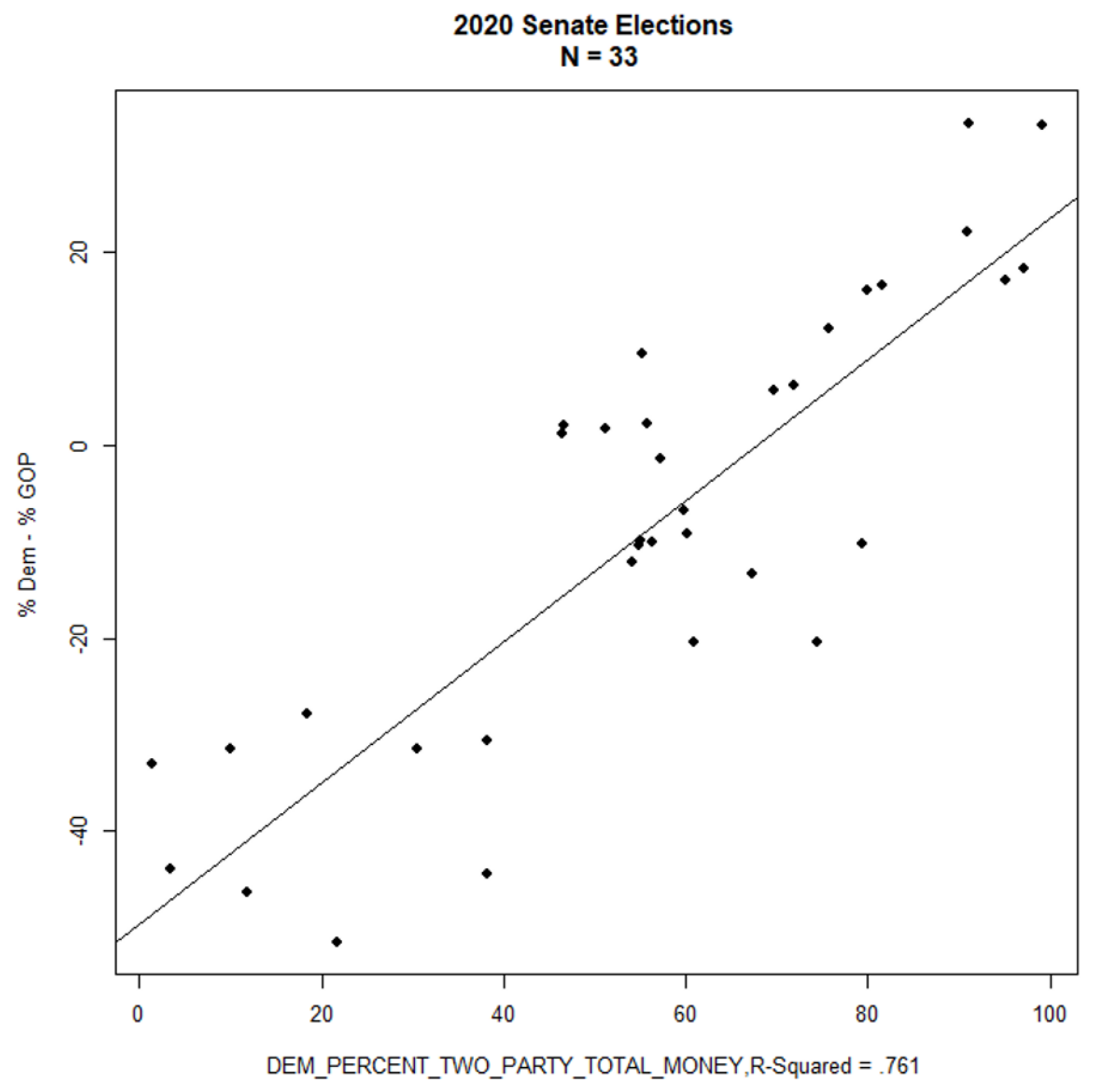

Data: Money From the FEC; Votes from Leip's Atlas of U.S. Presidential Elections

Display Includes the Special Senate Elections in Georgia in January, Though They Are Not Included in the Summary Statistics - See Appendix 2

The spread of the dots around the line - outcomes of actual races - shows how far reality diverged from the pure linear model. The discordance in 2020, as in so many elections before, 
was not much. Some races did deviate - they always do, and in 2020 Democrats lost some close ones they might normally have won. But the big story is the continued dominance of the linear model. The best ways to summarize the model's strength are highly technical; we thus put the details in our Appendix 2, along with a brief explanation of how to see through the perennial last hope of orthodox political science and economics, that seeing cannot be believing, because the money must be following polls. Comparisons of gambling odds with money flows demonstrate the opposite. ${ }^{143}$

Now let us consider what our analysis of 2020 implies about some of the dynamics of opposition within the Republican Party. The most important conclusion derives from our findings about how geography and industrial structures combine in space.

Our earlier study of the 2016 election documented how Trump won important support from major energy sectors and extreme laissez faire parts of finance (that is, private equity), especially in the closing stages of the campaign as he woke up to the true costs of waging a national campaign. The coal industry also backed him heavily. ${ }^{144}$ These patterns repeated themselves in 2020, but with a striking twist.

Our 2016 data showed clearly that not private equity in general but the "big business" players within the sector were the true Trump enthusiasts. ${ }^{145}$ For 2020, we undertook an especially detailed investigation of this sector that now bulks so large in American life and politics. What we found is sobering and sends a clear message about the future. As Appendix 5 shows, at first glance, Biden looks to have garnered more support from this sector than Trump: almost \$20 million dollars compared to Trump's $\$ 13$ million. But when one examines where those sums came from, a startling difference emerges. Fully seventy-six percent of Trump's come from the "big business" end of private equity, compared to $13 \%$ of Biden's money. ${ }^{146}$

\footnotetext{
${ }^{143}$ For a detailed discussion, see (Ferguson et al., 2019); also the statistical analysis of bandwagons in (Chen, Ferguson, \& Jorgensen, 2020). The case of 2016 is particularly stark: money was clearly reshaping polls and outcomes in the final few weeks of the campaign.

144 (Ferguson et al., 2018), but see also (Ferguson et al., 2020).

145 "Big business" here refers to private equity investors in the Forbes 400 or firms ranking in the top 350 firms on the Fortune list or privately held firms of equivalent size. See (Ferguson et al., 2018). Identifying private equity firms outside of the big business lists is fraught with difficulty. We cross-listed the list of private equity firms provided by Private Equity Info (https://www.privateequityinfo.com/) with the list of firms in the 2020 campaign finance records to find all known private equity campaign contributors, including firms, executives, and PACs. ${ }^{146}$ These totals and all the ones below for the Presidential campaign count only contributions narrowly focused on the presidency; not all political contributions. Contributions to the Republican and Democratic National Committees are counted as part of the presidential money, though not the many millions that pass through to other campaigns, especially to Congress. To identify coal and oil and gas contributors, including firms, executives, and PACs, we cross-listed the list of firms provided by Dun \& Bradstreet Hoovers (https://www.dnb.com/) with the list of firms in the 2020 campaign finance records. We conducted a manual search through the campaign finance records to find additional smaller firms. To generate the list from Dun \& Bradstreet Hoovers, we defined oil and gas using the following 4-digit sic codes: 1311, 1321, 1381, 1382, 1389, 2911, 4612, 4613, 4619, 4922, 4923, 4924, 4925, 4932,
} 
Put simply, the biggest and most aggressive players in this ascendant sector overwhelming supported Donald Trump for reelection. The full significance of this finding emerges when one reflects that our results refer only to public, on the record, funds. They take no account of socalled "dark money" that allows donors to take advantage of famously lax regulatory structures and route contributions through legal entities that are required only to report their expenditures, not where the money came from. Given the lopsided skew of top incomes in the United States, it is safe to conclude that many private equity titans are among the most likely users of such vehicles. Our results, accordingly, likely underestimate the true political reach of this group by a considerable magnitude.

By contrast, the cases of coal and oil are easier to parse, especially the former. In 2020, just as in 2016, coal companies overwhelmingly favored Trump. As Appendix 5 indicates, essentially all the contributions by coal companies in the presidential campaign, totaling just under $\$ 2$ million dollars, went to Trump. Biden by contrast picked up just under $\$ 17,000$. Oil was also lopsidedly for Trump and the volume of money was vastly larger. Again, as detailed in Appendix 5, the oil and gas sector gave more than \$28 million dollars to Trump. Almost exactly half of that came from Big Oil, in the sense of firms and investors whose operations place them among the top 350 largest firms on the Fortune 500 list, comparably large private firms, or the Forbes 400 list of richest Americans.

Another time we can take up in in more detail the question of "green investors" and pressures on energy companies. The bottom line among heavy carbon emitters, though, remains the bottom line. When large international oil majors respond to "green" investor pressures by selling off shale oil holdings, many smaller oil firms, themselves huge when measured against anything smaller than Exxon or Shell, are happy to buy them. They are well aware that those holdings can yield a stream of profits for a long time, especially if firms protect their investments by deploying political money on a large scale. In more than a few cases, these energy companies are assisted or even owned by gigantic private equity and commodity dealing firms. ${ }^{147}$ Coal companies also remain significant players in American politics too, as does the Koch group of companies, whose major ties to the Trump administration came through Vice President Pence's office. $^{148}$

Add heavy industry, paper, the chemical industry, and other heavy polluters discussed in our earlier paper on the 2012 election as part of the core of the Republican Party and you have a powerful bloc of firms to bulwark a go-slow, conservative coalition against serious measures of

5983, 5984, 5989, 6792, and the largest firms in 5172 and 5541. For coal, we used 1221, 1222, and 1241 in addition to a manual search of the campaign finance records.

${ }^{147}$ For a striking example, cf. (Kennedy \& Biesheuvel, 2021).

${ }^{148}$ For the transfers of oil assets from super-majors to other large firms and private equity, see (Jenkins, 2021);

(Raval, 2021). For the Kochs and Pence, see (Wolff, 2021) and more generally (MacLean, 2017). 
climate change, higher taxes, or tighter regulatory policies. ${ }^{149}$ In many cases, they view increased government efforts to combat climate change as creeping socialism and aggressively promote the claim.

Our analysis of the 2020 election adds important spatial detail about the sources of this bloc's rock-like stability. Agriculture as a sector nowadays provides major allies to this conservative industrial bloc. We do not want to overstate the case. Conflicts within and between agricultural sectors have flared throughout American history and they figured importantly in the battles over the renewal of Farm Bill in 2018. ${ }^{150}$ But since the early decades of the last century, a pivotal factor in farm policy deliberations has been clashes between major crop groups. For a long time, the most important of those were corn, cotton, and wheat, though soybeans and other crops have since risen dramatically in significance. ${ }^{151}$ The steady growth of world demand for meat has altered how some of these sectors do business, as have the changing world market conditions facing each crop. Many more players have also joined the fray, including finance and firms producing vital inputs such fertilizer and seeds. ${ }^{152}$

But the broad shape of what has happened to the farm sector is apparent, as is its significance for American politics. Big farms, often increasingly tied into major processing, fertilizer, and other food related giants, dominate the system. They are responsible for over $51 \%$ percent of farm output, up from $31 \%$ as recently as $1991 .{ }^{153}$ Intermediate sized producers have been almost entirely squeezed out. While many small producers still exist, their collective share of output is minuscule: barely $1 \%{ }^{154}$ The big firms garner the lion's share of federal support and for many years agricultural research conducted by government and most other sources serves principally their interests. ${ }^{155}$

\footnotetext{
${ }^{149}$ For 2012, see (Ferguson, Jorgensen, \& Chen, 2013); that paper documented the huge influence in the GOP of polluting firms.

${ }^{150}$ (Winders, 2020).

151 (Winders, 2004).

${ }^{152}$ (Scheingate, Scatterday, Martin, \& Nachman, 2017). Many political science treatments identify state policies constructed by independent experts as the most important shapers of farm policy in the New Deal and often after. (Ferguson, 1997) observed that the paradigm case cited in favor of the importance of experts rested on a mistaken attribution; the key document was in fact ghosted by Beardsley Ruml, perhaps the most important of all the Rockefeller advisers, not any academic. There is no reason to deny that state structures influence farm politics; cf., for example, the long Southern dominance of the Congress and the Supreme Court's Baker vs. Carr decision forcing reapportionment. Nor any reason to scoff at notions that rising urban populations contribute to increasing scrutiny of farm programs. But for detailed evidence of how crop bloc coalitions in the world market drive the process, see (Winders, 2004) or (Winders, 2009). Some social scientists who should know better also treat the increasing role of finance, fertilizer, and other interests as the spread of "pluralism." These simply bring other giants into the deliberations; typical investor-driven politics.

153 (MacDonald, Hoppe, \& Newton, 2018). 'Large farms' refers to farms with a total value of production over a $\$ 1$ million dollars, adjusted for price changes. For an economic analysis, see (MacDonald, 2012)

${ }^{154}$ (MacDonald et al., 2018). Livestock is an exception to these trends, though it is now under a lot of pressure.

155 (Donald Hadwiger \& Talbot, 1967).
} 
It is a truism that large farmers dominate the American Farm Bureau Federation and that the Bureau has historically been very close to the Republican Party, but we repeat our caution that sectoral crop bloc building is critical and often spills over into party politics. Just as with major industrial firms, major agricultural investors and farms are powerful actors in their own right and smaller "coalitions of the willing" form all the time. ${ }^{156}$ But the focus on specific crops helps smother any chance small producers have of asserting interests of their own. ${ }^{157}$ In periods of falling prices, the smaller producers occasionally break away to form new interest groups, but these only rarely succeed. ${ }^{158}$ Big farmers love subsidies (justified in public, however absurdly, in the name of preserving "family farms"), but they share the intense hostility of heavy industry to efforts to regulate pollution - indeed, in the world as a whole, the food system may be responsible for a third of all greenhouse gas emissions. ${ }^{159}$ They are also very jealous of water rights and wary of increases in taxation either on their enterprises or themselves. Inheritance taxes are a particular bane for some, also, since farm size is closely associated to economic viability. They also are very sensitive to regulations on farm labor and safety issues and strongly anti-union. When Trump tapped into this vast and powerful set of interests, he knew what he was doing. And his approach - massive direct payments - spoke a language both he and the recipients understood. Media stories predicting a revolt on the farm over his China policy were hopelessly off base.

In an age in which serious weather and climate problems are now chronic, whether the Democrats can cobble any viable response together is an interesting question. For decades now, the Party has toyed with various formulas, but with little success. The context has admittedly been difficult. A stylized set of facts pinpoints the challenge: since the late New Deal, the once mixed hue blue and red states of the farm belt have turned ever more monochromatically red. This evolution is completely mystified if it is approached principally in ideological terms or differences in "education." New Deal Democrats once ran strongly in many states that are today Republican bastions. Once the halcyon days of the New Deal had passed, they could still win votes in some crop areas from smaller farmers and in towns and cities in Iowa, Wisconsin, Michigan, Ohio, Indiana, and other states that once also had thriving industrial bases. Together this crop-specific, small farmer - worker coalition was viable for decades. But over time, both pillars of the Democratic Party base splintered and then collapsed: small and intermediate sized farms became increasingly less important; while import competition, technological change, and runaway shops that globalization enabled wrecked the industrial heartland and unions anchored

\footnotetext{
${ }^{156}$ See, e.g., (Donald Hadwiger, 1976) or (Donald Hadwiger \& Talbot, 1967). This is to restate the point in (Ferguson, 2020); social scientists spend way too much time on peak organizations.

157 This was brilliantly summarized by Donald Hadwiger: "the commodity coalition eventually prevented the development of any structures which could serve or speak for the interests of small farmers or farm workers. Power, both economic and political, went to the larger farmers-also to the agribusiness firms which assumed much of the production function. Those institutions that had been created to serve small-unit agriculture were converted by stages to serve large-farm agriculture" (Donald Hadwiger, 1976).

158 (Donald Hadwiger, 1971).

159 (Crippa et al., 2021).
} 
there. ${ }^{160}$ In many areas, population declined proportionately and sometimes even absolutely, impelling further outward flows of people and money. During the Obama presidency, the Democrats left the field, sometimes literally. The party famously rejected proposals by former Vermont Governor Howard Dean to build up organizations in all fifty states, in favor of concentrating on urban America. Today, conservative big farmers and their industrial and financial allies dominate most farm area politics, though giant anti-labor retailers are also moving in to build warehouses paying modest wages.

In the Pacific Northwest, Minnesota, and some other areas, another dynamic compounds the Democrats' problems with voters in the periphery. Here our results for saw mills and the Trump vote are striking. Many parts of Oregon, Washington state, Minnesota, and other areas were once flourishing timber producers, often with sizeable unions. But federal regulations championed by environmentalists whose political strength is mostly centered in urban, bi-coastal areas has seriously affected the old industries. Their populations, mostly white and less well educated, do not see the federal government as a friendly force. We are not surprised that groups like the Proud Boys appear to recruit rather heavily from such areas. ${ }^{161}$

The growing chasm between cities - "world cities" in current parlance - and the periphery raises deep questions about the future of American democracy. The historically inclined will inevitably think of France after 1848, when rural areas fiercely resisted urban efforts to tax them for the benefit of cities or, indeed, many parts of Europe today. The spatial implications of the American dual economy are a mainspring of the Trump electoral phenomenon, though we caution that within the big cities the growing urban-based, low wage dual economy nourishes the Sanders wing of the Democratic Party and related radical movements. The slow collapse of public goods such as transportation and education also leads more and more of the middle class in the direction of the Sanders coalition.

In both the country and cities, the economy was working for only a small portion of the population when COVID hit. The pandemic made matters worse, though for a while federal support programs significantly cushioned its crushing weight on many Americans. As it assumed power, the Biden administration moved boldly to push through far-reaching relief programs. But back to "Normalcy" is unviable. The status quo ante is what produced Trump. The new administration is trying to follow up its first success with designs for further large scale reconstruction. Some combine serious proposals on climate change with programs that hold

\footnotetext{
160 "Small" here means very small in the sense of (MacDonald et al., 2018), p. 5. To some extent the numbers over time are artificially swelled by absolutely rising prices, which means that firms too tiny to make it into older censuses now appear. Many of these dwarfs, one suspects, represent either hobbies by families that probably vote elsewhere, garner most of their income from other jobs, or are sad cases reminiscent of Tobacco Road. Note that many minority owned farms are small and sparse and have long been shortchanged by the Department of Agriculture.

${ }^{161}$ A few areas with abundant water resources have sometimes transited into leisure-based recreational centers and have thrived, often in the process become more liberal.
} 
promise for preserving wages and jobs for average Americans, notably the proposals to encourage electric cars and remake the automobile sector.

Whether these efforts are big enough to meet the need is, perhaps, doubtful. But immediate problems loom, even if the administration succeeds in putting across its truncated infrastructure and human capitals programs. The party establishment remains closely tied to Silicon Valley, big finance, and major parts of telecommunications, paralyzing efforts for real change. Both the administration and Democratic congressional leaders are also dug in on protecting the disastrous and fabulously expensive system of private medical care that clearly fails most of the population.

Republicans and establishment Democrats also pushed the President to let lapse the special legislative and regulatory measures put in place during COVID to protect the poor and vulnerable, such as the moratoria on evictions and student loan payments. The Supreme Court threw out the administration's halting, last minute attempt to postpone evictions again after it had collected campaign cash from real estate groups. ${ }^{162}$ The supplementary unemployment payments have now expired and there are questions about how long the restrictions on charges for COVID tests and other medical assistance will survive. It is clear that many hospitals have continued to bill patients all through the pandemic. ${ }^{163}$

Most ominously of all, every passing day suggests that the administration is failing to keep up with COVID's mutations. Though it is spending a lot of money, when it assumed power, it failed to prioritize cheap, accessible tests open to anyone who needs them, left too much basic data gathering to scholars or the media, and made at best half-hearted pushes in favor of improved ventilation, air filters, and other obvious steps that would minimize indoor COVID problems, especially in schools. ${ }^{164}$ It also did essentially nothing to put reliable face masks in the hands of the population and failed even to set standards for advertising and sales of facemasks, leaving a vast market to charlatans. It still has no program in place for large scale random testing that can swiftly identify new variants and it has failed to create an effective national set of statistics with public dashboards anyone can access. Essentially it has staked everything on vaccines that will need regular, costly updates in a country with no national healthcare system. It is obvious that the administration's hopes for an end to the COVID nightmare are premature.

Beyond all this sits the giant dilemma highlighted by the tumultuous American exit from Afghanistan. The entire Democratic establishment bought into the administration's sunny foreign policy rhetoric that "America is back" and the importance of maintaining a rules-based international order. The new Biden foreign policy team missed few opportunities to lecture China, Russia, Iran, and other revisionist countries about the importance of adhering to norms

\footnotetext{
162 (Perez \& Warner, 2021).

163 (Kliff, 2021).

164 (Parramore, 2021); (Gurdasani et al., 2021).
} 
and standards in diplomacy. Most of the Republican establishment shares this conviction, in stark contrast to the Trump wing of the party. ${ }^{165}$

But there is a fundamental problem: the approach presupposes a stable world order with a clear hegemon. We no longer live in this setting, but in a multipolar world more akin to the nineteen twenties and thirties. Listening to the commentary about global supply chains and the importance of access to "rare earths" that are vital for production in the digital age, one must wonder how long the administration's focus on internal reconstruction can survive. The motivation for Biden's decision not to prolong the U.S. presence in Afghanistan past August $31^{\text {st }}$ is easy to understand: he did not want to be rolled by the military and its industrial suppliers like Obama was and that only Trump finally overrode on his way out. But the President's national security advisers did not pick up on the real situation on the ground. No one in authority seems to have anticipated the swift collapse of the deeply corrupt Afghan government. The result is the military and foreign policy counterpart of 2008's Great Financial Crisis: the failure of a clueless national security state leadership that is out of touch with reality and whose "theories" of international relations and diplomacy are as delusional as free market fundamentalism. ${ }^{166}$ Already one can see an alliance forming between inflation hawks and war hawks in both parties in favor of new rounds of military spending that glosses over the history of corruption and mendacity that enabled both Vietnam and the Afghan war and efforts to blame China for policy failures that were mostly Made in America. ${ }^{167}$

Which brings us to the most important question of all: if the Biden administration fails, what then? At the opening of this essay, we saw how most of big business, even parts of it otherwise friendly to Trump's policies, were not prepared to tolerate the disjointed efforts by the President and a minority of his supporters to overthrow the election results. But it is already obvious that the resonant promises by many businesses to cut off supporters of the January 6 putsch from future political funding are hollow.

The threat is not yet mortal. Most of big business is well aware that Joe Biden is no Socialist or even Franklin D. Roosevelt, even as anxieties rise that he might be Jimmy Carter. For all the talk about inflation, the fact is that the Democratic congressional effort to raise the minimum wage

${ }^{165}$ Though the discussion predates the Biden administration's assumption of power, see above all (Kurth, 2019).

166 The comparison with the nineteen seventies is inevitable, though we think it is more than a little misleading. But that is for another essay. Much recent literature on the revival of the right in American political life pays little attention to budget tensions between "world order" and domestic reconstruction, especially from the standpoint of Neoliberal economics. See by contrast, (Ferguson \& Rogers, 1986).

167 The literature is already vast and will grow. A succinct first-hand account of corruption in Afghanistan is (Chayes, 2021); on the broader issue of misinformation and mendacity, see, e.g., the sketch in (Greenwald, 2021). Comparisons of the rest of this decade with the nineteen seventies are inevitable, though we think they are likely more than a little misleading. But that is for another essay. Much recent literature on the revival of the right in American political life pays little attention to (claimed) budget tensions between "world order" and domestic reconstruction, especially from the standpoint of Neoliberal economics. See by contrast, (Ferguson \& Rogers, 1986). On rare earths, see, e.g., (Dizard, 2021). On the over-extension of military spending, see, e.g., (Galbraith, 2021). 
failed. So did the vast union effort to organize Amazon in Alabama, and despite pre-election promises, the Occupational Health and Safety Administration has been slow to issue stricter rules on worker safety, even as COVID rates remain high and the special pandemic programs lapse, leaving many Democratic voters in the lurch.

Despite a lot of rhetoric, the Biden regime at best parallels the First, not the Second New Deal. ${ }^{168}$ But while we share the administration's confidence that sustained general inflation is not in the cards, food and energy price rises are running very high, while wages are not keeping pace. Especially if the administration cannot get a better grip on COVID (which heavily impacts day care, schools, and older workers near retirement and thus labor supply), then serious deterioration in the living standards of many Americans becomes a real possibility. Recent statistical studies suggesting that "deaths of despair" and related pathologies largely mirrored dismal existing patterns rather than increasing should be a red flag, given the lapse of pandemic support programs. ${ }^{169}$

Yet despite the great rise in the stock market with the vast upward transfer of wealth that it implies, every major business organization in the United States opposes the quite moderate Biden tax proposals. ${ }^{170}$ Green New Deal programs are facing massive opposition. Republicans are now mounting major campaigns to restrict voting rights and, most alarming of all, give state legislators far more active roles in supervising elections and counting ballots. Total spending in campaigns for state offices that have influence over the counting of ballots is increasing markedly. ${ }^{171}$ That is a warning sign that only fools can miss. One must wonder what could happen in the event of another economic downturn or a resurgence of movements for social justice and the defense of living standards squeezed by food and energy price inflation. Putsch attempts that started out looking like opéra bouffe have sometimes led to much worse.

\footnotetext{
${ }^{168}$ For the difference, see (Ferguson, 1995a).

169 (Case \& Deaton, 2021). The administration's new child tax credit assuredly helps families with children, but the program is too narrow to reach broad masses of voters in major ways.

170 Some environmental levies have attracted some business support; these are an exception.

171 (Kagan, 2021); (Reid, Layne, \& Lange, 2021).
} 


\section{Appendix 1}

\section{The Formal Model of the Election}

This Appendix sets out our formal model of the election. We want to explain the difference in the percentage of votes Trump received between 2016 and 2020 in the different counties of the United States. We subtract Trump's percentage in 2016 from the figure for 2020, so that positive signs on the model's coefficients indicate factors associated with gains for Trump and negative ones signal losses. ${ }^{172}$

Counties are not random points; they are located in specific geographical areas with definite neighbors. From many previous efforts, we expected to find strong spatial correlation in our data. Spatial autocorrelation rather resembles temporal autocorrelation: both make trouble for statistical analysis. Moran tests are the customary method for discovering whether spatial autocorrelation is present in the data. When our tests showed that it was, we switched from ordinary least squares regression to spatial error regression based on Lagrange Multiplier tests. ${ }^{173}$

The model is a spatial version of a fixed effect general linear model. This includes separate intercepts for each state to take account of heterogeneity between them.

Formally, let $Y_{i j}, i=1, \cdots, s, j=1, \ldots, n_{i}$, where $s$ is the number of states, $s=49, n_{i}$ is the number of counties in $i^{\text {th }}$ state, $N=\sum_{i=1}^{s} n_{i}=3042$, is the total number of counties in the sample, be the dependent variable, which is the difference between Trump's percentage of all votes between 2020 and 2016 and $X_{i j, p}, p=1, \cdots, 24$ be the predictors then the spatial fixed effect model is defined as the following:

$$
Y_{i j}=\alpha_{i}+\beta_{1} X_{1, i j}+\cdots+\beta_{24} X_{24, i j}+\lambda \sum_{\substack{i \neq k \\ o r \\ j \neq l}} w_{i j, k l} u_{k l}+\varepsilon_{i j}
$$

where $\alpha_{i}$ are state-specific intercepts that capture heterogeneities across states and $\lambda$ is the spatial correlation. Spatial dependence is captured through spatial autoregressive specification of the

\footnotetext{
${ }^{172}$ As discussed in the text, Alaska is not included in the analysis. Data for a few counties in some variables our model draws on is missing, so that a few counties had to be dropped. The data for 2020 come from David Leip's Atlas of U.S. Presidential Elections, https://uselectionatlas.org/ The 2016 data come from the MIT Election Data and Science Lab, https://electionlab.mit.edu/data We made small corrections to reported votes in a few counties in Arizona in 2016 based on official county election returns. Because of the way Leip reports results in Jackson County, Missouri, we also have adjusted his statistics for that one county. We paid careful attention to multicollinearity as we developed our model. The Condition Index of the full model is well under the widely employed rule of thumb of 30 .

173 (Anselin, 2002); (LeSage \& Pace, 2009).
} 
error terms $\lambda \sum_{i \neq k} w_{i j, k l} u_{k l}$ and $\varepsilon_{i j} \sim N\left(0, \sigma^{2}\right)$. The coefficients are estimated in the following tables with Nagelkerke Pseudo-R-squared $=.637$ and spatial correlation $\lambda=0.499$. 


\section{Appendix Table 1}

Fixed effects spatial error model for the difference in county votes for Trump in 2020 vs. 2016; 22 variables and 2 interactions

\begin{tabular}{|c|c|c|c|}
\hline Explanatory Variables & Coefficient & Std. Error & P-Value \\
\hline \multicolumn{4}{|l|}{ Demographic Covariates } \\
\hline$\%$ Black & -0.024 & 0.005 & 0.000 \\
\hline \% Hispanic & 0.049 & 0.006 & 0.000 \\
\hline$\%$ Foreign Born & -0.023 & 0.012 & 0.000 \\
\hline Border (Yes vs. No) & 3.793 & .396 & 0.000 \\
\hline \multicolumn{4}{|l|}{ Socioeconomic Status } \\
\hline Median_Household_Income_2019 \$1,000 & -0.035 & 0.004 & 0.000 \\
\hline \% Unemployment Oct 2020 & 0.058 & 0.029 & 0.046 \\
\hline \% Diff Unemployment 2016 to 2019 & 0.215 & 0.050 & 0.000 \\
\hline \% Diff Population 2010 to 2019 & -5.168 & 0.544 & 0.000 \\
\hline \% Mormon & 0.129 & 0.009 & 0.000 \\
\hline \multicolumn{4}{|l|}{ Election } \\
\hline HighBiden --1 if $\%$ Trump $<40,0>=40$ & 0.300 & 0.238 & 0.207 \\
\hline \multicolumn{4}{|l|}{ COVID - 19} \\
\hline$\%$ Cov19Cases_1103Pct by population & -0.000 & 0.025 & 0.915 \\
\hline \multicolumn{4}{|l|}{ Events } \\
\hline Labor Protests & 0.021 & 0.007 & 0.002 \\
\hline Social Protests & -1.276 & 0.009 & 0.000 \\
\hline \multicolumn{4}{|l|}{ Industry } \\
\hline PCSciTechservices_541_bea & -0.033 & 0.017 & 0.054 \\
\hline PCfinance_52_bea & -0.121 & 0.025 & 0.000 \\
\hline PCPigWagesInd & 0.224 & 0.054 & 0.000 \\
\hline PCsawmill 3211_bea & 0.069 & 0.039 & 0.076 \\
\hline PCmetal_2122_bea & 0.074 & 0.022 & 0.001 \\
\hline
\end{tabular}




\begin{tabular}{l|lll} 
Soybeans & 0.661 & 0.368 & 0.073 \\
Rice & 2.563 & 1.027 & 0.013 \\
Apples & -11.893 & 2.843 & 0.000 \\
Corn_silage & 2.622 & 1.070 & 0.014 \\
Interaction & & & \\
COVID *HighBiden & -0.163 & 0.063 & 0.010 \\
Protest*Hisp & 0.045 & 0.000 & 0.000
\end{tabular}

Note that: Nagelkerke Pseudo-R-squared $=.637$. 


\section{Appendix 2}

\section{Campaign Contributions Data and Tables for Figures 9 and 10; Small Donor Calculations}

This appendix explains how we calculate this paper's data on political contributions and presents the data for the relevant tables.

We begin with our Figures 9 and 10 in the main text: Money and Major Party Votes in the House and Senate.

All our methods and data sources are spelled out in the Appendices to Thomas Ferguson, Paul, Jorgensen, and Jie Chen, "How Money Drives US Congressional Elections: Linear models of Money and Outcomes," Structural Change and Economic Dynamics 2019, https://doi.org/10.1016/j.strueco.2019.09.005.

For 2020, we proceeded as usual: we gather all candidate disbursements and outside money from any source spent in support of the candidate, including negative advertising against opponents, to construct the percent of all money favoring the Democratic candidate in each House and Senate election. The campaign spending data derives from multiple Federal Election Commission datasets (https://www.fec.gov/data/browse-

data/?tab=candidates, https://www.fec.gov/data/browse-data/?tab=spending )

containing candidate summary spending totals, independent expenditures (from Super PACs and dark money groups), party coordinated expenditures, electioneering communications (which we examine to clearly identify support of or opposition to candidates), and communications costs (campaigning internal to some corporations and unions). Note that these include "dark money," though those totals do not allow identification of the real source of the money.

For our models we drop races without two major party candidates; see our Structural Change and Economic Dynamics discussion. In many cases those are best viewed as auctions. We always test for spatial autocorrelation in races. This is often present in House elections and sometimes for Senate elections. We include the final outcomes of the Georgia Senate races on the graph, but since they were stand alones, not in calculating the model fit for 2020.

The strongly linear character of the models, which holds for all elections for which data exists, has been a standing embarrassment to voter centered accounts of politics from the moment it was published. Many critical responses are simply silly; they don't pay enough attention to details. But we take the force of the objection that in theory the money could be following polls, in whole or in part, making the apparent correlation spurious.

The usual social science device to deal with problems of "endogeneity" is some form of instrumental variable. In our earlier work, we developed a spatial version of the latent instrumental variable model developed by Peter Ebbes and analyzed in detail by Irene Hueter to 
assess such possibilities. ${ }^{174}$ Our Structural Change piece discusses these, but in addition, shows how to use published gambling odds to confirm our conclusions that while two-way causality happens, it does not dominate; the 2016 Republican Senate recovery was a particularly dramatic case in point. Note that since we developed the linear model, other researchers find evidence for it in other countries; it is not specific to the United States.

Our presentation of results here follows those in our longer essay. As usual, the House elections in Figure 9 showed marked spatial autocorrelation based on a Moran I test. This indicated that the residuals of the OLS model displayed significant spatial dependence $(\mathrm{PV}(\mathrm{I})<.001)$. For the House we thus report, successively, results using ordinary least squares, then a spatial Durbin model, followed by the Bayesian spatial latent instrumental variable regression with 4 clusters we prefer, along with Pseudo R squared measures for both spatial models, followed by N, the number of cases.

Appendix Table 2:

Modeling Money and Major Party Votes in 2020 Congressional Elections

House

\begin{tabular}{|l|c|c|c|c|c|c|}
\hline & \multicolumn{2}{|c|}{ Coefficients (SE) } & SBLIV4 & Rsq/ & Pv (I) & N \\
& OLS & Spatial Model & Median (95\% CI) & PsdoRsq & & \\
\hline House & $.825(.023)$ & $.718(.023)$ & $.731(.679, .781)$ & $.759 / .810$ & .000 & 404 \\
\hline Senate & $.732(.074)$ & & $.729(.587, .873)$ & .761 & & 33 \\
\hline
\end{tabular}

Our Figure 10 for the Senate includes the final outcomes of the Georgia Senate races on the graph, but since they were stand alones, not in calculating the model fit. Spatial models were unnecessary for the Senate elections, so the table does not show any. We present results for the OLS model and for a Bayesian latent instrumental variable regression with 3 clusters.

Modeling Money and Major Party Votes in the Senate

\begin{tabular}{|c|c|c|c|l|l|}
\hline Year & $\begin{array}{c}\text { OLS } \\
\text { Coefficients ( SE) }\end{array}$ & & BLIV3 & R-square & N \\
\hline 2020 & $.732(.074)$ & & Median ( 95\% Cl) & & \\
\hline
\end{tabular}

${ }^{174}$ See the discussion and references to their work in (Ferguson et al., 2019). 


\section{Small Donor Calculations}

Obtaining the percentage of small donors to a single committee representing a candidate, group, company, union, or party is a straightforward procedure. Each committee reports an "unitemized" total, which sums money contributed by individuals who give the committee \$200 dollars or less in the two-year election cycle. Each committee also reports its total receipts for that same cycle. A committee's reliance upon small donors to fund its operation is the percentage of total receipts it receives from unitemized donors. We downloaded this and other data required for more nuanced accounting, which we document below, from the Federal Election Commission (https://www.fec.gov/data/browse-data/?tab=committees).

Unfortunately, the figure for the reliance on small donors of any one committee is not of much interest since that committee is likely to be unrepresentative of the whole. For example, using the above method, small donors to the Democratic Congressional Campaign Committee represented $25.12 \%$ of its total receipts, while the figure was $30.63 \%$ for the Democratic Senatorial Campaign Committee and 23.91\% for the Democratic National Committee. The equivalent Republican committees were roughly comparable, as small donors to the National Republican Congressional Committee represented $27.45 \%$ of its total receipts, while the figure was $23.59 \%$ for the National Republican Senatorial Committee and $28.41 \%$ for the Republican National Committee.

But the parties also operate super PACs that spend millions of dollars. The percentages of small donors for these are far lower. For the Democrats, the House Majority PAC received 3.57\% of its total receipts from small donors and for the Senate Majority PAC it was $7.95 \%$. For the Republican equivalents, the percentages were even lower. The Congressional Leadership Fund reported $1.27 \%$ of its total receipts coming from small donors and the Senate Leadership Fund (think Mitch McConnell) reported a miniscule .022\%. A true picture of the role small donors play in party fundraising requires an accounting method that accurately aggregates unitemized donors and total receipts across the full spectrum of committees owned and operated on behalf of candidates and parties.

Our sample includes all committees known to be operated by or on behalf of the Democratic and Republican general election candidates for the U.S. House of Representatives and Senate. These committees include the candidates' principal campaign committees, leadership committees, and super PACs. Our sample includes all the joint committees operated by those candidates and two major parties. We also include the six major party committees (DNC, RNC, DSCC, NRSC, DCCC, NRCC), and the super PACs affiliated with each party in each chamber. Some of these outside spending committees are organized as "hybrids", which are committees with two bank accounts, one for direct cash contributions to federal candidates and another for either advertising and other expenditures that benefit candidates or non-federal disbursements. While it is conventional to refer to the House Majority PAC as a super PAC, as we do above, it is formally organized as a hybrid committee with different accounts. Our sample includes the 
presidential equivalent of all these committees, including principal campaign committees, joint committees, and super/hybrid PACs. We do not include candidate committees of candidates who lost in the House, Senate, or Presidential primaries.

Finally, our sample includes all super and hybrid PACs that are not directly affiliated with either political party but spend money in ways that help either the Democrats or Republicans exclusively in congressional, senatorial, and/or presidential races. We call these "para-party" committees. Examples include The Lincoln Project for Democrats and American Crossroads for Republicans. We do not include industries or groups that have a policy focus, which aligns with one party in this particular political era as "para-party" committees. For example, we do not include Planned Parenthood, union-run committees, or the Chamber of Commerce; however, these organizations do contribute large sums to the "para-party" committees and those show in our tabulations. By including these "para-party" organizations, our sample covers $88 \%$ of all super PAC receipts. In other words, we can link $88 \%$ of all super PAC money either directly to candidate-run operations or to efforts to help one party or the other exclusively.

We identified all super PACs registered with the FEC for the 2020 election cycle. Those super PACS not included either spent money on behalf of both Republican and Democratic candidates or represented a particular industry that could not be tied to the parties. Our hybrid PAC sample includes all of those committees that are associated with either the Democratic or Republican Parties or associated directly with a general election candidate, plus the "para-party" hybrid PACs that are in the top 150 of hybrid PACs ranked by total receipts. Our sample thus includes 93\% of all hybrid PAC money, but two big party fund aggregators, ActBlue and WinRed, are not included in these totals even though they are officially registered as committees with a noncontribution account used to disseminate money at the state level.

We do not include a direct analysis of ActBlue and WinRed at this juncture because they act primarily as conduits and help link donors to candidate and party committees. We proceed this way to minimize double counting. Money coming through the two conduit groups will still show in our data. ActBlue and WinRed itemize all their donors and transactions regardless of whether a donor aggregates to below \$200. This reporting practice means that ActBlue and WinRed do receive money from donors who give less than or equal to $\$ 200$ but itemize those donors rather than report a lump sum. ActBlue reported zero unitemized contributions in 2020, and $\$ 4,318,377,981$ in itemized total receipts. WinRed, following ActBlue's reporting standard in this specific instance, received \$2,240,123,103 and listed only \$2,009 in unitemized contributions. The FEC decides which of those donors to ActBlue and WinRed appear in the itemized file using the $\$ 200$ threshold. A few small donors below that threshold will sometimes appear in the FEC itemized file, but those donors represent an extremely small percent of the small donor pie. A complete analysis of small donor contributions funneled through these conduits would therefore require a comparison of their filings with the FEC itemized file. The small donors using ActBlue or WinRed should be included in the unitemized total reported by each candidate. We are planning a detailed inventory as part of our future research, but from past 
experiences we are confident already that any differences with totals reported here will be very small.

Increasing the sample size from one committee to an entire slate of candidates, parties, or even Congress as a whole requires still more nuanced accounting procedures. Rather like the market for inter-bank funds, candidates often operate more than one committee and these committees all contribute and transfer money to other candidate and party committees. These contributions and transfers to other committees would inflate total receipts and cause an artificial deflation of small-donor percentages. When interest is centered on one committee, as in the examples above, it is rational to keep these transfers and contributions because it shows how much the committee relies on others in addition to small donors. The recipient committee may not know or care how much its contributors acquired their receipts from small donors; however, there are times when transfers and other contributions should be subtracted from the total receipts of a committee.

It is likely that a candidate, especially an incumbent, will run a principal campaign committee, a leadership committee, and a super PAC. Small donors and receipts from those three committees must be aggregated appropriately to obtain a true total for that candidate. When candidates are aggregated into larger groups, such as Democrats and Republicans, total receipts balloon because the committees of one candidate give to the committees of other candidates and party committees. In other words, the total receipts of one committee become part of the total receipts of another committee. In the samples and percentages reported in the paper, we account for all transfers and contributions (read: recycled money) that occur within the sample. Accounting for this recycled money requires additional data than what is provided in the summary finance files. We use the itemized transaction files provided by the Federal Election Commission (https://www.fec.gov/data/browse-data/?tab=bulk-data). These files require a sizeable amount of computing and processing power to clean and reorganize the data to avoid mistakes.

These itemized files contain each transfer and contribution from one committee in the sample to another. Flow of funds in this system is treacherous: Transfers and contributions between committees can be missed or double-counted because both the donor and recipient can report the same transaction. It is more common for a committee to report giving money to another committee (a transaction labeled with $24 \mathrm{~K}$ by the FEC) than receiving money from another committee (a transaction labeled as $18 \mathrm{~K}$ ).

Given that the number of $24 \mathrm{~K}$ transactions greatly outpaces the number of $18 \mathrm{~K}$ transactions, when they should be equal, it is tempting to only count the $24 \mathrm{~K}$ transactions and assume the $18 \mathrm{~K}$ transactions are duplicates. This assumption is incorrect. It is possible that committees will report receiving money $(18 \mathrm{~K})$, but the committee giving the money does not report that transaction $(24 \mathrm{~K})$. We developed a transaction-matching routine to identify when an $18 \mathrm{~K}$ transaction is duplicated and when it is not. In the 2020 election cycle, committees reported giving $\$ 1,570,957,935$ to other committees $(24 \mathrm{~K})$. Committees reported receiving $\$ 553,875,524$ (18K), or just $35 \%$ of what was reported being given. To assume that all of that nearly $\$ 554$ million 
dollars are duplicated would miss $\$ 146,609,340$ of unique committee contributions that are only reported by the committee receiving them - over a quarter of the amount that could be mistakenly assumed away.

A similar problem occurs with committee contributions to super PACs. The super PAC reports receiving the contribution (a transaction labeled with 10 by the FEC) and the committee reports giving to the super PAC (24K). With super PACs, the problem is compounded because the committee identification numbers are stripped from the super PAC reporting of the contribution. In other words, the committee name is listed as the donor without the committee identification number. We adjusted our transaction-matching routine to find the duplicate and unique committee contributions to super PACs. In the 2020 election cycle, super PACs reported receiving $\$ 1,501,110,754$, but $\$ 315,224,685$ or $21 \%$ of that amount were committees contributing to super PACs, which duplicated the transactions found elsewhere in the data. Of the committees we tabulate in our sample, our transaction-matching routine found $\$ 75,516,149$ of contributions to super PACs that did not have the appropriate committee identification number and were not duplicated elsewhere in the data.

The problem of generating an accurate figure of total receipts when aggregating committees into larger groups is exacerbated by the presence of joint committees. Joint committees are umbrella organizations that raise money in large increments and then distribute subdivisions of those large checks to committees that are constituent members of the joint committee. These member committees can be principal campaign committees, leadership committees, and party committees. When we include joint committees in our sample with candidates and parties, we subtract the amount of subdivided contributions that the joint committee provides to its constituent committees, to eliminate double counting.

\section{Results}

\section{Congressional (House, Senate) Candidates Only}

This sample includes all general election candidates for House and Senate from the two major parties, and all the known committees associated with those candidates. These committees include the principal campaign committees, leadership committees, and super/hybrid PACs connected to the candidates. We include the House and Senate party-run super/hybrid PACs in this sample because they are closely associated with the party leaders of the chamber. More specifically, the House Majority PAC is tied to Rep. Nancy Pelosi, the Senate Majority PAC is tied to Sen. Charles Schumer, the Congressional Leadership Fund is tied to Rep. Kevin McCarthy, and the Senate Leadership Fund is tied to Sen. Mitch McConnell. Sen. Schumer did not have an election in 2020 but is counted as a candidate and winner for this analysis because he ran the top super PAC for the Democrats in the Senate and remains in office after the 2020 election. 
All Candidates for House \& Senate (of those who raised money, $\mathrm{n}=874$ )

Min. Percentage Unitemized $=0$

Max. Percentage Unitemized $=100 \%$

Mean Percentage Unitemized $=19.61 \%$

St. Dev. Percentage Unitemized $=18.43 \%$

Median Percentage Unitemized $=13.9 \%$

Sum of Unitemized $=\$ 1,188,008,663$

Sum of Total Net Receipts $=\$ 5,058,490,961$

Percent Small Donors for All House \& Senate Candidates $=23.49 \%$

$\underline{\text { All Candidates for House \& Senate - Republicans (of those who raised money, } n=420 \text { ), }}$

Min. Percentage Unitemized $=0$

Max. Percentage Unitemized $=76 \%$

Mean Percentage Unitemized $=17.93 \%$

St. Dev. Percentage Unitemized $=17.43 \%$

Median Percentage Unitemized $=12.72 \%$

Sum of Unitemized $=\$ 434,901,755$

Sum of Total Net Receipts $=\$ 2,325,857,732$

Percent Small Donors for Rep. House \& Senate Gen. Elect. Candidates $=18.7 \%$

All Candidates for House \& Senate - Democrats (of those who raised money, $n=454$ )

Min. Percentage Unitemized $=0$

Max. Percentage Unitemized $=100 \%$

Mean Percentage Unitemized $=21.15 \%$

St. Dev. Percentage Unitemized $=19.2 \%$ 
Median Percentage Unitemized $=15.21 \%$

Sum of Unitemized $=\$ 753,106,908.1$

Sum of Total Net Receipts $=\$ 2,732,633,229$

Percent Small Donors for Dem. House \& Senate Gen. Elect. Candidates $=27.56 \%$

All Winners for House \& Senate (includes Schumer \& Senate Majority PAC, $\mathrm{n}=470$ )

Min. Percentage Unitemized $=0$

Max. Percentage Unitemized $=77 \%$

Mean Percentage Unitemized $=10.93 \%$

St. Dev. Percentage Unitemized $=12.72 \%$

Median Percentage Unitemized $=6 \%$

Sum of Unitemized $=\$ 629,608,083.8$

Sum of Total Net Receipts $=\$ 3,136,169,487$

Percent Small Donors for House \& Senate Winners $=20.08 \%$

All Losers for House \& Senate (of those who raised money, $\mathrm{n}=404$ )

Min. Percentage Unitemized $=0$

Max. Percentage Unitemized $=100 \%$

Mean Percentage Unitemized $=29.7 \%$

St. Dev. Percentage Unitemized $=18.92 \%$

Median Percentage Unitemized $=27.36 \%$

Sum of Unitemized $=\$ 558,400,579.3$

Sum of Total Net Receipts $=\$ 1,922,321,474$

Percent Small Donors for House \& Senate Losers $=29.05 \%$ 
All Winners for House \& Senate - Republicans ( $\mathrm{n}=233)$

Min. Percentage Unitemized $=0$

Max. Percentage Unitemized $=65 \%$

Mean Percentage Unitemized $=11.43 \%$

St. Dev. Percentage Unitemized $=13.08 \%$

Median Percentage Unitemized $=6.25 \%$

Sum of Unitemized $=\$ 268,660,361.9$

Sum of Total Net Receipts $=\$ 1,743,771,944$

Percent Small Donors for Rep House \& Senate Winners $=15.41 \%$

All Winners for House \& Senate - Democrats (includes Schumer \& Senate Majority PAC, $\underline{\mathrm{n}=237)}$

Min. Percentage Unitemized $=0$

Max. Percentage Unitemized $=77 \%$

Mean Percentage Unitemized $=10.45 \%$

St. Dev. Percentage Unitemized $=12.37 \%$

Median Percentage Unitemized $=5.99 \%$

Sum of Unitemized $=\$ 360,947,721.8$

Sum of Total Net Receipts $=\$ 1,392,397,543$

Percent Small Donors for Dem House \& Senate Winner $=25.92 \%$

All Joint Committees for House and Senate (of those that raised money, $\mathrm{n}=838$ )

Min. Percentage Unitemized $=0$

Max. Percentage Unitemized $=100 \%$

Mean Percentage Unitemized $=5.71 \%$ 
St. Dev. Percentage Unitemized $=16.8 \%$

Median Percentage Unitemized $=.17 \%$

Sum of Unitemized $=\$ 29,895,257.06$

Sum of Total Net Receipts $=\$ 570,325,551.3$

Percent Small Donors in Joint Committee System $=5.24 \%$

All Joint Committees for House and Senate - Republicans (of those that raised money, $\mathrm{n}=378$ )

Min. Percentage Unitemized $=0$

Max. Percentage Unitemized $=59 \%$

Mean Percentage Unitemized $=1.77 \%$

St. Dev. Percentage Unitemized $=7.18 \%$

Median Percentage Unitemized $=.0000 \%$

Sum of Unitemized $=\$ 18,784,189.95$

Sum of Total Net Receipts $=\$ 360,251,621.4$

Percent Small Donors in Joint Committee System $=5.21 \%$

$\underline{\text { All Joint Committees for House and Senate - Democrats (of those that raised money, } \mathrm{n}=460 \text { ) }}$

Min. Percentage Unitemized $=0$

Max. Percentage Unitemized $=100 \%$

Mean Percentage Unitemized $=8.95 \%$

St. Dev. Percentage Unitemized $=21.19 \%$

Median Percentage Unitemized $=.78 \%$

Sum of Unitemized $=\$ 11,111,067.11$

Sum of Total Net Receipts $=\$ 210,073,929.8$

Percent Small Donors in Joint Committee System $=5.29 \%$ 
All Para-Party (Hybrid \& Super PACs, of those that raised money, $\mathrm{n}=727$ )

Min. Percentage Unitemized $=0$

Max. Percentage Unitemized $=100 \%$

Mean Percentage Unitemized $=20.77 \%$

St. Dev. Percentage Unitemized $=32.67 \%$

Median Percentage Unitemized $=.94 \%$

Sum of Unitemized $=\$ 299,025,713.7$

Sum of Total Net Receipts $=\$ 1,750,838,672$

Percent Small Donors in Para-Party System $=17.1 \%$

Cut Off for Top 25\% of Hybrid/Super PACs by Total Net Receipts $=\$ 648,533, \mathrm{n}=182$

Top 25, Total Net Receipts $=1,694,993,689.54$ (96.8\% of Total Net Receipts)

Top 25, Total Unitemized $=290,681,221.19(97.2 \%$ of Total Unitemized $)$

Top 25, Percent Small Donors $=17.15 \%$

Cut Off for Top 10\% of Hybrid/Super PACs by Total Net Receipts $=\$ 3,733,085.58$, $\mathrm{n}=72$

Top 10, Total Net Receipts $=\$ 1,525,087,780.22$ (87.1\% of Total Net Receipts)

Top 10, Total Unitemized $=\$ 266,739,222.48(89.2 \%$ of Total Unitemized $)$

Top 10, Percent Small Donors $=17.49 \%$

Top 10, of those 72 PACs, mean $=18.4 \%$, median $=.48 \%, \min =0, \max =99 \%$

Cut Off for Top 1\% of Hybrid/Super PACs by Total Net Receipts $=\$ 68,909,090.71, \mathrm{n}=7$

Top 1, Total Net Receipts $=\$ 583,660,995.58$ (33.3\% of Total Net Receipts) 
Top 1, Total Unitemized $=\$ 101,298,149.14$ (33.88\% of Total Unitemized)

Top 1, Percent Small Donors $=17.36 \%$

Top 1 , of those 7 PACs, mean $=16.34 \%$, median $=.89 \%, \min =0, \max =57 \%$

Appendix 2 Table 1

Small Donor Percentages of Top 1\% of Para-Party Hybrid/Super PACs by Total Receipts

\begin{tabular}{|l|c|c|c|}
\hline \multicolumn{1}{|c|}{ Hybrid/Super PAC } & Para-Party & Total Receipts & Small Donor\% \\
\hline Stop Republicans & Democratic & $\$ 89,209,026$ & $57 \%$ \\
\hline The Lincoln Project & Democratic & $\$ 87,299,908$ & $35 \%$ \\
\hline Fair Fight & Democratic & $\$ 89,359,620$ & $21 \%$ \\
\hline $\begin{array}{l}\text { AB Pac (American } \\
\text { Bridge) }\end{array}$ & Democratic & $\$ 82,915,016$ & $1 \%$ \\
\hline Club for Growth Action & Republican & $\$ 71,688,792$ & 0 \\
\hline American Crossroads & Republican & $\$ 81,809,711$ & 0 \\
\hline Democracy Pac & Democratic & $\$ 81,378,923$ & 0 \\
\hline
\end{tabular}

All Major Party Committees (RNC, DNC, NRSC, DSCC, NRCC, DCCC, n=6)

Min. Percentage Unitemized $=24 \%$

Max. Percentage Unitemized $=31 \% \%$

Mean Percentage Unitemized $=27.48 \%$

St. Dev. Percentage Unitemized $=2.78 \%$

Median Percentage Unitemized $=28.16 \%$

Sum of Unitemized $=\$ 721,196,050.6$

Sum of Total Net Receipts $=\$ 2,625,902,044$

Percent Small Donors to Major Party Committees $=27.46 \%$

The presidential sample includes the committees operated by and/or aligned with Trump and Biden. These figures do not include the RNC or DNC, which we customarily group with the party nominees. We analyze the party committees separately regarding small donors and then group the parties, candidates, and para-party committees together for a final judgment about party reliance on small donors. For Trump and Biden, we group together their principal 
campaign committees, joint committees, and all outside committees that are associated with them. We do not include the para-party PACs that certainly spent money to promote Biden or Trump.

Presidential - Trump \& Biden

Unitemized Total $=\$ 1,271,226,175$

Total Net Receipts $=\$ 3,596,194,842$

Small Donor Percentage $=35.35 \%$

Presidential - Trump

Unitemized Total $=\$ 777,347,105.6$

Total Net Receipts $=\$ 1,830,462,046$

Small Donor Percentage $=42.47 \%$

Presidential - Biden

Unitemized Total $=\$ 493,879,039.73$

Total Net Receipts $=\$ 1,765,732,795$

Small Donor Percentage $=27.97 \%$

All Entities (Candidates, Parties, Joint, Hybrid, Super PACs, n=2447)

Unitemized Total $=\$ 3,509,351,830$ (74.19\% of the entire unitemized figure of $\$ 4,730,278,801)$

Total Net Receipts $=\$ 11,823,609,744.43$

Small Donor Percentage $=29.68 \%$

All Entities - Republicans (Candidates, Parties, Joint, Hybrid, Super PACs, n=1,124)

Unitemized Total $=\$ 1,698,129,797$ 
Total Net Receipts $=\$ 5,503,647,399$

Small Donor Percentage $=30.85 \%$

All Entities - Democrats (Candidates, Parties, Joint, Hybrid, Super PACs, n=1,323)

Unitemized Total $=\$ 1,811,222,033$

Total Net Receipts $=\$ 6,319,962,346$

Small Donor Percentage $=28.66 \%$

\section{Summing Up:}

These results show yet again that large donors supply the vast majority of campaign funds in federal elections. There are small differences: candidates who win their races rely less on small donors than those who lose those races. Winners in the House and Senate, as a group, rely on small donors for only $20 \%$ of their campaign stash, but that figure jumps to $30 \%$ for the losers of those races. Summaries of total spending need to take full account of the large sums of money that come in the form of "outside" advertisements and "outside" money. When we include these spending streams, including contributions to the Super PACs raising and spending in the presidential race, we find that small donors fund approximately $30 \%$ of federal general elections. It is obvious that understanding elections and party conflict requires analyzing the large donors who supply the other $70 \%$ of the funds supporting the two major political parties in the U.S. 


\section{Appendix 3}

\section{Data Issues for Industry and Agriculture and Sources}

Most of our data comes from standard sources in the list appended below and do not raise particularly thorny questions. But the county data we rely on for industries and some segments of agriculture require a word of explanation. Our paper draws heavily on wage data for individual industries and counties from the United States Bureau of Labor Statistics. The basic source we drew upon for those data is here; https://data.bls.gov/cew/apps/data_views/data_views.htm\#tab=Tables But these, like many other U.S. government data sources, including many from the U.S. Department of Agriculture, deliberately mask entries that could be used to reveal information about individual businesses. The tables and explanatory material are clear about this and usually indicate where masking happens. Other researchers who have relied on this or similar government data sources make adjustments for this. A popular one is to take the midpoint of a range of values.

It became clear that this could be a very hazardous strategy. A single example can make the point. Hancock County in Kentucky "is dominated by aluminum smelters and aluminum products companies." 175 But the entry for Hancock in the full downloaded table for 2019 (the county does not appear at all in the short summary table that the site offers without downloading) shows zero employment and no wages in NAICS Industry 3313, which should include those subsectors. ${ }^{176}$ The same holds for the more detailed 331315, which as indicated below, employs hundreds of workers there, as do several other subsectors. This is masking in a form that taking the midpoint will not catch.

Fortunately, a group of economists have recently reworked the data using linear programming and other techniques and made their files available to researchers. We are grateful for what appears to be very careful work and we use their data, which we regard as a major contribution to spatial studies of industry. ${ }^{177}$ They caution that their data for 2017 and 2018 are more hazardous because of a change in masking techniques. We accordingly use the data for 2016. Note that their data does not cover the entire economy; some very substantial sectors are left out, including much of agriculture. Total employment in counties in the sense we require it cannot, accordingly, be found by summing their totals. Given that the data is for establishments as explained in our main text, we need data that covers all jobs in the county. We thus turned to the data compiled by the U.S. Bureau of Economic Analysis for total employment in 2016. See the discussion of the data from different government bureaus and the BEA's own tables here: https://www.bea.gov/data/employment/employment-county-metro-and-other-areas

\footnotetext{
175 (DeSilver, 2019).

176 Here:

https://data.bls.gov/cew/apps/table maker/v4/table maker.htm\#type=1\&year=2019\&qtr=A\&own=5\&ind=3313\&su $\mathrm{pp}=0$

177 (Eckert et al., 2021a); (Eckert et al., 2021b).
} 


\section{Appendix 4:}

Map of Differences in Trump's Share of the Vote Between 2016 and 2020 in Counties

A Positive Value Indicates His Share Rose

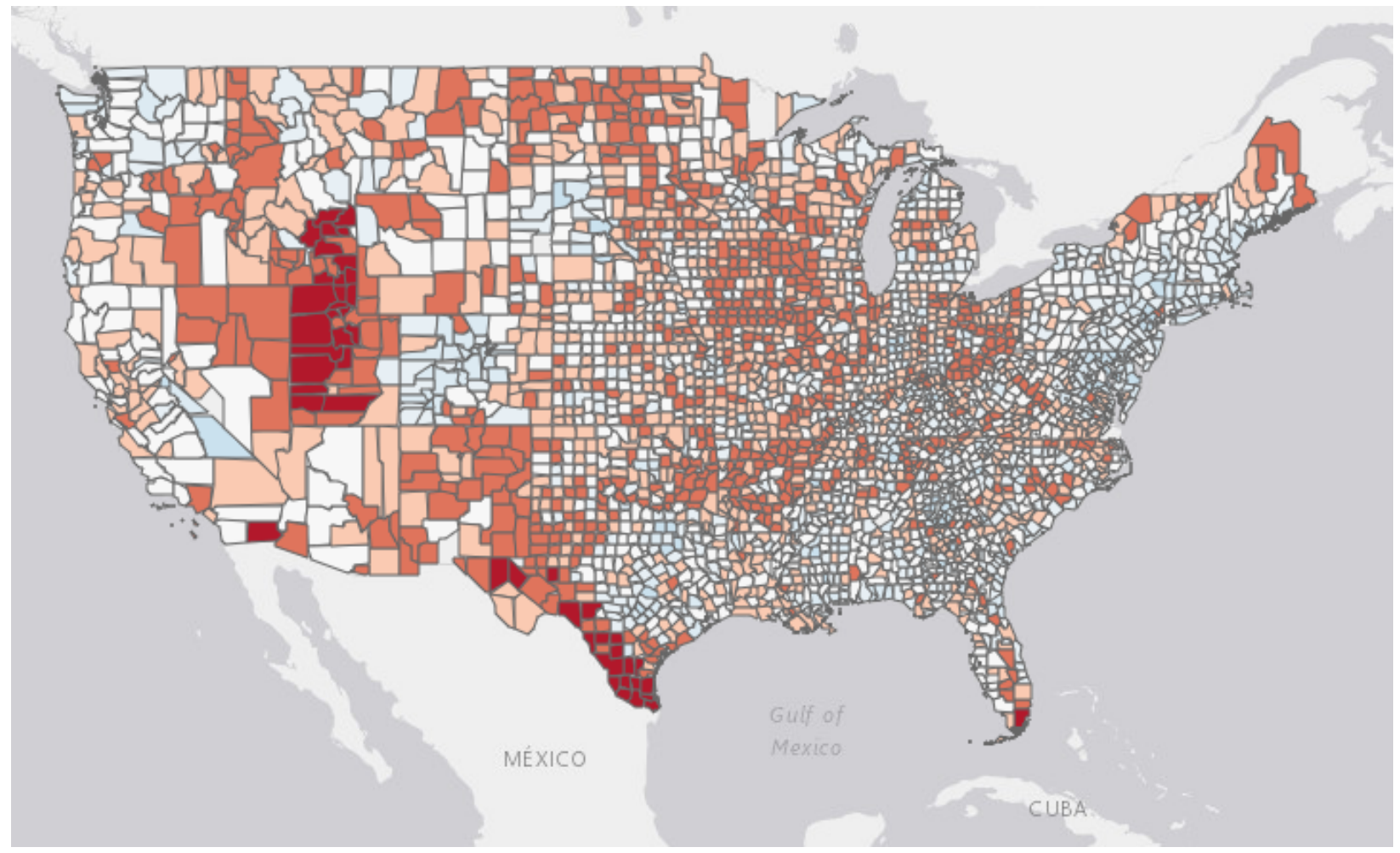

Key:

$$
\begin{array}{|}
\text { Change of Vote } \\
\begin{array}{|l}
-7.1 \text { to }-3.0 \\
-3.0 \text { to }-1.5 \\
-1.5 \text { to } 0.0 \\
0.0 \text { to } 1.5 \\
1.5 \text { to } 3.0 \\
3.0 \text { to } 10.0 \\
10.0 \text { to } 29.0
\end{array} \\
\hline
\end{array}
$$




\section{Appendix 5}

\section{Campaign Contributions from Private Equity, Coal, and Oil}

These totals are compiled along the lines of our previous work. ${ }^{178}$ Unlike most studies, we try to include individual contributions from executives in firms, as well as PAC contributions, and socalled 527 money, which is only available in data from the Internal Revenue Service (IRS). We combine the IRS statistics with the FEC data in the totals below. These industries and many others contribute large sums to 527's such as the major party governors' associations. So-called "dark money" is not included here since it cannot be attributed reliably. "Big business" firms refers to enterprises on the scale of the top 350 firms on the Fortune 500 list and comparably sized private firms, along with investors on the Forbes 400 lists for 2019 and 2020.

Identifying private equity firms outside of the big business lists is fraught with difficulty. We cross-listed the list of private equity firms provided by Private Equity Info (https://www.privateequityinfo.com/) with the list of firms in the 2020 campaign finance records to find all known private equity campaign contributors, including firms, executives, and PACs. To identify coal and oil and gas contributors, including firms, executives, and PACs, we crosslisted the list of firms provided by Dun \& Bradstreet Hoovers (https://www.dnb.com/) with the list of firms in the 2020 campaign finance records. We conducted a manual search through the campaign finance records to find additional smaller firms. To generate the list from Dun \& Bradstreet Hoovers, we defined oil and gas using the following 4-digit sic codes: 1311, 1321, 1381, 1382, 1389, 2911, 4612, 4613, 4619, 4922, 4923, 4924, 4925, 4932, 5983, 5984, 5989, 6792, and the largest firms in 5172 and 5541. For coal, we used 1221, 1222, and 1241 in addition to a manual search of the campaign finance records.

Appendix Table 5: Campaign Contributions from Private Equity, Coal, and Oil \& Gas

\begin{tabular}{|c|c|c|c|}
\hline Industry & $\begin{array}{c}\text { Trump } \\
\text { (Big Business Subset) }\end{array}$ & $\begin{array}{c}\text { Biden } \\
\text { (Big Business Subset) }\end{array}$ & $\begin{array}{c}\text { Other } \\
\text { (Big Business Subset)* }\end{array}$ \\
\hline Private & $\$ 13,403,624$ & $\$ 19,540,236$ & $\$ 131,893,063$ \\
Equity & $(\$ 10,263,450)$ & $(\$ 2,550,630)$ & $(\$ 70,768,669)$ \\
\hline Coal & $\$ 1,813,796$ & $\$ 16,976$ & $\$ 5,625,731$ \\
& $(\$ 4,033)$ & $(0)$ & $(\$ 676,482)$ \\
\hline Oil \& Gas & $\$ 28,133,879$ & $\$ 2,141,970$ & $\$ 147,874,545$ \\
& $(\$ 13,859,392)$ & $(\$ 602,701)$ & $(\$ 75,263,134)$ \\
\hline
\end{tabular}

*This column alone includes contributions to industry PACs as well as industry PAC spending to other entities outside the presidential general election candidates. The PAC spending should be discounted to avoid double counting industry totals. Private equity PACs spent \$1,402,000; coal PACs spent \$1,365,752; and oil and gas PACs spent \$19,769,314.

178 (Ferguson et al., 2018); (Ferguson et al., 2013); (Ferguson et al., 2019). 


\section{References}

Abutaleb, Y., \& Dawsey, J. (2021, August 31, 2020). New Trump Pandemic Adviser Pushes Controversial 'Herd Immunity' Strategy, Worrying Public Health Officials Washington Post. Retrieved from

https://www.washingtonpost.com/politics/trump-coronavirus-scott-atlas-herd-immunity/2020/08/30/925e68fe-e93b11ea-970a-64c73a1c2392 story.html

Addo, F. R., \& Derity, W. R., Jr. (2021). Disparate Recoveries: Wealth, Race, and the Working Class After the Great Recession. Annals of the American Academcy, 695 (May), 173-192. Retrieved from https://doi.org/10.1177\%2F00027162211028822

Agriculture, Department of (2019). Market Facilitation Program 2019 County Per Acre Payment Rate. Retrieved from https://www.farmers.gov/sites/default/files/documents/PaymentRates.pdf

Alvelda, P., Ferguson, T., \& Mallery, J. (2020). To Save the Economy, Save People First Retrieved from Institute for New Economic Thinking; https://www.ineteconomics.org/perspectives/blog/to-save-the-economy-save-people$\underline{\text { first }}$

Amadeo, K. (2021, June 11, 2021 Updated). How Every President Since Hoover Has Affected the Economy. The Balance. Retrieved from https://www.thebalance.com/gdp-growth-by-president-highs-lows-averages-4801102

Anselin, L. (2002). Under the Hood: Issues in the Specification and Interpretation of Spatial Regression Models. Agricultural Economics, 27(3), 247-267.

Artiga, S., Rae, M., Pham, O., Hamel, L., \& Muñana, C. (2020). COVID-19 Risks and Impacts Among Health Care Workers by Race/Ethnicity. Retrieved from KFF.org.com: https://www.kff.org/report-section/COVID-19-risks-andimpacts-among-health-care-workers-by-race-ethnicity-issue-brief/

Autor, D., Dorn, D., Hansen, G., \& Majlesi, K. (2020). Importing Political Polarization? The ElectoralConsequences of Rising Trade Exposure. American Economic Review, 110(10), 3139-3183. Retrieved from

https://doi.org/10.1257/aer.20170011

Autor, D., Dorn, D., Hanson, G., \& Majlesi, K. (2016). Importing Political Polarization? The Electoral Consequences of Rising Trade Exposure. Retrieved from Cambridge, Massachusetts:

https://www.americanprogress.org/issues/economy/news/2016/11/29/293816/the-role-of-midwestern-housinginstability-in-the-2016-election/

Autor, D., Dorn, D., Hanson, G., \& Majlesi, K. (2017). A Note on the Effect of Rising Trade Exposure on the 2016 Election. Retrieved from Cambridge, Massachusetts: https://economics.mit.edu/files/12418

Axios. (2021). 1 Big Thing ... "Off the rails": Swan Series on Trump's Final Days.

Baccini, L., Brodeur, A., \& Weymouth, S. (2021). The COVID-19 Pandemic and the 2020 US Presidential Election. Journal of Population Economics, 34, 739-767. Retrieved from

https://link.springer.com/article/10.1007\%2Fs00148-020-00820-3

Ball, M. (2020, February 4). The Secret History of the Shadow Campaign That Saved the 2020 Election. Time. Retrieved from https://time.com/5936036/secret-2020-election-campaign/

Barker, K., \& Harris, A. J. (2021, Updated March 15, 2021). Playing Russian Roulette': Nursing Homes Told to Take the Infected. New York Times. Retrieved from https://www.nytimes.com/2020/04/24/us/nursing-homescoronavirus.html

Barth, B. (2019). Can the Democrats Win Back Farm Country? . Modern Farmer. Retrieved from https://modernfarmer.com/2019/07/can-the-democrats-win-back-farm-country/ 
Beard, D. (2021). Three Explanations for the Shift Towards Trump Among Latino Voters. Retrieved June 4 https://www.dailykos.com/stories/2021/3/12/2020739/-Three-explanations-for-the-shift-towards-Trump-amongLatino-voters

Bianchi, F., Thilo, K., \& Kung, H. (2019). Threats to Central Bank Independence: High-Frequency Identification with Twitter. Retrieved from Cambridge: https://www.nber.org/system/files/working papers/w26308/w26308.pdf

Bjorklund, K. (2020). The Inside Story of How Sweden Botched Its Coronavirus Response. Retrieved from https://foreignpolicy.com/2020/12/22/sweden-coronavirus-COVID-response/

Blaine, S. B. (2019, September 22, 2019). Opinion: Trump's Tariffs Are Killing Apple Farmers Like Us. The Oregonian. Retrieved from https://www.oregonlive.com/opinion/2019/09/opinion-trumps-tariffs-are-killing-applefarmers-like-us.html

Brown, C. (2021). The US-China Trade War and Phase One Agreement. Peterson Institute for International Economics Working Paper 21-2; Retrieved from https://www.piie.com/publications/working-papers/us-china-tradewar-and-phase-one-agreement

Brown, E. (2020). Meet BlackRock, the New Great Vampire Squid. Common Dreams. Retrieved from https://www.commondreams.org/views/2020/06/22/meet-blackrock-new-great-vampire-squid

Bruggeman, L. (2020, April 18, 2020). Inside the Silicon Valley 'Brain Trust' Taking Aim at COVID-19. ABC News. Retrieved from https://abcnews.go.com/Health/inside-silicon-valley-brain-trust-taking-aim$\underline{\text { COVID/story?id }=70214888}$

Burleigh, N. (2021). Virus: Vaccinations, the CDC, and the Hijacking of America's Response to the Pandemic. New York: Seven Stories Press.

Cadava, G. (2020, December 29, 2020). The Deep Origins of Latino Support for Trump. The New Yorker. Retrieved from https://www.newyorker.com/news/the-political-scene/the-deep-origins-of-latino-support-for-trump

Camous, A., \& Matveev, D. (2019). Furor over the Fed : Presidential Tweets and Central Bank Independence. Retrieved from Ottawa, Canada: https://www.bankofcanada.ca/wp-content/uploads/2019/12/san2019-33.pdf

Campo-Flores, A., \& Findell, E. (2020, November 5 Updated). Latino Voters Drifted From Democrats in Florida and Texas Wall Street Journal. Retrieved from https://www.wsj.com/articles/latino-voters-drifted-from-democratsin-florida-and-texas-11604582691

Carmiel, O. (2020). Business Leaders Urge Trump to Begin Presidential Transition. Retrieved June 8, 2021 https://www.bloomberg.com/news/articles/2020-11-23/business-leaders-urge-trump-to-begin-transition-n-y-timessays?sref=pyiu6SiD

Case, A., \& Deaton, A. (2021). The Great Divide: Education, Despair, and Death. National Bureau of Economic Research, Working Paper No. 29241: https://www.nber.org/papers/w29241

Cavallaro, M. (2021). Local David Versus Global Goliath: Populist Parties and the Decline of Progressive Politics in Italy Institute for New Economic Thinking Working Paper No. 80. Retrieved from

https://www.ineteconomics.org/research/research-papers/local-david-versus-global-goliath-populist-parties-and-thedecline-of-progressive-politics-in-italy

CBSNews.com. (2021). Transcript: Matt Pottinger on "Face the Nation," February 21, 2021. Retrieved from https://www.cbsnews.com/news/transcript-matt-pottinger-on-face-the-nation-february-21-2021/

Chang, A., Ferguson, T., Rothschild, J., \& Page, B. (2021). Ambivalence About International Trade in Open- and Closed-ended Survey Responses. Institute for New Economic Thinking Working Paper No. 162, 
https://www.ineteconomics.org/research/research-papers/ambivalence-about-international-trade-in-open-and-closedended-survey-responses

Chayes, S. (2021). The Ides of August. www.sarahchayes.org. Retrieved from https://www.sarahchayes.org/post/the-ides-of-august

Chen, J., Ferguson, T., \& Jorgensen, P. (2020). Using Scan Statistics for Cluster Detection: Recognizing Real Bandwagons. Methodology and Computing in Applied Probability, 20, 1481-1491. Retrieved from https://link.springer.com/article/10.1007\%2Fs11009-019-09737-1

Cheng, Y., \& Hillberry, R. (2018). U.S. County-Level Impacts of Growth in China's Demand for Agricultural Imports. Paper presented at the Presented at the 21st Annual Conference on Global Economic Analysis, Cartagena, Columbia. https://www.gtap.agecon.purdue.edu/resources/download/9078.pdf

Chudik, A., Koech, J., \& Wynne, M. (2021). The Heterogeneous Effects of Global and National Business Cycles on Employment in US States and Metropolitan Areas. Oxford Bulletin of Statistics and Economics 83(2), 495-517. Retrieved from https://onlinelibrary.wiley.com/doi/abs/10.1111/obes.12402

Chudik, A., \& Pesaran, M. H. (2016). Theory and Practice of GVAR Modelling. Journal of Economic Surveys, 30(1), 165-197. Retrieved from https://onlinelibrary.wiley.com/doi/full/10.1111/joes.12095

Cigna, S., Meinen, P., Schulte, P., \& Steinhof, N. (2020). The Impact of US Tariffs Against China on US imports: Evidence for Trade Diversion? Frankfurt: European Central Bank Retrieved from https://www.google.com/url?sa=t\&rct=j\&q=\&esrc=s\&source=web\&cd=\&ved=2ahUKEwin5pnMjaTxAhVBmAKHYjVA0YQFjAAegQIBBAF\&url=https $\% 3 \mathrm{~A} \% 2 \mathrm{~F} \% 2 \mathrm{Fwww}$.ecb.europa.eu $\% 2 \mathrm{Fpub} \% 2 \mathrm{Fpdf} \% 2 \mathrm{Fscpwps} \% 2 \mathrm{Fecb}$. wp2503 ca71d98a53.en.pdf\&usg=AOvVaw319-1GRfmNiP5jPWuGQYHx

Cleary, E., Jackson, M., \& Ledley, F. (2020). Government as the First Investor in Biopharmaceutical Innovation:Evidence From New Drug Approvals 2010-2019. Retrieved from New York:

https://www.ineteconomics.org/research/research-papers/government-as-the-first-investor-in-biopharmaceuticalinnovation-evidence-from-new-drug-approvals-2010-2019

Cliff, A. D., \& Ord, J. K. (1981). Spatial Processes: Models and Applications. London: Pion Limited.

CNN. (2020a). America's Choice 2020: Presidential Results. https://www.cnn.com/election/2020/results/president Retrieved June 3, 2021

CNN. (2020b). America's Choice 2020: Primaries and Caucuses. Retrieved from https://www.cnn.com/election/2020/primaries-and-caucuses . Retrieved June 5, 2021.

CNN. (2020c). Exit Polls. Retrieved from https://www.cnn.com/election/2020/exit-polls/president/national-results Retrieved June 4, 2021.

Cochrane, E., \& Tankersley, J. (2020, December 2, 2020). Top Democrats Back Compromise Plan to Revive Stimulus Talks. New York Times. Retrieved from https://www.nytimes.com/2020/12/02/us/politics/coronavirusstimulus-talks-congress.html

Cohen, J. (2020, March 27, 2020). Caught Between Herd Immunity And National Lockdown, The Netherlands Hit Hard By COVID-19 (Update). Forbes. Retrieved from https://www.forbes.com/sites/joshuacohen/2020/03/27/caught-between-herd-immunity-and-national-lockdownholland-hit-hard-by-COVID-19/?sh=6226a4713557

Collins, S. (2020). Trump Made Gains with Black Voters in Some States. Here's why. Retrieved from https://www.vox.com/2020/11/4/21537966/trump-black-voters-exit-polls

. Retrieved June 3, 2020 
Collman, A. (2020). Trump's New Tactic for Reelection is Blaming Governors for the Coronavirus Response. Retrieved from https://www.businessinsider.com/trump-coronavirus-blaming-governors-reelection-tactic-2020-4

Condon, C. (2019, July 21, 2019 Updated). Bloomberg. Com. Here's a Timeline of Trump's Key Quotes on Powell and the Fed. Retrieved from https://www.bloombergquint.com/politics/all-the-trump-quotes-on-powell-as-fedremains-in-the-firing-line-7

Congressional Research Service. (2021). The Federal Reserve's Response to COVID-19: Policy Issues. Washington, D.C. Retrieved from https://crsreports.congress.gov

Copp, T. (2020). If Trump Loses But Refuses to Leave the White House, What Will the Military Do? Retrieved from https://www.mcclatchydc.com/news/politics-government/election/article247017117.html

Crippa, M., Solazzo, E., Guizzardi, D., Montforti-Ferrario, Tubiello, F. N., \& Leip, A. (2021). Food Systems Are Responsible For a Third of GlobalAnthropogenic GHG Emissions. Nature Food, 2(March), 198-209. Retrieved from https://www.nature.com/articles/s43016-021-00225-9

Dealbook. (2020, April 3, 2020). The Business Leaders Trump Asks for Advice on the Coronavirus. New York Times. Retrieved from https://www.nytimes.com/2020/04/03/business/dealbook/trump-coronavirus-advisors.html

DeSilver, D. (2019). As Trade Disputes Intensify, U.S. Counties That Rely Most on Exports Tend To Be Small and in South, Midwest. Pew Research Center. Retrieved from https://www.pewresearch.org/fact-tank/2019/06/19/uscounties-that-rely-most-on-exports-tend-to-be-small-in-south-midwest/

Dingel, J., \& Neiman, B. (2020). How Many Jobs Can Be Done at Home? National Bureau of Economic Research Working Paper No. 26948; https://www.nber.org/system/files/working_papers/w26948/w26948.pdf

Dippel, C., Heblich, S., \& Gold, R. (2015). Globalization and Its (Dis-)Content: Trade Shocks and Voting Behavior. National Bureau of Economic Research Working Paper No. 21812: https://www.nber.org/papers/w21812

Dipple, C., S., Gold, R., Heblich, S., \& Pinto, R. (2021). The Effect of Trade on Workers and Voters Economic Journal, in press. Retrieved from https://doi.org/10.1093/ej/ueab041

Dizard, J. (2021, August 20, 2021). War Will Shape the Future of the US Industrial Base. Financial Times. Retrieved from https://www.ft.com/content/636d15c1-c4ef-44de-bffc-43752d4bf552

Dorning, M. (2020). Tyson Suspends Managers Accused of COVID Betting Pool. Retrieved from https://www.bloomberg.com/news/articles/2020-11-19/tyson-suspends-workers-after-lawsuits-allege-COVIDbetting-pool?sref=pyiu6SiD . Retrieved June 13, 2021

Eban, K. (2020, July 30, 2020). How Jared Kushner's Secret Testing Plan “Went Poof Into Thin Air”. Vanity Fair. Retrieved from https://www.vanityfair.com/news/2020/07/how-jared-kushners-secret-testing-plan-went-poof-intothin-air

Eckert, F., Fort, T. C., Schott, P. K., \& Yang, N. J. (2021a). County Business Pattern Database. http://www.fpeckert.me/cbp/

Eckert, F., Fort, T. C., Schott, P. K., \& Yang, N. J. (2021b). Imputing Missing Values in the US Census Bureau's County Business Patterns. National Bureau of Economic Research Working Paper No. 26632; https://www.nber.org/papers/w26632

Elhorst, J. P., Gross, M., \& Terenau, E. (2021). Cross-Sectional Dependence and Spillovers in Space and Time: Where Spatial Econometrics and Global VAR Models Meet. Journal of Economic Surveys, 35(1), 192-226. Retrieved from https://onlinelibrary.wiley.com/doi/full/10.1111/joes.12391

Elsom, J. (2020, April 26, 2020 Updated). Tory Grandees Urge Boris Johnson to Ease Coronavirus Lockdown: Six Donors Including Phones4U Founder John Caudwell and Three Cabinet Ministers Join Calls for Action. Daily Mail 
Online. Retrieved from https://www.dailymail.co.uk/news/article-8257513/Six-Tory-donors-urge-Boris-Johnsonease-coronavirus-lockdown.html

Emma, C., \& Levine, M. (2020). Breaking Down the \$900B stimulus package and \$1.4T Omnibus Bill. Politico. Retrieved from https://www.politico.com/news/2020/12/20/details-stimulus-package-omnibus-bill-449499

Erickson, B. (2021, March 23, 2021). Teachers Union "Not Convinced" Social Distancing Can Safely Be Cut to 3 Feet. CBSNews.com. Retrieved from https://www.cbsnews.com/news/school-social-distancing-3-feet-teachers-not$\underline{\text { convinced/ }}$

Fabian, J., \& Jacobs, J. (2020). Trump Hears Testing Pleas From Companies in Talks on Reopening. Retrieved from https://www.bloomberg.com/news/articles/2020-04-15/trump-s-task-force-to-reopen-u-s-becomes-a-day-of-phonecalls?sref=pyiu6SiD . Retrieved June 8, 2021

Farmer, B. (2020, October 22, 2020). Hospital Bills For Uninsured COVID-19 Patients Are Covered, But No One Tells Them. Retrieved from https://www.npr.org/sections/health-shots/2020/10/22/925942412/hospital-bills-foruninsured-COVID-19-patients-are-covered-but-no-one-tells-them

Ferguson, T. (2020). Affluent Authoritarianism: McGuire and Delahunt's New Evidence on Public Opinion and Policy Institute for New Economic Thinking. Retrieved from https://www.ineteconomics.org/perspectives/blog/affluent-authoritarianism-mcguire-and-delahunts-new-evidenceon-public-opinion-and-policy

Ferguson, T. (2021). Is the World Undergoing A Fiscal/Debt Revolution? International Economy Magazine, Winter 2021, 20. Retrieved from http://www.international-economy.com/

Ferguson, T. (1995a). From 'Normalcy' To New Deal: Industrial Structure, Party Competition and American Public Policy in the Great Depression. In T. Ferguson (Ed.), Golden Rule: The Investment Theory of Party Competition and the Logic of Money-Driven Political Systems (pp. 113-172). Chicago: University of Chicago Press.

Ferguson, T. (1995b). Golden Rule: The Investment Theory Of Party Competition And The Logic Of Money-Driven Political Systems. Chicago: University of Chicago Press.

Ferguson, T. (1997). Review of Finegold and Skocpol, State and Party in America's New Deal. Journal of American History, 84(2), 713-714. Retrieved from https://doi.org/10.2307/2952691

Ferguson, T. (2020). Affluent Authoritarianism: McGuire and Delahunt's New Evidence on Public Opinion and Policy Institute for New Economic Thinking. Retrieved from https://www.ineteconomics.org/perspectives/blog/affluent-authoritarianism-mcguire-and-delahunts-new-evidenceon-public-opinion-and-policy

Ferguson, T. (2021). Is the World Undergoing A Fiscal/Debt Revolution? International Economy Magazine, Winter 2021, 20. Retrieved from http://www.international-economy.com/

Ferguson, T., Jorgensen, P., \& Chen, J. (2013). Party Compeititon and Industrial Structure in the 2012 Elections: . International Journal of Political Economy, 42(2), 3-41.

Ferguson, T., Jorgensen, P., \& Chen, J. (2018). Industrial Structure and Political Outcomes: The Case of the 2016 Election. In I. Cardinale \& I. Scazzeri (Eds.), The Palgrave Handbook of Political Economy (pp. 333-440). London: Palgrave.

Ferguson, T., Jorgensen, P., \& Chen, J. (2019). How Money Drives US Congressional Elections: Linear Models of Money and Outcomes. Structural Change and Economic Dynamics. Retrieved from https://doi.org/10.1016/j.strueco.2019.09.005 
Ferguson, T., Jorgensen, P., \& Chen, J. (2021; February, 11, 2021). Big Money Drove the Congressional Elections-Again Institute for New Economic Thinking. Retrieved from https://www.ineteconomics.org/perspectives/blog/big-money-drove-the-congressional-elections-again

Ferguson, T., Page, B., Rothschild, J., Chang, A., \& Chen, J. (2020). The Roots of Right-Wing Populism: Donald Trumpin 2016. International Journal of Political Economy, 49, 102-123. Retrieved from https://www.tandfonline.com/doi/full/10.1080/08911916.2020.1778861

Ferguson, T., \& Rogers, J. (1986). Right Turn: The Decline Of The Democrats And The Future of American Politics. New York: Hill \& Wang.

Ferleger, L., \& Lazonick, W. (1993). The Managerial Revolution and the Developmental State: The Case of U.S. Agriculture Business and Economic History 22(2), 67-98. Retrieved from http://www.jstor.org/stable/23702908

Ferman, M. (2020, November 13, 2020). Donald Trump Made Inroads in South Texas This year. These voters Explain Why. Texas Tribune. Retrieved from https://www.texastribune.org/2020/11/13/south-texas-voters-donaldtrump/

Findell, E. (2020, November 8, 2020). Why Democrats Lost So Many South Texas Latinos - the Economy Wall Street Journal. Retrieved from https://www.wsj.com/articles/how-democrats-lost-so-many-south-texas-latinostheeconomy-11604871650

Flaaen, A., \& Pierce, J. (2019). Disentangling the Effects of the 2018-2019 Tariffs on a Globally Connected U.S. Manufacturing Sector (2019-086). Board of Governors of the Federal Reserve System, Finance and Economics Discussion Series 2019-086. Retrieved from https://doi.org/10.17016/FEDS.2019.086

Fontanari, C., Palumbo, A., \& Salvatori, C. (2019a). Demand-Determined Potential Output: A Revision and Update of Okun's Original Method Institute for New Economic Thinking Working Paper No. 93; Retrieved from https://www.ineteconomics.org/research/research-papers/demand-determined-potential-output-a-revision-andupdate-of-okuns-original-method

Fontanari, C., Palumbo, A., \& Salvatori, C. (2019b). Is it Really "Full Employment"? Margins for Expansion in the US Economy in the Middle of 2019. Retrieved from https://www.ineteconomics.org/perspectives/blog/is-it-reallyfull-employment

Fox, L. E., \& Burns, K. (2021). The Supplemental Poverty Measure: 2020. (P60-275). Washington, D.C.: Census Bureau Retrieved from https://www.census.gov/library/publications/2021/demo/p60-275.html

Frey, W. H. (2020). Exit Polls Show Both Familiar and New Boting Blocs Sealed Biden's Win. Retrieved June 3, 2021 https://www.brookings.edu/research/2020-exit-polls-show-a-scrambling-of-democrats-and-republicanstraditional-bases/

Friedman, T. (2020, April 18, 2020). Trump Is Asking Us to Play Russian Roulette With Our Lives. New York Times; https://www.nytimes.com/2020/04/18/opinion/trump-coronavirus-testing.html

Galbraith, J. (2021, August 20, 2021). Afghanistan Was Always About American Politics. Project Syndicate. Retrieved from https://www.project-syndicate.org/commentary/afghan-war-was-about-us-politics-by-james-kgalbraith-2021-08

Gale, J. (2021, May 16, 2021). COVID Is Airborne, Scientists Say. Now Authorities Think So, Too. Bloomberg.com. Retrieved from https://www.bloomberg.com/news/articles/2021-05-16/COVID-is-airbornescientists-say-now-authorities-think-so-too?sref=pyiu6SiD

Gelman, A. (2016, December 8, 2016). 19 Things We Learned From the 2016 Election. Statistical Modeling, Causal Inference, and Social Science. Retrieved from http://andrewgelman.com/2016/12/08/19-things-learned-2016election/ 
Gelman, A., Morris, G. E., Vittert, L., \& Xiao-Lee, M. (2020). Post-Election Interview with Andrew Gelman and G. Elliott Morris. Harvard Data Science Review. Retrieved from https://hdsr.mitpress.mit.edu/pub/qqms394f/release/1?readingCollection=f10c13ea

General, O. o. I. (2021). COVID-19: Increased Worksite Complaints and Reduced OSHA Inspections Leave U.S. Workers' Safety at Increased Risk. (19-21-003-10-105). Washington, D.C. Retrieved from https://www.oig.dol.gov/cgi-bin/oa rpts-v4.cgi?s=\&y=2021\&a=all

Gezici, A., \& Ozay, O. (2020). How Race and Gender Shape COVID-19 Unemployment Probability. Retrieved from Amherst, Massachusetts: https://www.peri.umass.edu/publication/item/1335-how-race-and-gender-shape-COVID$\underline{19-u n e m p l o y m e n t-p r o b a b i l i t y ~}$

Ghitza, Y., \& Robinson, J. (2021). What Happened in 2020? Retrieved from https://catalist.us/wh-national/. Retrieved June 3, 2021 https://catalist.us/wh-national/

Gollwitzer, A., Martel, C., Brady, W. J., Pärnamets, P., Freedman, I., Knowles, E. D., \& Van Bevel, J. J. (2020). Partisan Differences in Physical Distancing Are Linked to Health Outcomes During the COVID-19 Pandemic. Nature Human Behavior, 4, 1186-1197. Retrieved from https://www.nature.com/articles/s41562-020-00977-7

Golshan, T. (2020, February 13). Tom Steyer Really Is Everywhere In South Carolina. Huff Post. Retrieved from https://www.huffpost.com/entry/tom-steyer-south-carolina_n_5e446833c5b626d15fdd68cd

Greenwald, G. (2021). The U.S. Government Lied For Two Decades About Afghanistan. Glenn Greenwald Retrieved from https://greenwald.substack.com/p/the-us-government-lied-for-two-decades

Griffin, R. (2020, November 10). Don't trust the exit polls. This explains why. Washington Post. Retrieved from https://www.washingtonpost.com/politics/2020/11/10/dont-trust-exit-polls-this-explains-why/

Grinczel, S. (2021). Biden's Trade Actions Could Mirror Trump's. Farmer's Exchange Online Edition. Retrieved from http://www.farmers-exchange.net/detailPage.aspx?articleID=20385

Gurdasani, D., Alvelda, P., \& Ferguson, T. (2021). New CDC Guidelines to Reopen Schools Could be Dangerous Institute for New Economic Thinking. Retrieved from https://www.ineteconomics.org/perspectives/blog/new-cdcguidelines-to-reopen-schools-could-be-dangerous

Hadwiger, D. (1971). The Freeman Administration and the Poor. Agricultural History, 45(1), 21-32. Retrieved from https://www.jstor.org/stable/3741941

Hadwiger, D. (1976). Farmers in Politics. Agricultural History, 50(1), 156-170. Retrieved from https://www.jstor.org/stable/3741913

Hadwiger, D., \& Talbot, R. B. (1967). Government Programs: What are the Near-Term Prospects? In R. K. Buck, L. V. Mayer, C. B. Baker, \& J. W. Goodwin (Eds.), Abundance and Uncertainty...Farm Policy Problems (pp. 131148). Ames, Iowa: Iowa State University.

Hilsenrath, J. (2020, October 20, 2020). The Verdict on Trump's Economic Stewardship, Before COVID and After Wall Street Journal. Retrieved from https://www.wsj.com/articles/trumps-economic-record-is-divided-beforeCOVID-and-after-11602684180

Hirtzer, M. (2020). Senators Blast 'Feckless' OSHA Response to Meat Plants' Virus Outbreaks. Retrieved from https://www.bloomberg.com/news/articles/2020-09-22/senators-say-osha-feckless-to-virus-safety-at-u-s-meatplants?sref=pyiu6SiD. Retrieved June 13, 2021 https://www.bloomberg.com/news/articles/2020-09-22/senatorssay-osha-feckless-to-virus-safety-at-u-s-meat-plants?sref=pyiu6SiD 
Holmes, A. (2020). Roughly Half of the Twitter Accounts Pushing to 'Reopen America' are Bots, Researchers Found. Retrieved from https://www.businessinsider.in/tech/news/roughly-half-of-the-twitter-accounts-pushing-toreopen-america-are-bots-researchers-found/articleshow/75897895.cms. Retrieved June 9, 2021 https://www.businessinsider.in/tech/news/roughly-half-of-the-twitter-accounts-pushing-to-reopen-america-are-botsresearchers-found/articleshow/75897895.cms

Jan, T. M., Jena, \& Hoyer, M. (2021, August 23, 2021). Corporate America's $\$ 50$ Billion Promise. Washington Post. Retrieved from https://www.washingtonpost.com/business/interactive/2021/george-floyd-corporate-americaracial-justice/

Jenkins, P. (2021). The Private Equity Backlash against ESG. Financial Times. Retrieved from https://www.ft.com/content/7e8edfd5-fccd-4f3c-9fda-c616b805c856

Kagan, R. (2021, September 23, 2021). Our Constitutional Crisis Is Already Here. Washington Post. Retrieved from https://www.washingtonpost.com/opinions/2021/09/23/robert-kagan-constitutional-crisis/

Kane, E. J. (2020). Immaculate Deception: How (and Why) Bankers Still Enjoy a Global Rescue Network. Institute for New Economic Thinking Working Paper No. 130;

https://www.google.com/url?sa=t\&rct=j\&q=\&esrc=s\&source=web\&cd=\&ved=2ahUKEwj1-

dSL4Yb0AhVXoHIEHaFIDHIQFnoECAoQAQ\&url=https\%3A\%2F\%2Fwww.ineteconomics.org\%2Fuploads\%2F papers\%2FWP 130-Kane-Immaculate-Deception.pdf\&usg=AOvVaw2it8St tMNJzOE2qGDL65r

Kennedy, W., \& Biesheuvel, T. (2021, June 29, 2021 Updated). Billionaire Glasenberg's Last Deal Says Coal Isn't Dead Yet. Bloomberg. Retrieved from https://www.bloomberg.com/news/articles/2021-06-28/in-last-dealglasenberg-bets-on-coal-s-long-lucrative-twilight?sref=pyiu6SiD

Kim, S. E., \& Margalit, Y. (2021). Tariffs As Electoral Weapons: The Political Geography of the US-China Trade War. International Organization, 75(1), 1-38. Retrieved from https://doi.org/10.1017/S0020818320000612

Kimball, S. (2019, September 16, 2019 Updated). 'It's Not A Free Market': These Manufacturers Say Tariffs Help :evel the Playing Field with China. CNBC.com. Retrieved from https://www.cnbc.com/2019/09/15/americanmanufacturers-say-tariffs-can-level-the-playing-field-with-china.html

King, J. E. (2012). The Microfoundations Delusion: Metaphor and Dogma in the History of Macroeconomics. Northampton: Edward Elgar.

Kishi, R., Stall, H., Wolfson, A., \& Jones, S. (2021). A Year of Racial Justice Protests: Key Trends in Demonstrations Supporting the BLM Movement. Retrieved from https://acleddata.com/2021/05/25/a-year-of-racialjustice-protests-key-trends-in-demonstrations-supporting-the-blm-movement/

Klein, N. (2020, May 8, 2020). Screen New Deal. The Intercept. Retrieved from https://theintercept.com/2020/05/08/andrew-cuomo-eric-schmidt-coronavirus-tech-shock-doctrine/

Kliff, S. (2021, May 21, 2021). COVID Killed His Father. Then Came \$1 Million in Medical Bills. New York Times. Retrieved from https://www.nytimes.com/2021/05/21/upshot/COVID-bills-financial-longhaulers.html?searchResultPosition=7

Kohler, P., \& Storm, S. (2016). CETA without Blinders: How Cutting 'Trade Costs and More' Will Cause Unemployment, Inequality, and Welfare Losses. International Journal of Political Economy, 45, 257-293. Retrieved from https://www.tandfonline.com/doi/full/10.1080/08911916.2016.1270081

Kopp, E., Leigh, D., Mursula, S., \& Tambunlertchai, S. (2019). U.S. Investment Since the Tax Cuts and Jobs Act of 2017. Retrieved from https://www.imf.org/en/Publications/WP/Issues/2019/05/31/U-S-46942

Kurth, J. (2019). The American Way of Empire: How America Won a World--But Lost Her Way. Clearwater, Florida: Washington Books. 
Lake, J., \& Nie, J. (2021). Did COVID Cost Trump the Election? Center for Economic Studies and Ifo Institute. Working Paper No. 8856. Retrieved from Munich, Germany:

https://papers.ssrn.com/sol3/papers.cfm?abstract id=3774663

Lamothe, D. (2021, January 3). The Time to Question Election Results Has Passed, All Living Former Defense Secretaries Say. Washington Post. Retrieved from https://www.washingtonpost.com/national-security/formerdefense-secretaries-rebuke-trump-election/2021/01/03/1c708f64-4de5-11eb-b2e8-3339e73d9da2 story.html

Lawder, D. (2020, May 1, 2020). Conservative Groups Advising White House Push Fast Reopening, Not Testing. Reuters. Retrieved from https://www.reuters.com/article/us-health-coronavirus-usa-plans-analysisidUSKBN22D6BD

Lazonick, W. (2016). The Value Extracting CEO: How Executive Stock-Based Pay Undermines Investment in Productive Capabilities. Institute for New Economic Thinking Working Paper No. 54; https://www.ineteconomics.org/uploads/papers/WP 54-Lazonick-Value-Extracting-CEO-2016.pdf

Lazonick, W. (2017). The Functions of the Stock Market and the Fallacies of Shareholder Value. Institute for New Economic Thinking Working Paper 58; https://www.ineteconomics.org/uploads/papers/WP 58-LazonickFunctions-Fallacies-REVISED-20170720.pdf

Lazonick, W., Sakinç, M. E., \& Hopkins, M. (2020). Why Stock Buybacks Are Dangerous for the Economy. Harvard Business Review. Retrieved from https://hbr.org/2020/01/why-stock-buybacks-are-dangerous-for-theeconomy

Lazonick, W., Tulum, O., \& Jacobson, K. (2021). Mass Producing COVID-19 Vaccine. Institute for New Economic Thinking. Retrieved from https://www.ineteconomics.org/perspectives/blog/mass-producing-COVID-19-vaccine

Lenski, J., Webster, T., \& Brown, R. (2021). What We Learned from the 2020 Election Exit Polls Edson Research Blog. Retrieved from https://www.edisonresearch.com/what-we-learned-from-the-2020-election-exit-polls-2/

Leon, C. A., \& Elk, M. (2021, July 13, 2021). The Bureau of Labor Statistics Counted Only Eight Strikes in 2020, Payday Report Counted 1,200 Institute for New Economic Thinking Blog;

https://www.ineteconomics.org/perspectives/blog/the-bureau-of-labor-statistics-counted-only-eight-strikes-in-2020payday-report-counted-1-200

Leonnig, C., \& Rucker, P. (2021). I Alone Can Fix It: Donald J. Trump's Catastrophic Final Year. New York: Penguin.

LeSage, J., \& Pace, R. K. (2009). Introduction to Spatial Econometrics. Boca Raton: Chapman \& Hall/CRC Press.

Levine, M., \& Bresnahan, J. (2020). Republicans Struggle to Break Logjam on Coronavirus Relief. Politico (August 3, 2020 Updated). Retrieved from https://www.politico.com/news/2020/08/03/senate-faces-crucial-week-oncoronavirus-relief-talks-390907?nname $=$ playbook\&nid $=0000014 \mathrm{f}-1646-\mathrm{d} 88 \mathrm{f}-\mathrm{a} 1 \mathrm{cf}-5 \mathrm{f} 46 \mathrm{~b} 7 \mathrm{bd} 0000 \& \mathrm{nrid}=0000014 \mathrm{e}-$ f10f-dd93-ad7f-f90fe5eb0000\&nlid=630318

Li, M., Balistreri, E. J., \& Zhang, W. (2020). The U.S.-China Trade War: Tariff Data and General Equilibrium Analysis. Journal of Asian Economics, 69, 1-13. Retrieved from http://dx.doi.org/10.1016/j.asieco.2020.101216

Li, W., Qiu, B., Whang, Z., \& Zeng, Y. (2021). Armington Elasticities and the Third-Country Effects of Trade Conflicts.Forum for Research in International Trade, Working Paper 1751. Retrieved from https://www.freit.org/

Lipton, E., Sanger, D., Haberman, M., Shear, M., Mazzetti, M., \& Barnes, J. (2020, April 26, 2020 Updated). He Could Have Seen What Was Coming: Behind Trump's Failure on the Virus. New York Times. Retrieved from https://www.nytimes.com/2020/04/11/us/politics/coronavirus-trump-response.html 
MacDonald, J. M. (2012). Why Are Farms Getting Larger? The Case of the US. Schriften der Gesellschaft für Wirtschafts- und Sozialwissenschaften des Landbaues e.V., 47, 25-46. Retrieved from https://www.gewisola.de/schriftenreihe

MacDonald, J. M., Hoppe, R. A., \& Newton, D. (2018). Three Decades of Consolidation in U.S. Agriculture (EIB 189). Retrieved from Washington, D.C.: https://www.ers.usda.gov/publications/pubdetails/?pubid=88056\#: :text=\%20\%EE\%80\%80Three\%20Decades\%20of\%20Consolidation\%20in\%20U.S.\%20A griculture $\% \mathrm{EE} \% 80 \% 81$, in $\% 20$ pasture $\% 2$ Fgrazing $\% 20$ land $\% 20$ and $\% 20$ in $\% 20$ the $\% 20$ associated $\% 20$

MacLean, N. (2017). Democracy in Chains. New York: Viking.

Maguire, S. K., \& Delahunt, C. B. (2020). Predicting United States Policy Outcomes

with Random Forests. Institute for New Economic Thinking Working Paper No. 138. Retrieved from https://www.ineteconomics.org/research/research-papers/predicting-united-states-policy-outcomes-with-random$\underline{\text { forests }}$

Masket, S. (2021, January 27, 2021). How Much Did COVID-19 Affect The 2020 Election? . Fivethirtyeight.com. Retrieved from https://fivethirtyeight.com/features/how-much-did-COVID-19-affect-the-2020-election/

McFadden, A. (October 28, 2020, October 28, 2020). With \$1.5 Million Contributed, Blackstone CEO Is Collins' Biggest Billionaire Backer. Maine Beacon. Retrieved from https://mainebeacon.com/with-1-5-million-contributedblackstone-ceo-is-collins-biggest-billionaire-backer/

McNamara, A. (2020, March 28, 2020). Nurses Across the Country Protest Lack of Protective Equipment. CBSNews.com. Retrieved from https://www.cbsnews.com/news/health-care-workers-protest-lack-of-protectiveequipment-2020-03-28/

Meloni, W., Romaniello, D., \& Stirati, A. (2021). On the Non-Inflationary Effects of Long-Term Unemployment Reductions Retrieved from https://www.ineteconomics.org/research/research-papers/on-the-non-inflationary-effectsof-long-term-unemployment-reductions

Michaels, D., \& Wagner, G. (2021). How Biden Can Protect Workers on Day 1 Institute for New Economic Thinking. Retrieved from https://www.ineteconomics.org/perspectives/blog/how-biden-can-protect-workers-on-day$\underline{1}$

Milne, R. (2020, March 26, 2020). Coronavirus 'Medicine' Could Trigger Social Breakdown. Financial Times. Retrieved from https://www.ft.com/content/3b8ec9fe-6eb8-11ea-89df-41bea055720b

Molteni, M. (2021). The 60-Year-Old Scientific Screwup That Helped COVID Kill. Wired. Retrieved from https://www.wired.com/story/the-teeny-tiny-scientific-screwup-that-helped-COVID-kill/

Mongey, S., Pilossoph, L., \& Weinberg, A. (2021). Which Workers Bear the Burden of Social Distancing? Retrieved from https://www.nber.org/papers/w27085

Monnat, S., \& Brown, D. (2017). Deaths of Despair and Support For Trump in the 2016 Presidential Election. Journal of Rural Studies, 55(October), 227-236. Retrieved from http://www.sciencedirect.com/science/article/pii/S0743016717307386

Monrad, J. T., Sandbrink, J. B., \& Cherian, N. G. (2021). Promoting Versatile Vaccine Development for Emerging Pandemics. NPJ, 6. Retrieved from https://doi.org/10.1038/s41541-021-00290-y

Mosendz, P., Waldman, P., \& Mulvaney, P. (2020). U.S. Meat Plants Are Deadly as Ever, With No Incentive to Change. Retrieved from https:/www.bloomberg.com/news/features/2020-06-18/how-meat-plants-were-allowed-tobecome-coronavirus-hot-spots?sref=pyiu6SiD. Retrieved June 13, 2021 
https://www.bloomberg.com/news/features/2020-06-18/how-meat-plants-were-allowed-to-become-coronavirus-hotspots?sref=pyiu6SiD

Navarro, M. (2012, January 13, 2012). For Many Latinos, Racial Identity Is More Culture Than Color. New York Times. Retrieved from https://www.nytimes.com/2012/01/14/us/for-many-latinos-race-is-more-culture-thancolor.html?.?mc=aud dev\&adkeywords=auddevgate\&gclid=CjwKCAjw95yJBhAgEiwAmRrutNJxzwzNFJPzGXSntEZRv69E9ASu35o5L7Di16b1ZgSPRxMBiXe8hoCuC8QAvD BwE\&gclsrc=aw.ds

Nilsen, E., \& Zhou, L. (2020). The High-Stakes Fight Over A Coronavirus Economic Stimulus Package, Explained. Vox. Retrieved from https:/www.vox.com/2020/3/10/21173244/coronavirus-economic-stimulus-payroll-tax-cut

O'Connell, J., Dam, A. V., Gregg, A., \& Flowers, A. (2020, December 2, 2020). More Than Half of Emergency Small-Business Funds Went to Larger Businesses, New Data Shows. Washington Post. Retrieved from https://www.washingtonpost.com/business/2020/12/01/ppp-sba-data/

Office, G. A. (2020). USDA Market Facilitation Program: Information on Payments for 2019 Briefing to Senate Committee on Agriculture, Nutrition, and Forestry. Retrieved from https://www.gao.gov/pdf/product/708942

Parramore, L. (2020, October 20, 2020). Profits Over Human Life? ER Doctor's Story is Fearful Lesson for U.S. Workers During Pandemic Institute for New Economic Thinking. Retrieved from https://www.ineteconomics.org/perspectives/blog/profits-over-human-life-er-doctors-story-is-fearful-lesson-for-u-sworkers-during-pandemic

Parramore, L. (2021, August 19, 2021). "We Are Running A Giant Experiment on Children”: COVID Deniers Put Kids at Risk. Institute for New Economic Thinking. Retrieved from https://www.ineteconomics.org/perspectives/blog/we-are-running-a-giant-experiment-on-children-COVID-deniersput-kids-at-risk

Perez, A., \& Warner, J. (2021, August 3, 2021). Dems Scored Real Estate Cash Before Letting Eviction Ban Expire. The Daily Poster. Retrieved from https://www.dailyposter.com/dems-scored-real-estate-cash-before-lettingeviction-ban-expire/

Podkul, C., \& Lim, D. (2020, September 18, 2020). Fed Hires BlackRock to Help Calm Markets. Its ETF Business Wins Big. Wall Street Journal. Retrieved from https://www.wsj.com/articles/fed-hires-blackrock-to-help-calmmarkets-its-etf-business-wins-big-11600450267

Porter, E. (2021, May 10, 2021 Updated). How the American Unemployment System Failed. New York Times. Retrieved from https://www.nytimes.com/2021/01/21/business/economy/unemployment-insurance.html

Raval, A. (2021). A \$140bn Asset Sale: The Investors Cashing in on Big Oil's Push to Net Zero. Financial Times. Retrieved from https://www.ft.com/content/4dee7080-3alb-479f-a50c-c3641c82c142

Reid, T., Layne, N., \& Lange, J. (2021, September 22, 2021). Special Report: Backers of Trump's False Fraud Claims Seek to Control Next Elections. Reuters. Retrieved from https://www.reuters.com/world/us/backers-trumpsfalse-fraud-claims-seek-control-next-us-elections-2021-09-22/

Robinson, W. S. (1950). Ecological Correlations and the Behavior of Individuals. American Sociological Review, 15(3), 351-357.

Rosenberg, E. (2021, March 2, 2021). New Report Says Failures at OSHA Under Trump Could Have Put More Workers at Risk During Pandemic. Washington Post. Retrieved from https://www.washingtonpost.com/business/2021/03/02/osha-inspections-COVID-oig-report/

Rubin, R. (2020, April 17, 2020). Bringing the Economy Back to Life. New York Times. Retrieved from https://www.nytimes.com/2020/04/17/opinion/robert-rubin-coronavirus-economy.html 
Rubin, R. (2020). Building an "Army of Disease Detectives" to Trace COVID-19 Contacts. Journal of the American Medical Association, 323(23), 2357-2360. Retrieved from

https://jamanetwork.com/journals/jama/fullarticle/2766558

Saitone, T. L., Schaefer, K. A., \& Scheitrum, D. P. (2021). COVID-19 Morbidity and Mortality in U.S.

Meatpacking. Food Policy, 101(May). doi:https://dx.doi.org/10.1016\%2Fj.foodpol.2021.102072

Scheingate, A., Scatterday, A., Martin, B., \& Nachman, K. (2017). Post-Exceptionalism and Corporate Interests in US Agricultural Policy. Journal of European Public Policy, 23(11), 1641-1657. Retrieved from https://doi.org/10.1080/13501763.2017.1334082

Schueler, M. (2020, November 13, 2020). The \$15 Minimum Wage Won in Florida, But Biden Didn't. Here's Why. In These Times. Retrieved from https://inthesetimes.com/article/fight-for-15-minimum-wage-workers-seiu-laborjoe-biden-election

Seibel, K. (2020, March 22, 2020). Länger als drei Monate halten wir das nicht durch. Die Zeit. Retrieved from https://www.welt.de/wirtschaft/article206701063/Wirtschaftsweiser-Feld-Laenger-als-drei-Monate-halten-wir-dasnicht-durch.html

Congressional Research Service. (2021). The Federal Reserve's Response to COVID-19: Policy Issues. Washington, D.C. R46411. Retrieved from https://crsreports.congress.gov

Setser, B. (2018, July 9, 2018). U.S.-China Trade War: How We Got Here. Council on Foreign Relations Blog. Retrieved from https://www.cfr.org/blog/us-china-trade-war-how-we-got-here

Shipman, T., \& Wheeler, C. (2020, March 22, 2020). Coronavirus: Ten Days That Shook Britain — and Changed the Nation Forever. Sunday Times. Retrieved from https://www.thetimes.co.uk/article/coronavirus-ten-days-thatshook-britain-and-changed-the-nation-for-ever-spz6sc9vb

Shorter, E., \& Tilly, C. (1974). Strikes in France 1830-1968: Cambridge University.

Smith, A. (2020). Handful of GOP Senators Threaten to Delay Senate Coronavirus Bill Over Unemployment Payments. NBCNews.com. Retrieved from https://www.nbcnews.com/politics/congress/handful-gop-senatorsthreaten-delay-senate-coronavirus-bill-over-drafting-n1168766

Smith, N. (2020). No, Pandemic UI Didn't Kill Jobs. Noahpinion. Retrieved from https://noahpinion.substack.com/p/no-pandemic-ui-didnt-kill-jobs

Stiglitz, J. (2003). Globalization and Its Discontents. New York: Norton.

Stock, J. H., \& Watson, M. W. (2010). Introduction to Econometrics (3rd ed.). Boston: Pearson Addison Wesley.

Storm, S. (2017). The New Normal: Demand, Secular Stagnation, and the Vanishing Middle Class. International Journal of Political Economy, 46(4), 169-210. Retrieved from

https://www.tandfonline.com/doi/full/10.1080/08911916.2017.1407742

Storm, S. (2021a). Cordon of Conformity Why DSGE Models Are Not the Future of Macroeconomics. International Journal of Political Economy, 50(2), 77-98. Retrieved from https://www.tandfonline.com/doi/full/10.1080/08911916.2021.1929582

Storm, S. (2021b). Lessons for the Age of Consequences:COVID-19 and the Macroeconomy. Institute for New Economic Thinking Working Paper No. 152; https://www.ineteconomics.org/research/research-papers/lessons-forthe-age-of-consequences-COVID-19-and-the-macroeconomy 
Taylor, L., \& Barbosa-Filo, N. (2021). Inflation? It's Import Prices and the Labor Share! Institute for New Economic Thinking Working Paper No. 145; Retrieved from https://www.ineteconomics.org/research/researchpapers/inflation-its-import-prices-and-the-labor-share

Taylor, L., \& Ömer, Ö. (2020). Macroeconomic Inequality from Reagan to TrumpMarket Power, Wage Repression, Asset Price Inflation, and Industrial Decline. Cambridge: Cambridge University Press.

Telford, T. (2021, October 27, 2021). COVID Cases and Deaths Grossly Underestimated Among Meatpackers, House Investigation Finds. Washington Post. Retrieved from https://www.washingtonpost.com/business/2021/10/27/meatpacking-house-report/

Temin, P. (2016). Race and the Vanishing Middle Class. Cambridge: MIT Press.

Trump, D. (2020). Full Text: President Trump's 2020 RNC Acceptance Speech. Retrieved from https://www.nbcnews.com/politics/2020-election/read-full-text-president-donald-trump-s-acceptance-speech-rncn1238636. Retrieved June 18, 2021 https://www.nbcnews.com/politics/2020-election/read-full-text-presidentdonald-trump-s-acceptance-speech-rnc-n1238636

Wagner, C. R. H., Niles, M., \& Roy, E. D. (2019). US County-Level Agricultural Crop Production Typology. BMC Res Notes 12(552). Retrieved from https://doi.org/10.1186/s13104-019-4594-4

Washington, P., \& Spierings, M. (2021). Under A Microscope: A New Era of Scrutiny for Corporate Political Activity. Retrieved from New York: https://www.conference-board.org/publications/Under-a-Microscope-A-NewEra-of-Scrutiny-for-Corporate-Political-Activity

Washington Post, (2020, December 14). Exit Poll Results and Analysis for the 2020 Presidential Election. Retrieved from https://www.washingtonpost.com/elections/interactive/2020/exit-polls/presidential-election-exit-polls/

Washington Post (2021). Exit Poll Results From the 2021 Election for Virginia Governor. Washington Post. Retrieved from https://www.washingtonpost.com/elections/interactive/2021/exit-polls-virginia-governor/\#hY5IF6NZDJZFT3PK2ZNXGJRNMMQ

Webb, W. (2020). Techno-Tyranny: How The US National Security State Is Using Coronavirus To Fulfill An Orwellian Vision. Retrieved May 17, 2020 https://www.thelastamericanvagabond.com/top-news/techno-tyrannyhow-us-national-security-state-using-coronavirus-fulfill-orwellian-vision/

Wheeler, C., Shah, O., Harper, T., \& Calver, T. (2020, April 26, 2020). Tory Grandees Tell PM: It's Time to Ease the Coronavirus Lockdown. Sunday Times. Retrieved from https://www.thetimes.co.uk/article/tory-grandees-tellpm-its-time-to-ease-the-coronavirus-lockdown-dsc593ktm

Wiggins, R. Z., \& Feldberg, G. (2020). Mnuchin Clarifies that Treasury is Prepared to Lose Money on Fed Programs Retrieved from https://som.yale.edu/blog/mnuchin-clarifies-that-treasury-is-prepared-to-lose-money-onfed-programs

Wilson, K., Diaz, D., \& Klein, B. (2020). Former Trump Appointee Encouraged Herd Immunity Strategy for COVID-19, Internal Emails Reveal Retrieved from https://www.cnn.com/2020/12/16/politics/trump-administrationherd-immunity/index.html. Retrieved June 8, 2021 https:/www.cnn.com/2020/12/16/politics/trump-administrationherd-immunity/index.html

Winders, B. (2004). Sliding Toward the Free Market: Shifting Political Coalitions and U.S. Agricultural Policy, 1945-1975. Rural Sociology, 69(4), 467-489. Retrieved from https://doi.org/10.1526/0036011042722750

Winders, B. (2009). The Vanishing Free Market: The Formation and Spread of the British and US Food Regimes. Journal of Agrarian Change, 9(3), 315-344. Retrieved from https://doi.org/10.1111/j.1471-0366.2009.00214.x 
Winders, B. (2020). The Global Context of the US Farm Bill in 2018: World Markets, Instability and Policy Preferences in Agriculture. Renewable Agriculture and Food Systems, 35, 367-375. Retrieved from https://doi.org/10.1017/S1742170518000303

Wolff, M. (2021). Landslide: The Final Days of the Trump Presidency. New York: Henry Holt.

Woodward, B. (2020). Rage. New York: Simon \& Schuster.

Woodward, B., \& Costa, R. (2021). Peril. New York: Simon \& Schuster.

Wright, G. (2020). Voting Rights, Deindustrialization, and Republican Ascendancy in the South Retrieved from https://www.ineteconomics.org/research/research-papers/voting-rights-deindustrialization-and-republicanascendancy-in-the-south

Zaveri, M. (2020, July 22, 2020 Updated). An Amazon Vice President Quit Over Firings of Employees Who Protested. New York Times. Retrieved from https://www.nytimes.com/2020/05/04/business/amazon-tim-bray$\underline{\text { resigns.html }}$

Zhang, C., \& Fox, B. (2020, November 23). How A Coalition of Women Won It for Joe Biden. Financial Times. Retrieved from https://www.ft.com/content/2b0eba6f-ba33-42e6-b49a-f7e53d67341f 